\title{
III. Die arbeitsrechtliche Rechtsprechung im Dritten Reich
}

\section{x. Die Arbeitsgerichtsbarkeit}

Die erst 1927 geschaffene ${ }^{1}$ Arbeitsgerichtsbarkeit wurde während der gesamten Dauer des Dritten Reiches in ihrem Bestand nicht angetastet, doch büßte sie wesentliche Aufgaben ein. Da die politisch brisanten Zuständigkeiten ganz entfielen oder auf andere Behörden übertragen wurden, verloren die Arbeitsgerichte für die Gestaltung des Arbeitslebens erheblich an Bedeutung.

\section{Die Ausgangslage - Die Arbeitsgerichtsbarkeit vor 1933}

Bis 1927 waren für die Entscheidung zivilrechtlicher Streitigkeiten zwischen Arbeitgebern und Arbeitnehmern aus dem Arbeitsverhältnis je nach Gewerbezweig bzw. Arbeitnehmergruppe die Gewerbegerichte² (für die gewerblichen Arbeiter und geringer verdienenden technischen Angestellten), die Kaufmannsgerichte 3 (für die kaufmännischen Angestellten) oder die ordentlichen Zivilgerichte (für alle anderen Gruppen, insbesondere die land- und hauswirtschaftlichen Arbeitskräfte sowie die höher verdienenden Angestellten und die Arbeitnehmer im öffentlichen Dienst) zuständig. Das ArbGG hat diese vom Kaiserreich übernommene Rechtszersplitterung beseitigt ${ }^{4}$. Die Entscheidung der Rechtsstreitigkeiten, die sich aus dem seit 1918 neu geschaffenen bzw. rechtlich in vollem Umfang anerkannten System der kollektiven Gestaltung's des Arbeitslebens ergaben, war bis 1927 nur provisorisch geregelt worden ${ }^{6}$. Erst das ArbGG übertrug die Regelung dieser Streitigkeiten einheitlich einem Gerichtszweig, der neuen Arbeitsgerichtsbarkeit7. Diese Entscheidung des Gesetzgebers war ein bedeutender Schritt zur „Verrechtlichung“ der kollektiven Arbeitsstreitigkeiten und damit zur Verstärkung des richterlichen Einflusses auf die Gestaltung der Arbeitsbeziehungen. Der Einfluß der Arbeitsgerichtsbarkeit war um

I Durch das Arbeitsgerichtsgesetz (ArbGG) vom 23. 12. 1926, das am 1.7. 1927 in Kraft trat.

2 Gesetz betreffend die Gewerbegerichte vom 29.7. 1890, in größeren Gemeinden obligatorisch seit den Neufassungen vom 30.6. und 29.9. I90I.

3 Gesetz betreffend die Kaufmannsgerichte vom 6.7. 1904.

4 \2I Nr. 2 ArbGG.

s Die kollektive Gestaltung des Arbeitslebens erfolgte auf betrieblicher Ebene durch den Arbeitgeber und die Betriebsräte, auf überbetrieblicher Ebene durch die Arbeitgeber und ihre Verbände sowie die Gewerkschaften.

6 So wurden die in $\ 93$ BRG für die Entscheidung von Betriebsstreitigkeiten vorgesehenen Bezirkswirtschaftsräte nicht geschaffen. Die AVO vom 10. 12. 1923 zur SchlichtungsVO vom 30. 10. 1923 übertrug die Entscheidung dieser Streitigkeiten den Kaufmanns- und Gewerbegerichten und ersatzweise den Schlichtungsausschüssen.

$7 \$_{2}$ I Nr. I, 4 und s ArbGG. 
so bedeutsamer, als die Schaffung eines „einheitlichen Arbeitsrechts" ${ }^{\text {"8 }}$ den verschärften Klassenauseinandersetzungen zum Opfer fiel. Die danach noch bestehenden Lücken ${ }^{9}$ und Diskrepanzen ${ }^{10}$ in den arbeitsrechtlichen Regelungen der Weimarer Zeit eröffneten den Arbeitsgerichten (vor allem dem RAG) relativ weite Gestaltungsmöglichkeiten ${ }^{11}$.

Prägendes Element der neuen Arbeitsgerichtsbarkeit war - wie in vielen anderen Einrichtungen der Weimarer Arbeitsverfassung auch - die paritätische Beteiligung: Den Kammern der Arbeitsgerichte ${ }^{12}$ und Landesarbeitsgerichte ${ }^{13}$ sowie den Senaten des RAG $^{\mathrm{I4}}$ gehört je ein Laienbeisitzer aus den Kreisen der Arbeitnehmer und Arbeitgeber an; außerdem waren Vertreter der Koalitionen vor den Arbeitsgerichten ausschließlich und vor den Landesarbeitsgerichten neben den Rechtsanwälten als Prozeßvertreter zugelassen ${ }^{15}$. Vor dem RAG allerdings bestand Anwaltszwang. Hieran sowie an der Besetzung der Senate des RAG mit drei richterlichen und zwei Laienmitgliedern wird die Betonung des juristischen Elements (zumindest in der für die grundsätzliche Rechtsentwicklung wichtigsten Instanz) und damit ein anderer Aspekt der Tendenz zur Verrechtlichung der Arbeitsstreitigkeiten deutlich. Daß die Berufsrichter auch in der $\mathbf{I}$. und 2. Instanz in kritischen Fällen ein Übergewicht hatten, weil die Laienbeisitzer sich gegenseitig neutralisieren konnten, hat Franz Neumann plastisch beschrieben ${ }^{16}$ : „Das Arbeitsgericht bildet also in der Sphäre der Rechtsprechung gewissermaßen eine Koalitionsregierung, wobei der Richter etwa die Rolle des Reichspräsidenten spielt.“

Hat nun die Arbeitsgerichtsbarkeit - und in ihr vor allem die Berufsrichterschaft Gebrauch von den Gestaltungsmöglichkeiten gemacht, ist sie zum wesentlichen Gestaltungsfaktor ${ }^{17}$ der Arbeitsverfassung in der zweiten Hälfte der Weimarer Republik

8 Art. I59 WRV.

9 Z.B. blieb das gesamte Arbeitskampfrecht ungeregelt.

10 Nach Auffassung des Reichsgerichts (Urteil vom 6. 2.1923, RGZ 106, 272.) paßten beispielsweise die Risikoverteilung des $\$ 6$ I5 BGB und die seit 1918 anerkannten solidarischen Kampfmaßnahmen der Arbeitnehmer nicht zueinander, so daß das Gericht sich zu einer korrigierenden Interpretation des $₫ 6$ Is BGB zur Einschränkung des Arbeitgeberrisikos veranlaßt sah.

"Vgl. Silberschmidt, Das Reichsgericht und der Begriff des Sozialen, Reichsgerichts-Festschrift, Bd. II, S. I ff., und Franz Neumann, Die politische und soziale Bedeutung der arbeitsgerichtlichen Rechtsprechung, Berlin 1929, S. rof.

12 \S 17,20 ArbGG.

$13 \int S 35,37$ ArbGG.

${ }^{14} \mathbb{S} \$ 4 \mathrm{r}, 43$ ArbGG.

is $\$$ I I ArbGG.

16 Neumann, Die politische und soziale Bedeutung der arbeitsgerichtlichen Rechtsprechung, S. 25 .

17 Thilo Ramm, Vorwort zu: Arbeitsrecht und Politik, Neuwied und Berlin 1966, S. XII, folgert aus dem „Versagen des Gesetzgebers“ der Weimarer Republik, daß „der Richter zur beherrschenden Figur im Arbeitsrecht aufrückte“. Ähnlich sprach auch Franz Neumann, Die politische und soziale Bedeutung der arbeitsgerichtlichen Rechtsprechung, S. 7, von der „außerordentlichen Bedeutung der arbeitsrechtlichen Rechtsprechung für Arbeitsverhältnis und Lebensverhältnis des arbeitenden Menschen". Im folgenden geht es darum, diese Bedeutung in Bezug zum Gewicht der anderen Ge- 
geworden? Das starke Interesse, das die Rechtsprechung des RAG schon nach kürzester Zeit in der arbeitsrechtlichen Literatur fand ${ }^{18}$, und die Einschätzung ihrer Bedeutung für die Arbeitsrechtentwicklung durch die zeitgenössischen Autoren ${ }^{19}$ legen diese Bewertung nahe. Doch haben die Arbeitsgerichte bei weitem nicht alle Funktionen übernommen, die die politischen Parteien im Parlament bei der gesetzlichen Gestaltung und die Tarifvertragsparteien bei der tariflichen Gestaltung der Arbeitsbeziehungen aufgrund der verhärteten Gegensätze nicht mehr ausreichend wahrnahmen; einen Großteil dieser Gestaltungsaufgaben erfüllte in der Endphase der Weimarer Republik die Ministerialbürokratie, die die Notverordnungen des Reichspräsidenten Hindenburg ausarbeitete ${ }^{20}$, viele der staatlichen Schlichter für die Tarifauseinandersetzungen stellte ${ }^{2 x}$ und in der Wirtschaftskrise immer häufiger dazu überging, Tarifabschlüsse für allgemeinverbindlich zu erklären ${ }^{22}$.

Wenn auch in den Entscheidungen des RAG gewisse Grundstrukturen (die Ideen der

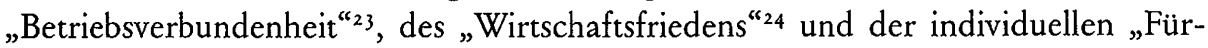
sorge ${ }^{{ }^{\prime 25}}$ ) erkennbar wurden, konnte es doch nicht die Versäumnisse des Gesetzgebers im vollen Umfang ausgleichen und beispielsweise eine den neuen Bedingungen der kollektiven Arbeitsrechtsgestaltung angepaßte, konsistente Regelung des Arbeitsverhältnisses oder des Arbeitskampfes schaffen. Hierfür war die Zeitdauer vom Inkrafttreten des ArbGG bis zur Machtübernahme Hitlers mit ca. fünfeinhalb Jahren zu kurz, zumal die auf Einzelfallentscheidungen ${ }^{26}$ und Kompromisse ${ }^{27}$ angelegte Struktur der Arbeitsgerichte einen großen Zeitraum zur Entwicklung eines arbeitsrechtli-

staltungsfaktoren zu setzen, die - wie vor allem der Gesetzgeber - ihre Gestaltungsmöglichkeiten nur teilweise nutzten und dementsprechend Raum für Aktivitäten anderer offenließen.

18 Vgl. neben Franz Neumanns Schrift von 1929: Otto Kahn-Freund, Das soziale Ideal des Reichsarbeitsgerichts, Mannheim I93 I, wieder abgedruckt bei: Thilo Ramm (Hrsg.), Arbeitsrecht und Politik, S. $149 \mathrm{ff}$.

19 Vgl.vor allem Kahn-Freund, Das soziale Ideal des Reichsarbeitsgerichts, S. 207: „Seit dem Beginn seines Bestehens, d. h. seit etwa 3 Jahren, hat das Reichsarbeitsgericht unter Heranziehung der bereits vorangegangenen Rechtsprechung des Reichsgerichts das Arbeitsrecht innerlich von Grund auf umgestaltet. ... war es einstmals ein Hilfsmittel des unterdrückten Klassen zu ihrem Aufstieg, so ist es heute in der Hand des Reichsarbeitsgerichts ein Mittel des Staates zur Niederhaltung von Klassengegensätzen und zum Schutz des Individuums geworden."

20 Vgl. zur Notverordnungspolitik der Regierungen Brüning und von Papen: Preller, Sozialpolitik, S. 395 ff.

${ }^{21}$ Vgl. zur Diskussion um das Schlichtungswesen und zu seiner Regelung und Durchführung in der Endphase der Weimarer Republik: Preller, Sozialpolitik, S. 399 ff.

22 Ebenda, S. $407 \mathrm{ff}$.

${ }^{23}$ Kahn-Freund, Das soziale Ideal des Reichsarbeitsgerichts, S. $172 \mathrm{ff}$.

${ }^{24}$ Ebenda, S. 16rff.

${ }^{25}$ Ebenda, S. $194 \mathrm{ff}$.

${ }^{26}$ Franz Neumann, Die politische und soziale Bedeutung der arbeitsgerichtlichen Rechtsprechung, S. $26 \mathrm{ff}$.

27 Wegen der Beteiligung der Laienbeisitzer beider sozialer Seiten; Neumann, a. a. O., S. 25 , verglich die Arbeitsgerichte insofern mit der Regierungskoalition im Reich, die aktionsunfähig sei und notwendig von Kompromiß zu Kompromiß streben müsse. 
chen Systems erfordert hätte. In dem beschriebenen und etwas eingeschränkten Gestaltungsbereich bewirkten die Arbeitsgerichte immerhin eine Fortentwicklung des Arbeitsrechts, die wie Neumann ${ }^{28}$ und Kahn-Freund ${ }^{29}$ feststellten, dahin tendierte, Härten im Einzelarbeitsverhältnis, die sich gegen Arbeitnehmer richteten, zu beseitigen; nach Neumann ${ }^{30}$ ließen die Arbeitsgerichte hier „soziales Mitleid“ walten. Auf der betrieblichen Ebene betonte das RAG den Gedanken der sozialen Arbeits- und Betriebsgemeinschaft ${ }^{31}$, was beispielsweise höhere Anforderungen an die Arbeitsdisziplin $^{32}$ oder die Einbeziehung der Arbeitnehmer in bestimmte wirtschaftliche Risiken des Arbeitgebers ${ }^{33}$ zur Folge hatte. Damit ergänzte das RAG quasi das Betriebsrätegesetz von 1920 um betriebliche Pflichten, die dem Zweck des BRG, die betrieblichen Rechte der Arbeitnehmer auszubauen, zuwiderliefen. Auch gegenüber der „Idee des Kollektivismus" ${ }^{34}$ verhielt das RAG sich in den Augen seiner Kritiker allzu reserviert: Die Kritik richtete sich beispielsweise gegen die Anerkennung der 'Tariffähigkeit von Arbeitnehmervereinigungen durch das RAG, deren Gegnerunabhängigkeit zweifelhaft sein konnte, und damit gegen eine drohende Schwächung und Zersplitterung der Gewerkschaftsbewegung. Diese sozial konservativen Tendenzen in der Rechtsprechung des RAG fanden sich im AOG von 1934 in gesteigerter Form wieder ${ }^{35}$; die Übernahme vertrauter Denk- und Argumentationsmuster in das AOG, wie z.B. der "Treue- und Fürsorgepflicht“ ( $\$ 2$ II AOG) oder der „Betriebsgemeinschaft“ und „Gemeinsamkeit" zwischen Arbeitgeber und Belegschaft ( $\mathbb{S}$ I und 2 AOG), schuf eine Brücke, die die Fortführung der bisherigen Rechtsprechung im Bereich des Individualarbeitsrechts und damit einen relativ reibungslosen Übergang der Arbeitsgerichtsbarkeit in das „Dritte Reich“ ermöglichte.

\section{Die gesetzlichen Regelungen über die Arbeitsgerichtsbarkeit im Dritten Reich}

Als Teil des gesamten Staatsapparates unterlag auch die Arbeitsgerichtsbarkeit denjenigen nationalsozialistischen Regelungen, die die politische Gleichschaltung und Kontrolle sowie die rassistische "Säuberung" der Beamten- und Richterschaft bezweckten ${ }^{36}$. Aufgrund des „Gesetzes zur Wiederherstellung des Berufsbeamtentums“

${ }^{28}$ Ebenda, S. $24 \mathrm{ff}$.

29 Otto Kahn-Freund, Das soziale Ideal des Reichsarbeitsgerichts, S. I49ff.

30 Ebenda, S. 27.

${ }^{31}$ Neumann, a.a.O., S. 29.

${ }^{32}$ Kahn-Freund, a.a. O., S. $184 \mathrm{ff}$., $188 \mathrm{ff}$.

33 Ebenda, S. $173 \mathrm{ff}$.

34 Neumann, a.a.O., S. 33 ff.

35 Bemerkenswert ist in diesem Zusammenhang, daß schon Kahn-Freund 1930 (a.a.O., S. 170f., 192 f. und 20I) auf die Parallelen der Rechtsprechung des RAG und der Entwicklung des faschistischen Arbeitsrechts in Italien hingewiesen hatte.

${ }^{6}$ Vgl. hierzu Albrecht Wagner, Die Umgestaltung der Gerichtsverfassung und des Verfahrens- und Richterrechts im nationalsozialistischen Staat, in: Weinkauff/Wagner, Die deutsche Justiz und der Nationalsozialismus, Bd. I, Stuttgart 1968, S. 195 ff., $205 \mathrm{ff}$, $223 \mathrm{ff}$. und $232 \mathrm{ff}$.; außerdem Hubert 
vom 7. April $1933^{37}$ wurden jüdische und den Arbeiterparteien angehörende oder nahestehende Richter - teils mit, teils ohne Pension - in den Ruhestand versetzt ${ }^{38}$, die freiwerdenden Stellen erhielten bevorzugt Parteigänger des NS-Regimes ${ }^{39}$. Das „Deutsche Beamtengesetz“ vom 26. Januar 1937 verpflichtete auch die Richterschaft auf das nationalsozialistische Gedankengut und auf den Führer Adolf Hitler. Aus der unabhängigen Justiz war damit endgültig und mit Gesetzeskraft ein „Vollstrecker des von der NSDAP getragenen Staates“ ( $\$$ I DBG) geworden, nachdem schon seit 1933 durch die Vielzahl der Parteibeitritte von Richtern ${ }^{40}$, die Neueinstellung NS-freundlicher Richter, die Ausrichtung der Juristenausbildung ${ }^{41}$ an nationalsozialistischen Überzeugungen und andere Arten der Beeinflussung die Richterschaft auf das NSRegime faktisch eingeschworen worden war.

Während des Krieges hielt das NS-Regime eine noch weitergehende Beeinflussung der Justiz zum Zwecke eines noch aktiveren Eintretens der Richter für nationalsozialistische Anschauungen für erforderlich: Mit den Richterbriefen ${ }^{42}$ wurde eine einheitliche nationalsozialistische Rechtsprechung insbesondere im Strafrecht und im Familienrecht sowie bei der Behandlung von Juden angestrebt; soweit sich die Ziele der politischen Machthaber nicht im Gerichtsverfahren erreichen ließen, hatten sie schon von Anbeginn an nicht davor zurückgeschreckt, durch polizeiliche Gewaltmaßnah-

Schorn, Der Richter im Dritten Reich, Frankfurt 1959; sowie Hans Mommsen, Beamtentum im Dritten Reich, Stuttgart 1966.

37 RGBI I 1933, S. 175 .

${ }^{8}$ Vgl. die Zahlenangaben für den Geschäftsbereich des Preußischen Justizministeriums, dessen Statistik Az I, 9629/34 wieder abgedruckt ist bei: Schorn, a.a. O., S. 730 f. Danach verblieben von 938 „nichtarischen “ Referendaren nur 65 im Dienst, von 238 "nichtarischen“ Gerichtsassessoren 35 und von 500 ,nichtarischen“ fest eingestellten Beamten des höheren Dienstes 2 I 4 . Entsprechende Zahlen für die Arbeitsgerichtsbarkeit konnten nicht ermittelt werden, doch dürften die Relationen dort eher noch ungünstiger gewesen sein, da die Arbeitsgerichtsbarkeit erst 1927 eingerichtet worden war und daher vor allem die Richter an den Arbeitsgerichten (I.Instanz) zum großen Teil so jung gewesen sein dürften, daß sie weder als Teilnehmer des Ersten Weltkriegs noch als Beamte des Kaiserreichs die für diese Personengruppen geltenden Erleichterungen ( $\$ 3$ II des Gesetzes vom 7.4. 1933) in Anspruch nehmen konnten.

39 Vgl. Schorn, a.a.O., S. 83 ff., und Mommsen, a.a. O., S. $39 \mathrm{ff}$.

$4^{\circ} \mathrm{Vgl}$. Schorn, a.a. O., S. 35; er spricht davon, daß sehr viele, wenn nicht die meisten Richter Mitglieder der NSDAP waren, bagatellisiert aber diesen Befund damit, daß „nicht alle" Parteimitglieder sich mit der nationalsozialistischen Gesinnung identifizierten (S.42).

4i Vgl. hierzu K. A. Eckhardt, Das Studium der Rechtswissenschaft (Der deutsche Staat der Gegenwart, Heft II, I935), sowie eine zeitgenössische Kritik an der neuen Studienordnung vom is. I. 1935 bei Heinrich Lange, Die Entwicklung der Wissenschaft vom Bürgerlichen Recht seit 1933 (Recht und Staat in Geschichte und Gegenwart, Heft 128 ), Tübingen r94I, S. I $3 \mathrm{f}$.

${ }^{42}$ Vgl. Schorn, a.a.O., S. 57 ff., sowie die ausführliche Dokumentation bei Heinz Boberach (Hrsg.), Richterbriefe, Boppard 1975. In den Richterbriefen wurden vom RMJ Urteile der verschiedenen Gerichte einer - positiven oder negativen - Kritik unterzogen; damit sollte allen Richtern die Auffassung des RMJ über die Auslegung des Rechts nach nationalsozialistischen Kriterien besonders nahegebracht werden. Richterbriefe über arbeitsgerichtliche Urteile sind nicht erschienen. 
men die gerichtlichen Urteile zu korrigieren ${ }^{43}$. Im Krieg sicherte sich das NS-Regime weitere gleichgerichtete Korrekturmöglichkeiten durch die Mitwirkung des Staatsanwalts auch in bürgerlichen Rechtsstreitigkeiten ${ }^{44}$; seine Einschaltung diente der schärferen Kontrolle dieses Gerichtszweigs - einschließlich der Arbeitsgerichtsbarkeit $(\$ 7)$. Zur Beseitigung politisch unerwünschter Zivilurteile, selbst wenn sie schon längere Zeit rechtskräftig waren, konnte ein vom Oberreichsanwalt zu beantragendes Wiederaufnahmeverfahren benutzt werden $(\mathbb{2} 2)$.

Die totale Indienstnahme - und, wenn nötig, Ausschaltung - der Gerichte fand ihren Abschluß in dem „Beschluß des Großdeutschen Reichstags“ vom 26. April $1942^{45}$, in dem Adolf Hitler sich als „oberster Gerichtsherr" bestätigen ließ; wichtig für seine Machtstellung gegenüber der Justiz war sein „Recht“, den Richter wie alle anderen Beamten, Funktionäre usw. „mit allen ihm geeignet erscheinenden Mitteln zur Erfüllung seiner Pflichten anzuhalten und bei Verletzung dieser Pflichten ... ihn im besonderen ohne Einleitung vorgeschriebener Verfahren aus seinem Amte zu entfernen“. Für die Arbeitsgerichtsbarkeit waren diese Vorbehalte des NS-Regimes, jederzeit in die Rechtsprechung einzugreifen, Urteile abzuändern oder mißliebige Richter abzusetzen, nicht so sehr wegen ihrer tatsächlichen Anwendung, sondern wegen des durch sie erzeugten immer stärker werdenden psychologischen Anpassungsdrucks auf die Richter von Bedeutung ${ }^{46}$.

Neben den allgemein für die gesamte Justiz geltenden Regelungen ergingen weitere Gesetze und Verordnungen, die speziell die Arbeitsgerichtsbarkeit betrafen; sie schränkten vor allem die sachliche Zuständigkeit der Arbeitsgerichte erheblich ein und änderten die Vorschriften über die Laienbeisitzer und die Prozeßvertretung vor den Arbeitsgerichten; die Gesetzesänderungen ergaben sich zwangsläufig aus der Beseitigung der Gewerkschaften und des Tarif- und Arbeitskampfrechts sowie der Umwandlung des Betriebsverfassungsrechts ${ }^{47}$.

Die ersten Änderungen vom Frühjahr 1933 betrafen die Zulassung der NSBO und anderer - meist national-konservativer - Arbeitnehmervereinigungen zur Prozeßvertretung vor den Arbeitsgerichten ${ }^{48}$. Damit wurde jedoch nur eine Übergangsregelung

43 Auf dem Nebeneinander und der fast beliebigen Austauschbarkeit von rechtsförmigen Verfahren und Gewaltmaßnahmen beruhte die Theorie Ernst Fraenkels vom nationalsozialistischen Staat als „Doppelstaat“. Vgl. insbesondere die beiden bei Fraenkel, Der Doppelstaat, Frankfurt/Köln 1974, (erste, amerikanische Fassung „The Dual State“ 1940), S. 243 und 246 abgedruckten Berichte über den rechtsförmigen und den gewaltförmigen Ausgang zweier Gerichtsverfahren.

44 Gesetz vom I 5.7. 194I, RGBI I, S. 383.

45 RGBl I, S. 247.

${ }^{6} \mathrm{Vgl}$. hierzu noch unten die inhaltliche Analyse der Rechtsprechung der Arbeitsgerichte zu $\ 2$ II AOG.

47 Vgl. hierzu oben S.4I ff.

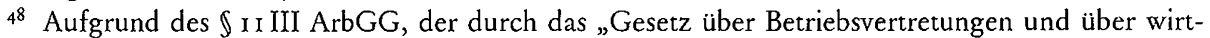
schaftliche Vereinigungen" vom 4.4. 1933 (RGBI I, S. I6r, RABI. I, S. I05) eingefügt wurde, erging am 8.4. I933 die „r. VO über die Zulassung zur Prozeßvertretung vor den Arbeitsgerichtsbehörden"; sie stellte die NSBO und die Stahlhelm-Selbsthilfe den noch bestehenden Gewerkschaften in dieser Beziehung gleich. Am 12.5. und 22. 5. folgten die 2. und 3.VO zum gleichen Thema, die we- 
bis zu dem Zeitpunkt geschaffen, in dem sich die endgültige Organisation der Arbeitnehmer im Dritten Reich herauskristallisiert hatte. Schon mit Erlaß des AOG vom 20. Januar $1934^{49}$ konnte die Prozeßvertretung für die I. arbeitsgerichtliche Instanz der schnell sich konsolidierenden DAF ausschließlich übertragen werden ( $\$ 66 \mathrm{III}$ AOG) $)^{\text {so }}$; für die Berufungs- und Revisionsinstanz wurde ohne Ausnahme der Anwaltszwang eingeführt ${ }^{s i}$.

Kurz nach der Ausschaltung der freien Gewerkschaften am 2. Mai 1933 erließ die NS-Regierung ein Gesetz ${ }^{52}$, das es ermöglichte, die gewerkschaftlichen Laienbeisitzer der Arbeitsgerichtsbarkeit durch regimetreue, vor allem der NSBO angehörende Beisitzer zu ersetzen. Die Amtszeit ${ }^{53}$ der auf dieser Grundlage von den Justizverwaltungen der inzwischen gleichgeschalteten Länder ${ }^{54}$ bzw. dem RMJss bestellten Beisitzer wurde bis zum Zeitpunkt des Inkrafttretens des AOG (insoweit I. Mai 1934) verlängert ${ }^{56}$. \$66 II AOG übertrug dann die Rechte der aufgelösten Gewerkschaften und Arbeitgeberverbände zur Benennung der Laienbeisitzer - aus den Kreisen der Arbeitnehmer und der Arbeitgeber - endgültig und einheitlich der DAF.

Die DAF hatte schon durch ihr Prozeßvertretungsmonopol in der I. Instanz sowie durch die Aufstellung der Listen, aus denen die Justizverwaltung die beiderseitigen Laienbeisitzer entnahm ${ }^{57}$, ganz erheblichen Einfluß auf die Entscheidung arbeitsrechtlicher Streitigkeiten im Dritten Reich gewonnen. Diese Position wurde noch durch die weitere Aufgabe der Rechtsberatungsstellen der DAF gestärkt, vor der Klageerhebung einen gütlichen Ausgleich zwischen den streitenden Arbeitgebern und

niger bedeutsame Arbeitnehmervereinigungen zuließen. (RGBII, S. 282, RABl I, S. I34, sowie RGBI I, Nr. 64, RABI I, S. I 55).

49 Insoweit trat das AOG am I. 5. 1934 in Kraft, vgl. $\$ 64$ I, S. 2 AOG.

so Die DAF konnte nach dem durch $\$ 66$ III AOG geänderten $\$ i I I S. I ArbGG Rechtsanwälte im Einzelfall zur Prozeßvertretung ermächtigen; soweit Nichtmitglieder der DAF eine Prozeßvertretung vor den Arbeitsgerichten benötigten, wurde erst durch das Gesetz zur Abänderung des ArbGG vom 20. 3. 1935 (RGBl I, S. 336, RABI I, S. 106) die Möglichkeit geschaffen, daß der Vorsitzende des Arbeitsgerichts dem Betreffenden einen Rechtsanwalt beiordnete.

sI Vgl. den durch \$66 III AOG geänderten \ x I II ArbGG (1935).

ऽ2 Gesetz über die Beisitzer der Arbeitsgerichts- und Schlichtungsbehörden und der Fachausschüsse für Hausarbeit vom r8. 5. 1933 , RGBI I, S. 276, RABI I, S. r 34.

s3 Sie endete turnusgemäß am Ende des Jahres 1933.

s4 Die Justizverwaltungen der Länder bestimmten die Beisitzer der Arbeitsgerichte und der Landesarbeitsgerichte; vgl. zur Gleichschaltung der bei der Machtübernahme des NS-Regimes noch nicht nationalsozialistisch regierten Länder im Lauf des Jahres 1933: Bracher, Stufen der Machtergreifung, S. $190 \mathrm{ff}$. Die Entwicklung wurde abgeschlossen durch das Gesetz über den Neuaufbau des Reichs vom 30. 1. 1934, dessen Artikel 2 kurz und bündig bestimmte: „Die Hoheitsrechte der Länder gehen auf das Reich über. Die Landesregierungen unterstehen der Reichsregierung."

ss Das RMJ bestellte die Beisitzer des RAG.

56 Gesetz über die Beisitzer der Arbeitsgerichts- und Schlichtungsbehörden und die Vertreter bei den Fachausschüssen für Hausarbeit sowie über Betriebsvertretungen vom 27. I2. 1933, RGBl I, S. I I 17 , RABl I 1934, S. 5 .

s7 Vgl. $\ 20$ des am 10.3. 1934 in neuer Fassung bekanntgemachten ArbGG, RGBl I, S. 319, RABl I, S. 104 . 
Arbeitnehmern anzustreben ${ }^{58}$. Sie machten so einen Teils9 der Güteverhandlungen vor den Vorsitzenden der Arbeitsgerichte $\left(\$ \varsigma_{4} A O G\right)$ überflüssig. Inwieweit sich diese Tätigkeit der DAF-Rechtsberatungsstellen auf die sinkende Zahl und die Struktur der arbeitsgerichtlichen Verfahren auswirkte, wird unten untersucht ${ }^{60}$.

Die Bedeutung der Arbeitsgerichte wurde jedoch nicht nur quantitativ geschmälert, es veränderte sich auch ihr inhaltlicher Tätigkeitsbereich tiefgreifend. Ihre Zuständigkeit für betriebliche und kollektive Rechtsstreitigkeiten nach $\mathbb{S}_{2} \mathrm{I}$ Nr. I, 4 und 5 ArbGG 1926 entfiel nach der Beseitigung der Tarifvertragsparteien und der Änderung der Betriebsverfassung durch das AOG ( $\mathbb{\int} 2-17$, Stellung von Betriebsführer, Gefolgschaft und Vertrauensrat ${ }^{65}$. Denn die in $\$ 2 I$ Nr. I ArbGG 1926 aufgeführten „bürgerliche(n) Rechtsstreitigkeiten zwischen Tarifvertragsparteien“ sowie die Rechtsstreitigkeiten „zwischen tarifvertragsfähigen Parteien ... aus unerlaubten, Handlungen, sofern es sich um Maßnahmen zu Zwecken des Arbeitskampfs oder um Fragen der Vereinigungsfreiheit handelt(e)“, waren im Dritten Reich von vornherein undenkbar. Dagegen behielten die Arbeitsgerichte immerhin die Möglichkeit, das Tarifrecht zu beeinflussen, obwohl ihre in \2 I Nr. I ArbGG 1926 enthaltene Zuständigkeit für Rechtsstreitigkeiten „über das Bestehen oder Nichtbestehen von Tarifverträgen “ ebenfalls entfiel ${ }^{62}$. Der Einfluß der Arbeitsgerichtsbarkeit im Tarifrecht ergab sich daraus, daß die Tarifordnungen allgemein als Rechtsverordnungen angesehen wurden ${ }^{63}$. Die Arbeitsgerichte hatten sie bei der Entscheidung von Individualstreitigkeiten anzuwenden und dabei nach den Regeln über die Auslegung von Gesetzen zu deuten. War der Wortlaut einer Tarifordnung nicht völlig eindeutig, so hatten die Arbeitsgerichte schon dadurch einen gewissen Gestaltungsspielraum. Denn die Auslegung durfte nach der Auffassung des RAG nicht engherzig sein und am Buchstaben des Gesetzes kleben, sondern sollte „dem Sinn und Zweck der Tarifordnung unter Berücksichtigung des Zusammenhangs ihrer Bestimmungen gerecht werden "664. Die relativ weite Fassung des Auslegungsspielraums macht schon deutlich, daß die Arbeitsgerichtsbarkeit sich eine gewisse Kontrollmöglichkeit gegenüber den Treuhändern der Arbeit sichern wollte, die die Tarifordnungen erließen. Eine weitere Möglichkeit der Einflußnahme der Arbeitsgerichte auf das Tarifrecht bot deren Recht, die Gültigkeit der Tarifordnungen zu überprüfen: Fehler beim Zustandekommen der Ta-

s8 Vgl. Th. Rohlfing, in: Io Jahre Arbeitsgericht. Festgabe, Berlin und Leipzig 1937, Einleitung S. 12; sowie Heinrich Jagusch, Die Rechtsberatungsstellen der Deutschen Arbeitsfront, Berlin-LeipzigWien 1940, der auf S. $32 \mathrm{ff}$. den Vorschlag machte, die insoweit ohnehin schon bedeutende Stellung der DAF auch rechtlich adäquat zu fassen und die Rechtsberatungsstellen zu Gütestellen im Sinn der ZPO zu machen, so daß die vor ihnen geschlossenen Vergleiche Vollstreckungstitel nach $\$ 794$ ZPO sein sollten.

s9 Vgl. zur statistischen Erfassung dieser Entwicklung in diesem Kapitel unten.

60 Siehe die inhaltliche Analyse der Rechtssprechung der Arbeitsgerichte zu $₫ 2$ II AOG auf S. $208 \mathrm{ff}$.

${ }_{61}$ Die faktisch schon vorher vollzogenen Maßnahmen wurden nachträglich gesetzlich sanktioniert: $\llbracket 6 s$ AOG hob das BRG, die TVVO und die VO über das Schlichtungswesen auf.

${ }_{62} \mathrm{Vgl}$. ${ }_{2} \mathrm{I}$ Nr. $\mathrm{x}$ und 2 ArbGG 1934, der nur noch die Individualstreitigkeiten aufführt.

${ }_{63}$ Hueck/Nipperdey/Dietz, AOG, $\$ 32$ Rdnr. I 8 .

${ }^{64}$ Ebenda, $\mathbb{3 2}$ Rdnr. I $32 \mathrm{~m}$. Nachw. einschlägiger Urteile des RAG. 
rifordnung, z.B. Unzuständigkeit des erlassenden Treuhänders der Arbeit oder Formmängel, hatten die Nichtigkeit der ganzen Tarifordnung zur Folge ${ }^{65}$. Derartige Verstöße kamen in der Praxis allerdings kaum vor.

Bedeutsamer waren Verstöße von Tarifordnungen gegen zwingende materiell-rechtliche Vorschriften: Verstießen einzelne Tarifbestimmungen gegen zwingendes Gesetzesrecht oder andere den Tarifordnungen übergeordnete zwingende Vorschriften ${ }^{66}$, so behandelten die Arbeitsgerichte diese Tarifbestimmungen als nichtig und wandten an ihrer Stelle das zwingende Recht an. Unter den Normen, die das RAG als zwingend ansah, waren mehrere Vorschriften aus dem Dienstvertragsrecht des BGB. Das ist deshalb bemerkenswert, weil in der juristischen Literatur zum Arbeitsrecht, gerade von den betont nationalsozialistischen Autoren, die Weitergeltung des „liberalistischen Arbeitsvertragsrechts" unter den veränderten Verhältnissen grundsätzlich in Zweifel gezogen wurde ${ }^{67}$. Daß die Arbeitsgerichte sich nicht scheuten, Tarifordnungen der Treuhänder der Arbeit für nichtig zu erklären, ihre Kontrolle mithin wirksam war, beweisen die in der Kommentarliteratur ${ }^{68}$ mitgeteilten Entscheidungen des RAG: So hat das RAG in einer Reihe von Entscheidungen Arbeitgeber verurteilt, ihren erkrankten Angestellten das Gehalt auch für die ersten drei Krankheitstage fortzuzahlen, obwohl die einschlägigen Tarifordnungen erst die Bezahlung vom vierten Tag an vorsahen und $\$ 6$ I6 II BGB lediglich den vertraglichen Ausschluß der Lohnfortzahlung verbot, den Ausschluß durch staatliche Tarifordnungen aber naturgemäß noch nicht hatte behandeln können. Das RAG wandte $\$ 6$ I6 II BGB entsprechend auf den Ausschluß der Lohnfortzahlung durch Tarifordnung an - dabei war diese Analogie durchaus nicht zwingend und widersprach den Bemühungen der nationalsozialistischen Arbeitsverwaltung, den Krankenstand durch tarifliche Vorschriften und nicht durch eine Aufsehen erregende gesetzliche Regelung zu senken ${ }^{69}$. Derartige Kontrollmöglichkeiten der Arbeitsgerichte beschränkten sich jedoch fast völlig auf

6s Ebenda, Vorbem. vor $\$ 18$ Rdnr. 18.

66 Vgl. die Aufzählung solcher Normen ebenda, AOG, $\$ 32$ Rdnr. 134 .

${ }_{67}$ Am entschiedensten wurde die neue Lehre von Wolfgang Siebert vertreten. Er begründete die Entwicklung vom Arbeitsvertrag zum „personenrechtlichen Arbeitsverhältnis“ ausführlich in: Das Arbeitsverhältnis in der Ordnung der nationalen Arbeit, Hamburg 1935. Der Meinungsstand des Jahres 1940 wird wiedergegeben bei: R. Lehmann, Entwicklung und Inhalt der Fürsorgepflicht des Unternehmers, Berlin-Leipzig-Wien 1940, S. 70 ff. Die pragmatische Haltung des RAG, das in den Generalklauseln des AOG weniger Anhaltspunkte zur Entscheidung konkreter Rechtsstreitigkeiten fand und sich daher zum Teil nach wie vor an das „liberalistische Arbeitsvertragsrecht" hielt, kritisierte Lehmann (S. 72) wie folgt: „Es kann schwerlich angenommen werden, daß das RAG bei der Erfassung des Arbeitsverhältnisses als, überwiegend personenrechtlich' oder, Rechtsverhältnis mit schuldrechtlichem Entstehungsgrund" wird stehen bleiben können."

68 Hueck/Nipperdey/Dietz, AOG, $\$ 32$ Rdnr. 134.

${ }_{69}$ Der Leitsatz der Entscheidung vom 2.6. I937 (ARS 30, 3 II ) lautet: „Bei dem Erlaß einer Tarifordnung muß sich der Treuhänder der Arbeit innerhalb der Grenzen halten, die durch zwingende Gesetzesvorschriften gezogen sind. Um eine solche Vorschrift handelt es sich im \$6 I6 I BGB, wie aus Absatz II hervorgeht. Deshalb ist die tarifliche Anordnung des Lohnfortfalls und der Lohnkürzung entgegen $\$ 6 \mathrm{1} 6 \mathrm{BGB}$ insoweit rechtsunwirksam. 
das Tarifrecht; denn die Entscheidung der betrieblichen Streitigkeiten oblag nunmehr den Treuhändern der Arbeit ${ }^{70}$. Soweit die Treuhänder der Arbeit in diesem Bereich Einzelweisungen erteilten, Verwaltungsakte erließen oder eine Art rechtsprechender Verwaltungstätigkeit ${ }^{71}$ ausübten - und dies betraf Entscheidungen über betriebliche Fragen, beispielsweise über die Notwendigkeit der Bestellung eines Vertrauensrates oder die Berechtigung des Unternehmers zur Arbeitsstreckung -, waren die Arbeitsgerichte an bestandskräftige Verwaltungsakte und -entscheidungen der Treuhänder der Arbeit gebunden ${ }^{72}$. Allerdings suchte das RAG auch in solchen Angelegenheiten, die den Treuhändern der Arbeit zur Entscheidung übertragen waren, seinen bisherigen Zuständigkeitsbereich zu behaupten oder wiederzugewinnen ${ }^{73}$.

Von geringfügigen Ausnahmen abgesehen, beschränkte sich die Tätigkeit der Arbeitsgerichte also seit 1934 auf die Entscheidung von Rechtsstreitigkeiten zwischen einzelnen Arbeitgebern und Arbeitnehmern; nur im Zusammenhang dieser Verfahren waren Rechtsfragen aus dem Tarifrecht gelegentlich als Vorfragen zu klären; betriebliche Streitigkeiten hatten die Arbeitsgerichte demgegenüber nicht mehr zu behandeln. Sie verloren damit den politisch und rechtlich brisanten Teil ihrer Funktionen.

Herschel hat dies 1938 wie folgt ausgedrückt ${ }^{74}$ : „Urteile zu grundlegenden Fragen unserer Sozial- und Volksordnung sind verhältnismäßig selten geworden. Dagegen treten Fragen von weniger grundsätzlicher Tragweite oder von nur vorübergehender Bedeutung stärker hervor, wie Eingruppierungsstreitigkeiten, Streitigkeiten aus dem Sonderarbeitsrecht der Reichsversicherungsträger, aus Gehalts- und Pensionskürzungen, aus dem Gesetz zur Wiederherstellung des Berufsbeamtentums." Gegenüber diesem unbestreitbaren Befund erscheint es als Abwehr der für die eigene Position bedrohlichen Erkenntnis, wenn Rohlfing 1937 meinte, „die zahlenmäßige Verminderung der Tätigkeit der Arbeitsgerichte [habe] nicht zur Folge, daß nunmehr die Arbeitsgerichte im Absterben begriffen wären", sondern daß nur noch diejenigen

70 \19INr. I-5 AOG.

7 Hueck/Nipperdey/Dietz, AOG, Vorbem. vor $\ 18$ Rdnr. 17, sprachen von der „rechtsprechenden Verwaltungstätigkeit des Treuhänders" durch „Verwaltungsentscheidungen“.

72 Die hier zulässige Kontrolle der Nichtigkeit durch die Arbeitsgerichte hatte in der Praxis keine Bedeutung. Vgl. hierzu: Hueck/Nipperdey/Dietz, AOG, Vorbem. vor $\$ 18$ Rdnr. 12-17. Die dort mitgeteilte Entscheidung des REG vom 24.7. I937, ARS 3 I, 86, ist vereinzelt geblieben. Dort sah der REG keine Grundlage für die Bestrafung eines Arbeitgebers, der sich wegen der zu geringen Zahl der beschäftigten Arbeitnehmer im Betrieb entgegen den mehrfachen Aufforderungen des Treuhänders der Arbeit geweigert hatte, einen Vertrauensrat in seinem Betrieb zu bilden. Der REG sah die Aufforderungen des Treuhänders der Arbeit als rechtswidrig an und kontrollierte damit die Rechtmäßigkeit einer Maßnahme des Treuhänders der Arbeit.

73 Vgl. das Urteil des RAG vom I 8. 12. 1940, ARS 4I, 67, in dem das RAG entgegen \$ I 8 II KWVO für sich in Anspruch nahm, statt des Treuhänders der Arbeit über die Lohnhöhe bei kriegsbedingten Versetzungen von Arbeitnehmern auf geringer bezahlte Arbeitsplätze zu entscheiden. Siehe auch die deutlich ablehnende Urteilsanmerkung von Mansfeld, a.a.O., S. $74 \mathrm{f}$.

74 Wilhelm Herschel, Der soziale Gedanke in der Rechtsprechung des RAG, SozPr 1938, S. 29 I ff. (29I/292). 
Streitigkeiten vor die Arbeitsgerichte kämen, die „wegen ihrer grundsätzlichen Bedeutung entschieden werden sollen oder wo die Streitigkeiten weder innerbetrieblich noch durch die Vermittlung der DAF beigelegt werden können"75. Daß der richterliche Einfluß im Bereich des Arbeitsrechts nach zehn Jahren nationalsozialistischer Sozial- und Rechtspolitik weitgehend geschwunden war, konnten auch die zahlreichen propagandistischen Verdrehungen im Resümee der Monatshefte für nationalsozialistische Sozialpolitik über zehn Jahre Rechtsprechung zum Arbeitsrecht im Dritten Reich nicht verdecken ${ }^{7}$ : „... so bewirkt heute die Dynamik des Rechts auf Arbeit, daß in aller Regel dem Rechte des Arbeiters ohne Kampf Genüge geschieht. Damit hat nicht nur unser Arbeitsleben gewonnen, damit haben auch die Arbeitsgerichte an Wert und Würde gewonnen. Während sie einst gezwungenermaßen ihre Hauptaufgabe darin sehen mußten, die trotz klarem Recht entstandenen Streitknäuel zu entwirren, können sie heute bevorzugt ihrer natürlichen Hauptaufgabe dienen, das Rechtsleben durch schöpferische Fortentwicklung des Rechtes zu bereichern."

\section{Der Rückgang des Geschäftsanfalls bei den Arbeitsgerichten}

Obwohl die Zahl der tatsächlich beschäftigten Arbeitnehmer in den Jahren von 1933 bis 1937 um mehr als sechs Millionen anstieg77, sank die absolute Zahl der vor den Arbeitsgerichten anhängigen Verfahren erheblich. Dies zeigt die Übersicht auf S. 202. Danach gingen die arbeitsgerichtlichen Verfahren besonders stark zurück in den Jahren 1933/34 - also im engen zeitlichen Zusammenhang mit der nationalsozialistischen Machtübernahme - sowie in den Jahren 1939/40 - d. h. bei Kriegsbeginn. Der Rückgang dürfte sich, wenn hierüber auch Zahlenangaben nicht ermittelt werden konnten, während des Krieges noch weiter fortgesetzt haben; die Kriegsbedingungen wurden bekanntlich allgemein zum Anlaß genommen, die Tätigkeit der zivilen Verwaltung und Justiz auf ein Mindestmaß zu beschränken. Im einzelnen ergibt die Auswertung der verfügbaren Zahlenangaben folgendes Bild: Die erstinstanzlichen und die zweitinstanzlichen Verfahren gingen in ungefähr gleichem Umfang zurück. Bei beiden halbierte sich die Zahl in etwa von 1932 bis 1934 und nochmals von 1938 bis 1940; der Arbeitsanfall der Arbeitsgerichte betrug 1940 nicht mehr ganz $25 \%$ des Volumens von 1932, und der der Landesarbeitsgerichte lag sogar unter $20 \%$. Dagegen halbierte sich die Zahl der Revisionen vor dem RAG nur einmal in den Jahren 1932 bis 1933 ; in den Jahren von 1933 bis 1940 betrug sie gleichbleibend etwa 400 . Der Anteil der Vergleiche, streitigen Endurteile und der anderen Erledigungsarten, die sich als nicht streitig kennzeichnen lassen (Versäumnisurteile, Klagerücknahmen, Anerkenntnisurteile), an der Gesamtzahl der arbeitsgerichtlichen Verfahren verschob sich

75 Theodor Rohlfing, Einleitung zu: 10 Jahre Arbeitsgericht, Berlin und Leipzig 1937, S. I 3 f. - Rohlfing war selbst Richter am Arbeitsgericht Berlin; vgl. ebenda, S. 94.

76 O.V., Wert und Würde der Arbeitsgerichte, in: Monatsheft für Nationalsozialistische Sozialpolitik I 943 , S. 39 .

77 Vgl. hierzu den 10. Bericht der RA für die Zeit vom 1.4. 1937-31.3. 1938, Beilage zum Reichsarbeitsblatt 1939, Nr. 3, S. 3 . 
nur geringfügig: Durch gerichtlichen Vergleich endete während des gesamten Zeitraums etwa ein Drittel aller Verfahren; der Anteil der streitigen Endurteile sank von etwa einem Sechstel (1932) kontinuierlich bis auf etwa ein Achtel (1940) aller Verfahren; dementsprechend stieg die Zahl der „unstreitigen“ Erledigungsarten geringfügig an.

Diese Verteilung der einzelnen Erledigungsarten läßt sich unterschiedlich deuten. Jedenfalls widerspricht sie der Auffassung von Rohlfing ${ }^{78}$. Denn wenn, wie er behauptete, verhältnismäßig mehr Streitigkeiten, die von grundsätzlicher Bedeutung oder zwischen den Parteien heftiger umstritten waren, vor die Arbeitsgerichte gekommen wären als vor 1933, so wäre ein Anstieg und nicht der festgestellte leichte Rückgang der streitigen Endurteile zu erwarten gewesen. Der zahlenmäßige Rückgang der arbeitsgerichtlichen Verfahren dürfte also noch durch die Reduzierung der Bedeutung dieser wenigen Verfahren verschärft worden sein 79 . Plausibel erscheint die Erklärung, daß im Rahmen der allgemeinen Anstrengungen im Dritten Reich, soziale Konflikte eher zu vermeiden und zu unterdrücken als sie offen auszutragen, auch im Gerichtssaal darauf hingewirkt wurde, die Streitigkeiten zu entschärfen und möglichst nicht "grundsätzlich“ zu entscheiden. Wichtiger erscheint es jedoch, den Gründen für den ganz enormen Rückgang der Zahl der arbeitsgerichtlichen Verfahren nachzugehen. $\mathrm{Daß}$ die kollektivrechtlichen Streitigkeiten wegfielen, kann hier vernachlässigt werden, da diese Streitigkeiten - ganz im Unterschied zu ihrer rechtlichen und politischen Bedeutung - quantitativ kaum ins Gewicht fielen.

Die Gründe für den zahlenmäßigen Rückgang der arbeitsgerichtlichen Verfahren sind vielschichtig. Mit den Fragestellungen, die Aufschluß über die Gründe für den Rückgang versprechen, kommen gleichzeitig allgemeinere Probleme in den Blick, die Gelegenheit bieten, die Bedeutung der Arbeitsgerichtsbarkeit in der Arbeitsverfassung des Dritten Reichs näher zu bestimmen und insbesondere die Abhängigkeit der Arbeitsgerichtsbarkeit von wichtigen Veränderungen der Arbeitsverfassung des Dritten Reichs zu untersuchen. Dabei ist bei all diesen Problemkreisen zu berücksichtigen, daß in arbeitsgerichtlichen Verfahren ganz überwiegend die Arbeitnehmer die Klägerrolle haben ${ }^{80}$. Dies ergibt sich aus dem Schutzcharakter der meisten arbeitsrechtlichen Vorschriften und aus der allgemeinen Struktur des Arbeitsverhältnisses, in dem der Arbeitgeber „das erste Sagen“ (Weisungsrecht, Ausspruch der Kündigung) hat, der Arbeitnehmer jedoch zur Durchsetzung seiner Interessen nur in Ausnahmefällen zur Selbsthilfe greifen kann. Da das AOG die Weisungsrechte des Arbeitgebers besonders umfassend ausgestaltet hatte ${ }^{81}$, gelten diese allgemeinen Aussagen verstärkt für die Arbeitsbeziehungen im Dritten Reich.

${ }_{78}$ Theodor Rohlfing, Einleitung zu: Io Jahre Arbeitsgericht, S. ${ }_{3} \mathrm{f}$.

79 Vgl. hierzu Herschels realistische Einschätzung aus dem Jahre 1938 in: Der soziale Gedanke in der Rechtsprechung des RAG, SozPr 1938, Sp. 29If.

80 Nach Blankenburg/Rogowski/Schönholz, Phänomene der Verrechtlichung und ihre Folgen Beobachtungen am Arbeitsgericht, Berlin (Wissenschaftszentrum) 1977, S. 19, waren im Jahre 1975 ca. $95 \%$ des Geschäftsanfalls der Arbeitsgerichte Klagen von Arbeitnehmern.

${ }^{81}$ \2 I AOG. 


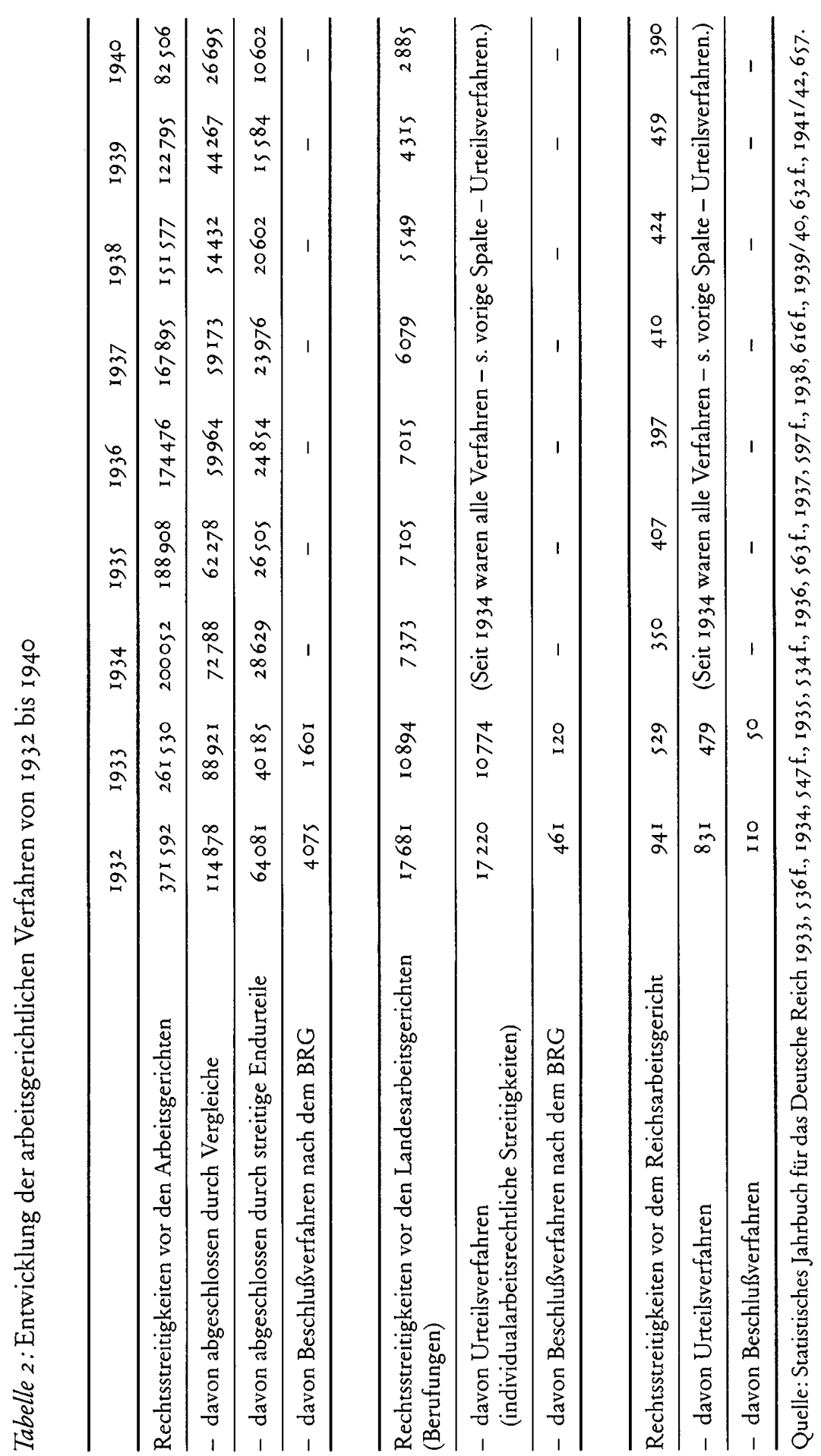


Die DAF konnte vor allem an zwei Punkten der Entstehung und Durchführung arbeitsrechtlicher Streitigkeiten eingreifen: Zum einen im Betrieb über ihre Betriebsobmänner und die Vertrauensräte, zum anderen über die DAF-Rechtsberatungsstel$l^{1 e n}{ }^{82}$. Rohlfing meinte 1937, der "Gedanke der Betriebsgemeinschaft", wonach Arbeitsstreitigkeiten zunächst betriebsintern zu bereinigen seien, habe sich zunehmend durchgesetzt ${ }^{8}$. Daran ist sicher richtig, daß oppositionelle Arbeitnehmer durch die Zerschlagung ihrer legalen und illegalen Organisationen und die polizeiliche und strafrechtliche Verfolgung ${ }^{84}$ entmutigt waren und wegen der vordergründigen innenund außenpolitischen Erfolge des NS-Regimes keine ausreichende personelle Basis mehr hatten; das hatte zur Folge, daß sie Konflikten mit dem Arbeitgeber, aus denen sich arbeitsrechtliche Streitigkeiten hätten ergeben können, aus dem Wege gingen. Auch für politisch nicht engagierte Arbeitnehmer bedeutete die Beseitigung der Gewerkschaften, daß ein wichtiger Rückhalt für das Durchstehen eines Rechtsstreites vor den Arbeitsgerichten fehlte. Zum anderen trifft es auch zu, daß Arbeitgeber nach 1933 eher zu sozialen Zugeständnissen bereit waren ${ }^{85}$ als vor der Zerschlagung der politischen und gewerkschaftlichen Organisationen der Arbeitnehmer durch das NSRegime, wenn auch die Größenordnung dieser Zugeständnisse schwer einzuschätzen ist. Denn die Arbeitgeber brauchten wegen der Kontrolle der DAF, der NSDAP und des Staatsapparates über die Arbeitnehmerschaft nicht zu befürchten, daß weitergehende, die Unternehmen ernsthaft belastende Forderungen aus der Arbeitnehmerschaft durchgesetzt werden könnten.

Weiter hat Rohlfing ${ }^{86}$ berichtet, daß die DAF-Rechtsberatungsstelle Berlin mit ca. 38000 außergerichtlichen „Vergleichen und Ausgleichsversuchen“ die Zahl der gerichtlichen Vergleiche mit ca. 9700 in den Jahren $1935 / 36$ erheblich übertraf. Selbst wenn die Richtigkeit dieser Zahlen unterstellt wird, begegnet ihre Aussagekraft einigen Bedenken: Erstens ist keineswegs sicher, daß alle bei den DAF-Rechtsberatungsstellen erfaßten Fälle ernsthafte Streitfälle waren, die jemals eine Chance gehabt hätten, vor Gericht gebracht zu werden. Zweitens macht Rohlfing keinerlei Angaben über ähnliche streitschlichtende Aktivitäten der gewerkschaftlichen und anwaltlichen Rechtsvertreter in Arbeitsstreitigkeiten vor 1933. Die Annahme liegt nahe, daß die DAF-Rechtsberatungsstellen hier wenigstens teilweise Funktionen übernommen haben, die zuvor andere rechtsberatende Stellen wahrgenommen hatten.

Im Zusammenhang mit der Vergleichsförderung durch die DAF-Rechtsberatungsstellen meinte andererseits Franz Neumann, es könne „kein einziger Rechtsstreit

${ }^{82}$ Vgl. zu ihrer Rechtsstellung im Arbeitsgerichtsverfahren oben S. $196 \mathrm{f}$.

83 Theodor Rohlfing, Einleitung zu: ro Jahre Arbeitsgericht, S. I 2. Ähnlich: o. V., Wert und Würde der Arbeitsgerichte, Monatshefte für nationalsozialistische Sozialpolitik 1943, S. 39.

${ }_{4} \mathrm{Vgl}$. hierzu Walter Wagner, Der Volksgerichtshof im nationalsozialistischen Staat, Stuttgart 1974, S.95-205.

8s So führten im Rahmen des von der DAF initiierten „Leistungskampfs“ zahlreiche Arbeitgeber soziale Reformen auf Betriebsebene durch. Vgl. hierzu Mason, Sozialpolitik, S. 25 If.

86 Theodor Rohlfing, Einleitung zu: ro Jahre Arbeitsgericht, S. I 2. 
ohne die Zustimmung der DAF vor die Arbeitsgerichte gebracht werden " ${ }^{487}$, und deutete damit eine weitere Erklärung für den Rückgang der arbeitsgerichtlichen Verfahren an. Auch Neumanns Aussage gilt nur mit Einschränkungen. Nach \x I I ArbGG I 934 hatte die DAF zwar das Monopol für die Prozeßvertretung vor den Arbeitsgerichten in erster Instanz, doch bestand hier kein Vertretungszwang - im Unterschied zur Berufungs- und Revisionsinstanz, wo nach \ Ir II ArbGG 1934 Anwaltszwang herrschte. Arbeitnehmer wie Arbeitgeber konnten also durchaus persönlich Klage vor den Arbeitsgerichten erheben und die Klage ohne Zustimmung der DAF bis in die letzte Instanz verfolgen. Entscheidend war jedoch - und dies bestätigt Neumanns Behauptung im wesentlichen -, daß die DAF einem nicht rechtskundigen Mitglied, in der Regel also einem Arbeitnehmer, die Prozeßführung erheblich erschweren konnte, indem sie die Gewährung des Rechtsschutzes versagte.

Nach Ziff. 4 und 5 ihrer Rechtsschutzordnung ${ }^{88}$ hatten die DAF-Rechtsberatungsstellen den Rechtsschutz nur zu gewähren, „wenn die beabsichtigte Rechtsverfolgung Aussicht auf Erfolg [bot] und mit den nationalsozialistischen Grundsätzen und den

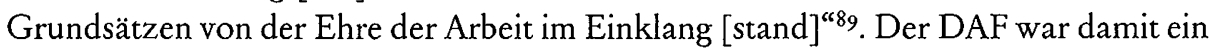
weites Ermessen bei der Entscheidung über die Rechtsschutzgewährung eingeräumt. Sie konnte daher den Rechtsschutz für Prozesse, die aus politischen oder sonstigen Gründen unerwünscht waren, ablehnen und auf diese Weise denjenigen, der sich dennoch zur Erhebung der Klage entschloß, als unbelehrbar oder politisch unzuverlässig brandmarken. Auch mit ihren Rechtsberatungsstellen hatte die DAF also ein Instrument zur Verfügung, mit dem sie arbeitsgerichtliche Verfahren verhindern konnte; es ist anzunehmen, daß sie davon auch Gebrauch machte, wenn es zur Sicherung des Arbeitsfriedens im nationalsozialistischen Sinne erforderlich erschien.

Der Rückgang der arbeitsgerichtlichen Verfahren könnte auch auf Veränderungen der Arbeitsmarktlage zurückgeführt werden. In der neueren rechtssoziologischen Literatur $^{9 \circ}$ wird eine derartige Beziehung zwischen der Häufigkeit arbeitsgerichtlicher Verfahren und der Entwicklung am Arbeitsmarkt hergestellt; danach nehmen insbesondere Kündigungsschutzprozesse und andere mit Entlassungen zusammenhängende Verfahren in Zeiten der Voll- oder Überbeschäftigung gegenüber Zeiten mit hoher Arbeitslosenquote $a b^{91}$; denn die Bereitschaft von Arbeitnehmern, einen Prozeß wegen eines gekündigten Arbeitsverhältnisses anzustrengen, hängt unter anderem auch

${ }^{87}$ Franz Neumann, Behemoth, S. 494 .

${ }^{88}$ Sie ist abgedruckt bei: Heinrich Jagusch, Die Rechtsberatungsstellen der DAF, Berlin-LeipzigWien 1940 , S. I $38 \mathrm{ff}$.

89 Ebenda, S. 138.

$9 \circ \mathrm{Vgl}$. Thilo Ramm, Zur Bedeutung der Rechtssoziologie für das Arbeitsrecht, in: Naucke/Trappe (Hrsg.), Rechtssoziologie und Rechtspraxis, Neuwied und Berlin 1970, S. I 54 ff., und Blankenburg/Rogowski/Schönholz, Phänomene der Verrechtlichung und ihre Folgen - Beobachtungen am Arbeitsgericht, Berlin (Wissenschaftszentrum) 1977.

${ }_{91}$ Vgl. Blankenburg, u. a., a.a. O., S. I : „Es bedarf keiner weiteren Erklärung, daß in einer wirtschaftlich angespannten Situation Konflikte aus dem Arbeitsverhältnis häufiger und härter auftreten und daß damit auch die Gerichte in größerer Zahl bemüht werden." 
von den Möglichkeiten ab, einen neuen Arbeitsplatz zu finden. Umgekehrt ändert sich auch das Kündigungsverhalten der Arbeitgeber mit den konjunkturellen Schwankungen: Die Massenarbeitslosigkeit wird tendenziell dazu benutzt, politisch unbequeme und weniger geeignete Arbeitnehmer zu entlassen und auf diese Weise eine besonders disziplinierte, einsatzbereite und qualifizierte Belegschaft zu bilden. Überbeschäftigung dagegen zwingt die Arbeitgeber dazu, auch weniger qualifizierte oder einsatzbereite Arbeitnehmer einzustellen und zu halten, weil sie nicht ersetzt werden können, und dazu, qualifizierten Arbeitnehmern Zugeständnisse zu machen, um sie von der Abwanderung in andere Betriebe abzuhalten. Kündigungen werden in dieser Arbeitsmarktlage möglichst vermieden. Diese Feststellungen treffen in besonderem Maße auf die Entwicklung im Dritten Reich zu, da die Arbeitsmarktlage sich in der Zeit von 1933 bis 1939 grundlegend änderte: An die Stelle der Massenarbeitslosigkeit des Jahres 1933 trat schon 1936 in einigen rüstungswirtschaftlich wichtigen Gewerbezweigen und 1939 ganz allgemein ein erheblicher Arbeitskräftemangel ${ }^{92}$. Die Beseitigung der Massenarbeitslosigkeit und die vom NS-Regime entfachte Rüstungskonjunktur haben somit ebenfalls zur Abnahme der arbeitsgerichtlichen Verfahren beigetragen ${ }^{93}$.

Der Rückgang der Verfahren vor den Arbeitsgerichten könnte weiter dadurch mitverursacht worden sein, daß sich durch Veränderungen des materiellen Arbeitsrechts die Chancen der Rechtsschutzsuchenden verschlechtert haben. Hier sollen zunächst nur die Gesetzesänderungen behandelt werden, die das Individualarbeitsrecht betrafen und nicht erst einer sehr weitgehenden Konkretisierung durch die Gerichte oder die Arbeitsverwaltung bedurften, wie vor allem die Generalklauseln des AOG, die die Weisungsbefugnisse der Arbeitgeber verstärkten ${ }^{94}$, den Austauschcharakter des Arbeitsverhältnisses abschwächten und statt dessen den durch Treue- und Fürsorgepflichten geprägten Gemeinschaftscharakter betonten"s und das Arbeitsverhältnis dem vom NS-Regime definierten „Gemeinwohl“ dienstbar machten ${ }^{96}$. Die Gesetzgebung des Dritten Reichs zum Individualarbeitsverhältnis beschränkte sich auf wenige Änderungen. Das geplante und in mehreren Entwürfen des RAM und des Arbeitsrechtsausschusses der Akademie für Deutsches Recht vorgelegte Gesetz über das Arbeitsverhältnis wurde nicht verabschiedet ${ }^{97}$. Deshalb blieb es während der gesamten Dauer des Dritten Reichs bei den generalklauselartigen Korrekturen, die das AOG am Individualarbeitsrecht anbrachte, und insbesondere bei einer Änderung des Kündigungsrechts ${ }^{9}$.

92 Hierzu ausführlicher oben $\mathrm{S} .73 \mathrm{ff}$.

93 Vgl. hierzu: o. V., Wert und Würde der Arbeitsgerichte, Monatshefte für nationalsozialistische Sozialpolitik 1943, S. 39.

$94 \$ 2$ I AOG.

95 $\ 2$ II AOG; vgl. zur Anwendung dieser Generalklausel durch die Arbeitsgerichte in diesem Kapitel unten.

96 \ $\mathrm{AOG}$.

97 Vgl. hierzu ausführlicher oben S. 95 ff.

98 IS $\varsigma 6 \mathrm{ff}$. AOG, ergänzt durch das Gesetz vom 30. I I. 1934, RGBl I, S. I 193, RABl I, S. 273. 
Der Kündigungsschutz wurde durch das AOG in zweierlei Hinsicht verschlechtert: Zum einen fielen die in $\$ 84 \mathrm{I}$ Nr. $1-3$ BRG aufgeführten zum Einspruch berechtigenden Gründe weg, die vor allem dem Schutz gewerkschaftlich und politisch engagierter Arbeitnehmer hatten dienen sollen ${ }^{99}$. Der für den „Normalfall“ einer nicht politisch, sondern durch das sonstige Verhalten des Arbeitnehmers oder durch wirtschaftliche Gründe bedingten Kündigung zentrale Einspruchsgrund der „unbilligen Härte" ${ }^{\text {"100 }}$ blieb dagegen bestehen. Bei der Auslegung dieses Begriffs hielten sich die Arbeitsgerichte an die von der nationalsozialistischen Gesetzgebung vorgezeichnete Linie: Im „Normalfall“ des nicht aus politischen Gründen gekündigten Arbeitnehmers änderte sich an der Auslegung nichts Wesentliches, da das RAG explizit an seine Rechtsprechung vor 1933 anknüpfte ${ }^{\mathrm{IOI}}$. Soweit dagegen eine Kündigung politisch begründet worden war, nahmen die Arbeitsgerichte einen Verstoß des Arbeitnehmers gegen den gemeinen Nutzen von Volk und Staat ( $\$$ r AOG) an und bestätigten dementsprechend diese Kündigungen ${ }^{\mathrm{IO}}$.

Einen gewissen Schutz gewährten die Arbeitsgerichte nur denjenigen gewerkschaftlich organisierten oder sozialdemokratischen Arbeitnehmern, die vor Erlaß des Gesetzes vom 4. April 1933 und damit vor der ersten Ächtung der bisherigen Betriebsräte und Gewerkschaften durch ein nationalsozialistisches Gesetz gewerkschaftliche oder betriebsverfassungsrechtliche Funktionen ausgeübt hatten, ohne sich aktiv gegen das NS-Regime betätigt zu haben. Diesen Arbeitnehmern attestierten die Arbeitsgerichte immerhin, daß sie die Auflösung des Arbeitsverhältnisses nicht im Sinne eines wichtigen Grundes für eine fristlose Kündigung verschuldet hatten ${ }^{103}$. Kommunistischen Arbeitnehmern enthielten die Arbeitsgerichte selbst diesen geringfügigen Schutz vor ${ }^{104}$. Zum anderen unternahm der nationalsozialistische Gesetzgeber schon kurz nach Erlaß des AOG den Versuch, die Wirksamkeit des eben erst geregelten und offensichtlich nicht ausreichenden Kündigungsschutzes zu verbessern; denn im Gesetz vom 30. November $1934^{105}$ wurde die Höhe der Entschädigung, die der Arbeitgeber dem zu Unrecht gekündigten Arbeitnehmer zu zahlen hatte, von höchstens vier Monatslöhnen ( $\$ 58$ S.2 AOG) auf höchstens sechs, in besonderen Fällen höchstens zwölf Monatslöhne heraufgesetzt ( $\$ 58$ S. 3 i.d.F. vom 30. November 1934). Damit wurde durchaus ein verstärkter Anreiz gegeben, gegen ungerechtfertigte Kündigun-

99 Danach berechtigten zum Einspruch: diskriminierende und politisch motivierte Kündigungen, Kündigungen ohne Angabe von Gründen sowie Kündigungen wegen Verweigerung einer vertraglich nicht vereinbarten Arbeitsleistung.

$100 \$ 84 \mathrm{INr} .4 \mathrm{BRG}$ und $\$ 56 \mathrm{I}$ AOG.

10r Vgl. die bei Hueck/Nipperdey/Dietz, AOG, $\mathbb{5 6} 6 \mathrm{Rdnr}$. 17, zusammengestellte Judikatur.

102 Vgl. die zahlreichen Beispiele bei K. Breucker, Gemeinschaftswidrigkeit als Kündigungsgrund in der neuesten arbeitsgerichtlichen Rechtsprechung, JW 1936, S. I 189 , sowie die Darstellung bei Michael Stolleis, Gemeinwohlformeln im nationalsozialistischen Recht, Berlin 1974, S. I $34 \mathrm{ff}$.

103 Vgl. z. B. die Urteile des LAG Frankfurt vom 27. I I. I933, ARS 19, S. 207, und des LAG Essen vom 3. I. 1934, ARS 20, S. 77.

104 Vgl. Die Urteile des RAG vom I 4. 3. 1934, ARS 20, S. 196, vom 28.3. 1934, ARS 20, S. 201 , und vom 21.3. 1934, ARS 20, S. 24 r.

1os RGBI I, S. I193, RABI I, S. 273. 
gen seitens des Arbeitgebers mit der Kündigungswiderrufsklage vorzugehen. Die Änderungen des Kündigungsschutzes dürften also vor allem diejenigen Arbeitnehmer, die sich in den ersten Jahren des Dritten Reichs in den Betrieben gegen das NSRegime engagierten und deshalb gekündigt wurden, von gerichtlichen Schritten abgehalten haben; doch erklärt dies den Rückgang der arbeitsgerichtlichen Verfahren nur zu einem relativ geringfügigen Teil.

Die Entwicklung des Arbeitsrechts im Dritten Reich tendierte zu einem Anwachsen des staatlichen Einflusses auf die Gestaltung der Löhne und Arbeitsbedingungen ${ }^{106}$ sowie auf die Begründung und Beendigung der Arbeitsverhältnisse ${ }^{107}$. Damit wurde die öffentlich-rechtliche Komponente des Arbeitsrechts immer stärker betont. Das hatte zur Folge, daß der Tätigkeitsbereich der Arbeitsgerichte mehr und mehr ausgehöhlt wurde; denn ihr Tätigkeitsbereich war auf zivilrechtliche Rechtsstreitigkeiten beschränkt ${ }^{\mathrm{108}}$; die durch Verwaltungsmaßnahmen der Treuhänder der Arbeit oder der Arbeitsämter entschiedenen Konflikte waren in der Regel der Beurteilung durch die Arbeitsgerichte entzogen.

Besonders deutlich wird diese Verschiebung zugunsten der Arbeitsverwaltung am Beispiel der Beendigung von Arbeitsverhältnissen gegen den Willen der betroffenen Arbeitnehmer; hatte vor 1933 nur der Arbeitgeber die Möglichkeit, das Arbeitsverhältnis durch Kündigung zu beenden, und ging er damit das Risiko ein, in einem Kündigungsschutzprozeß vor den Arbeitsgerichten zu unterliegen, so wurde ihm diese konfliktträchtige Maßnahme zunehmend durch die Arbeitsämter abgenommen; denn diese wurden, zunächst zum Zweck der Bekämpfung der Arbeitslosigkeit, dann aber vor allem zur Sicherung eines planmäßigen Arbeitseinsatzes in den für das NSRegime wichtigen Bereichen, ermächtigt, in bestehende Arbeitsverhältnisse einzugreifen und sie gegebenenfalls zu beenden: Schon einige der seit 1933 durchgeführten Maßnahmen zur Bekämpfung der Arbeitslosigkeit führten zur Beendigung von Arbeitsverhältnissen gegen den Willen der Betroffenen; so wurden die Arbeitsämter $1934^{109}$ ermächtigt, die Entlassung jüngerer Arbeitnehmer zu veranlassen, damit deren Arbeitsplätze für ältere Familienväter, die schon längere Zeit arbeitslos waren, aber auch für „alte Kämpfer" der NSDAP frei wurden. Die jungen Arbeitnehmer erhielten keine gleichwertigen Arbeitsplätze zugewiesen, sondern sollten vor allem in die Landwirtschaft gelenkt werden. Gegen die von den Arbeitsämtern angeordneten Entlassungen vor den Arbeitsgerichten zu klagen, hatte nur in Ausnahmefällen eine geringe Erfolgsaussicht.

Noch deutlicher tritt diese Entwicklung bei den Arbeitseinsatzmaßnahmen der Vorkriegs- und Kriegszeit hervor: Die Dienstverpflichtungen für kriegsvorbereitende Maßnahmen, wie beispielsweise den Bau des Westwalls 1938/39, oder für die Rüstungsproduktion im Kriege wurden von den Arbeitsämtern ausgesprochen; da diese

\footnotetext{
106 Vgl. hierzu oben S. $82 \mathrm{ff}$. und $133 \mathrm{ff}$.

107 Vgl. hierzu oben S. $73 \mathrm{ff}$. und $129 \mathrm{ff}$.

${ }_{108}^{\$ 2}$ ArbGG 1934 .

109 VO über die Verteilung von Arbeitskräften, RGBI I, S. 786, RABl I, S. r 99.
} 
Verwaltungsakte der Arbeitsämter direkt an die betroffenen Arbeitnehmer gerichtet waren, entfiel von vornherein die Zuständigkeit der Arbeitsgerichte für Streitigkeiten wegen dieser Dienstverpflichtungen. Dies ist um so bemerkenswerter, als die Drohung mit der Dienstverpflichtung als Disziplinierungsmittel von Arbeitgebern benutzt wurde, ja die Dienstverpflichtung nicht selten den Charakter einer disziplinarischen Maßnahme annahm und einer - besonders folgenschweren - Kündigung gleichkam. Daß es sich hierbei nicht um Einzelfälle handelte, geht aus der Häufung der Berichte aus dem Jahr 1939 über derartige Vorfälle hervor. So wurde aus mehreren Betrieben berichtet, daß die Wortführer bei Auseinandersetzungen über Akkordreduzierungen kurzerhand den Arbeitsämtern überantwortet wurden; diese sorgten dafür, daß die gemaßregelten Arbeitnehmer „bei Befestigungs- und Straßenbauten Verwendung“ fanden oder "nach dem Westen zu Befestigungsarbeiten gehen“ mußten ${ }^{10}$. Obwohl also durch die Dienstverpflichtungen mittelbar Individualstreitigkeiten zwischen Arbeitnehmern und Arbeitgebern mitgeregelt werden konnten und Arbeitgeber durch entsprechende Angaben bei den Arbeitsämtern Dienstverpflichtungen veranlassen konnten, wurden diese Streitigkeiten wegen des öffentlich-rechtlichen Charakters der staatlichen Maßnahmen nicht vor den Arbeitsgerichten ausgetragen. Für den Rückgang der arbeitsgerichtlichen Verfahren war sicher auch die indirekte Wirkung dieser Entwicklung von Bedeutung: Wer als Arbeitnehmer allzu konfliktfreudig auftrat und seine Interessen entschieden vor den Arbeitsgerichten vertrat, mußte damit rechnen, seinen Arbeitsplatz zu verlieren und zur Zwangsarbeit unter noch schlechteren Bedingungen herangezogen zu werden.

Schließlich könnte auch die Anwendung des materiellen Arbeitsrechts durch die Arbeitsgerichte selbst das Mißtrauen der Arbeitnehmer hervorgerufen haben, so daß sie wegen mangelnder Erfolgsaussichten von vorneherein darauf verzichteten, vor den Arbeitsgerichten zu klagen. Wenn, wie eingangs festgestellt wurde, die Arbeitnehmer in der weit überwiegenden Zahl der Verfahren die Kläger waren, so ist in unserem Zusammenhang danach zu fragen, ob die Rechtsprechung der Arbeitsgerichte Arbeitnehmern, wenn sie klagten, geringe Erfolgsaussichten bot, oder ob die Arbeitnehmer weiterhin auf eine sozial ausgleichende, die Arbeitgeber jedenfalls nicht bevorzugende Entscheidungspraxis vertrauen konnten. Damit stellt sich die Frage nach der inhaltlichen Entwicklung der arbeitsgerichtlichen Rechtsprechung.

\section{Die inhaltliche Entwicklung der Entscheidungspraxis -} am Beispiel der Rechtsprechung zu $\$ 2 I I A O G$

Die Arbeitsgerichte blieben im Dritten Reich im wesentlichen zuständig für bürgerlich-rechtliche Individualstreitigkeiten aus Arbeitsverhältnissen. Gerade in diesem Bereich hatten sich die Arbeitsgerichte in der Weimarer Zeit durch eine sozial einfühlsame und sachlich fundierte Rechtsprechung allgemeine Anerkennung vor allem auch

Io Deutschland-Berichte der Sopade 1939, S.46; vgl. auch S. 729, wo über die Drohung eines Arbeitgebers mit Verschickung an die „Westfront" berichtet wird. 
in der Arbeitnehmerschaft erworben ${ }^{11}$. Die materiellen Gesetzesänderungen des Individualarbeitsrechts während des Dritten Reichs standen einer Fortsetzung dieser jedenfalls nicht arbeitnehmerfeindlichen - Rechtsprechung nicht entgegen. Insbesondere die Generalklausel des $\ 2$ II AOG, die den Arbeitgebern eine „Fürsorgepflicht“ und den Arbeitnehmern eine "Treuepflicht" auferlegte und durchaus an die Rechtsprechung der Arbeitsgerichtsbarkeit zum Individualarbeitsrecht während der Weimarer Zeit anknüpfte ${ }^{112}$, bot den Arbeitsgerichten in einem begrenzten Rahmen Gelegenheit zur Beseitigung sozialer Mißstände in den Arbeitsbeziehungen.

Die maßgebliche Beteiligung der DAF an den arbeitsgerichtlichen Verfahren - durch Prozeßvertretung vor den Arbeitsgerichten und durch Benennung der Laienbeisitzer in allen Instanzen - schuf eine weitere Voraussetzung für die Entwicklung der arbeitsgerichtlichen Rechtsprechung in der angedeuteten Richtung. Denn die DAF setzte sich allgemein für soziale Verbesserungen - unterhalb einer Reizschwelle, die durch die gemeinsamen Interessen des NS-Regimes und der für die Aufrüstung wichtigen Wirtschaftszweige festgelegt war - ein ${ }^{\mathrm{r} 3}$, um dem NS-Regime das Vertrauen der Arbeitnehmerschaft zu sichern.

Inwieweit die Rechtsprechung der Arbeitsgerichte die damit vorhandenen Möglichkeiten zur Fortentwicklung der sozialen Komponente des Individualarbeitsrechts realisierte, läßt sich am sinnvollsten anhand der Judikatur zur „Treue- und Fürsorgepflicht" des $\ 2$ AOG untersuchen. Denn diese Generalklausel eröffnete den Arbeitsgerichten die Möglichkeit, bestehende Vorschriften über das Arbeitsverhältnis - vor allem diejenigen des Dienstvertrags- und allgemeinen Schuldrechts im BGB - neu zu interpretieren oder gar als unvereinbar mit dem neuen Recht nicht anzuwenden und auf diese Weise die Pflichten sowohl der Arbeitnehmer wie auch der Arbeitgeber auszuweiten.

\section{Die Auslegung des $\mathbb{2}_{2}$ II AOG in der Arbeitsrecbtswissenschaft}

Die Rechtsprechung der Arbeitsgerichte ist vor dem Hintergrund der Entwicklung in der arbeitsrechtlichen Literatur zu $\ 2$ AOG zu betrachten ${ }^{114}$; hier kamen die in $\ 2$

11 Franz Neumann, Die politische und soziale Bedeutung der arbeitsgerichtlichen Rechtsprechung, S. 36, spricht davon, daß die Arbeitsgerichtsbarkeit „trotz heftigster Kritik“ an bestimmten Urteilen „von der Arbeiterschaft absolut bejaht" wurde. Das dürfte nicht nur auf die Beteiligung von Arbeitnehmervertretern als Laienbeisitzer an der Rechtsprechung, sondern auf den Inhalt dieser Rechtsprechung zurückzuführen sein.

112 Vgl. Otto Kahn-Freund, Das soziale Ideal des Reichsarbeitsgerichts, S. 1 $72 \mathrm{ff}$. und $194 \mathrm{ff}$.

113 Vgl. zu den Aktivitäten der DAF für eine Verlängerung des Urlaubs und für die Verbesserung des betrieblichen Arbeitsschutzes: Mason, Sozialpolitik, S. $183 \mathrm{ff}$. und $187 \mathrm{ff}$.

114 Bernd Rüthers, Die unbegrenzte Auslegung, Frankfurt 1973, S. 379 ff., behandelt ebenfalls die Entwicklung des Arbeitsrechts in Wissenschaft und Rechtsprechung des Dritten Reichs, auch bei ihm steht wie in der vorliegenden Arbeit die Frage nach den Gestaltungsmöglichkeiten der Arbeitsgerichte im Vordergrund. Anders als hier geht Rüthers das Problem primär durch eine Analyse der wissenschaftlichen Lehrmeinungen zum „Wesen des Arbeitsverhältnisses“ - der Vertragstheorie (S. $38{ }_{3} \mathrm{f}$.) und der Eingliederungstheorie (S. $384 \mathrm{ff}$.) - an und untersucht die „Bedeutung, die der Wertgrundlage jedes Rechtsgebietes für die Auslegung und Anwendung des Rechtes zukommt“ 
AOG angelegten Gestaltungsmöglichkeiten der Arbeitsgerichte in verschiedenen Nuancierungen ${ }^{15}$ am klarsten zum Ausdruck. Starke wissenschaftliche Impulse ${ }^{116}$ erhielt die Fortentwicklung des Arbeitsrechts im Sinne des AOG und der nationalsozialistischen Anschauungen von der Gestaltung des Arbeitslebens vor allem von Wolfgang Siebert $^{117}$. Sein bahnbrechendes Wirken in der Arbeitsrechtswissenschaft des Dritten Reichs schätzte Siebert selbst 1943 wie folgt ein ${ }^{118}$ : „Die Möglichkeit, aus $\ 2$ II AOG unmittelbar bestimmte Ansprüche abzuleiten, habe ich mehrfach näher zu begründen und $\mathrm{zu}$ verteidigen versucht ... Sie ist zu Anfang nur noch vertreten worden von Grussendorf ${ }^{119}$ und von Höhn ${ }^{120}$. Im übrigen wurde sie zunächst ziemlich allgemein abgelehnt, weil sie zu einer Rechtsunsicherheit führen müsse; außerdem wurde nach dem Inkrafttreten des AOG allgemein die Notwendigkeit einer scharfen Unterscheidung zwischen der sozialen und öffentlich-rechtlichen Betriebsgemeinschaft und dem wirtschaftlichen und vertraglichen Arbeitsverhältnis vertreten ${ }^{121}$. Allmählich hat dann aber die Auffassung von der unmittelbaren Wirksamkeit des \2 II als Rechtsgrundlage für bestimmte Ansprüche im Schrifttum immer mehr Zustimmung gefunden ${ }^{122}$." Siebert betonte also von Anfang an die Bedeutung der Generalklauseln des AOG für die grundlegende Anpassung des Arbeitsrechts an nationalsozialistische Vorstellungen. Er wollte dabei die Generalklauseln des AOG in dreifacher Hinsicht angewandt wissen: Die Generalklauseln sollten Grundlage für die Auslegung arbeitsrechtlicher Vorschriften sein. Insofern deckte sich die Auffassung Siebers mit der allgemein vertretenen Meinung. Weiterhin befürwortete er, die Generalklauseln als Maßstab bei der Prüfung der Frage heranzuziehen, inwieweit die arbeitsvertraglichen Regelungen des $\mathrm{BGB}, \mathrm{HGB}$ und der $\mathrm{GewO}$ - insbesondere diejenigen, die den schuldrechtlichen

(S. 392). Während Rüthers sich also an den von der Rechtswissenschaft des Dritten Reichs entwikkelten "Theorien“ zum Arbeitsverhältnis orientiert, soll in der vorliegenden Arbeit der Schwerpunkt bei der Analyse der Billigkeitsrechtsprechung des RAG und damit bei der Einordnung und Bewertung seiner rechtsfortbildenden Tätigkeit gesetzt werden.

is Vgl. hierzu: R. Lehmann, Entwicklung und Inhalt der Fürsorgepflicht des Unternehmers, S. 70 ff.

116 Vgl. hierzu die zeitgenössische Einschätzung von Heinrich Lange, Die Entwicklung der Wissenschaft vom bürgerlichen Recht seit 1933, Tübingen 1941, S. I s : „Den stärksten Einfluß auf sie [die Rechtsprechung] übte deshalb Siebert aus, der seine Lehren in enger Anlehnung an die Bedürfnisse der Praxis entwickelte und der Rechtsprechung in der unzulässigen Rechtsausübung, im Rechtsmißbrauch und dem personenrechtlichen Gemeinschaftsverhältnis Prägungen schenkte, die diese vor allem als Deckmantel für Billigkeitsentscheidungen gegen das Gesetz aufgriff."

'17 Vgl. grundlegend Wolfgang Siebert, Das Arbeitsverhältnis in der Ordnung der nationalen Arbeit, Hamburg 1935 .

118 In: Reuss/Siebert, Die konkrete Ordnung des Betriebes, 3.ergänzte Auflage, Berlin-Leipzig-Wien 1943, S. 90.

119 Grussendorf, Kommentar zum AOG, Berlin 1934, S. 19.

120 Höhn, Rechtsgemeinschaft und Volksgemeinschaft, 1935, S.6I f.

221 Vgl. z.B. Mansfeld/Pohl/Steinmann/Krause, Die Ordnung der nationalen Arbeit, $\$ 2$ Anm. $2 \mathrm{~d}$, und Hueck/Nipperdey/Dietz, AOG, I. Aufl. München-Berlin 1934, $\$ 2$ Anm. I 5 ff., anders die 2. und 3. Aufl. $\$ 2$ Anm. I6s.

${ }_{122}$ Vgl. die Nachweise bei: Siebert, in: DAR 1937, S. 46 ff., und bei Hueck, Festschrift für Hedemann, 1938, S. $312 \mathrm{ff}$. 
Austauschcharakter des Arbeitsverhältnisses betonten und damit im Gegensatz zur nationalsozialistischen Gemeinschaftsideologie standen - unter der Herrschaft des Nationalsozialismus noch weitergelten sollten; diese Auffassung Sieberts war bis 1939 umstritten, konnte sich jedoch danach allgemein durchsetzen, da das bis dahin widerstrebende RAG sich seiner Auffassung mit dem Urteil vom 13 . September $1939^{123}$ anschloß. Das RAG stellte sich nunmehr ebenfalls auf den Standpunkt, daß die Anwendung von Vorschriften des allgemeinen Schuldrechts auf das Arbeitsverhältnis als „personenrechtliches, auf Treue und Fürsorge gegründetes Gemeinschatsverhältnis“ nicht ohne nähere Prüfung erfolgen könne, und daß insbesondere die $\mathbb{S} 323$ bis 326 BGB „nicht für das Arbeitsverhältnis passen“. Schließlich wollte Siebert aus den Generalklauseln unmittelbar Rechte und Pflichten der Parteien des Arbeitsverhältnisses abgeleitet wissen. Dies war der eigentliche Streitpunkt in der juristischen Diskussion; die juristische Literatur folgte hier Siebert etwas langsamer ${ }^{124}$, war jedoch etwa seit Beginn des Krieges so gut wie einhellig auf Sieberts Seite ${ }^{\mathrm{I} 25}$.

Lediglich das RAG verhielt sich bis zum Ende des Dritten Reichs reserviert gegenüber dieser Auffassung - zumindest beschränkte es sich auf vorsichtigere Formulierungen; daß die Unterschiede in der Sache jedoch geringer waren, als es die gelegentlich deutliche Polemik arbeitsrechtlicher Autoren ${ }^{\mathrm{I2}}$ gegen das RAG erwarten ließ, geht daraus hervor, daß das RAG unter Verwendung etwas flexiblerer, nicht allein auf $\mathbb{2}$ II AOG gestützter Formeln ${ }^{127}$ ebenfalls Rechte und Pflichten ableitete, die sich nicht

${ }_{123}$ ARS 37, S. 230 ff. Vgl. zu diesem Urteil, das über den Kündigungswiderspruch eines jüdischen Arbeitnehmers entschied, die ausführliche Besprechung bei: Bernd Rüthers, Die unbegrenzte Auslegung, S. 394 ff. Der Auffassung von Rüthers (S. 395), wonach in dieser Entscheidung „der Gemeinschaftsgedanke durch das RAG im entscheidenden Gegensatz zu seiner eigenen, eindeutig nationalsozialistischen Wertgrundlage verwendet" worden sei, kann nicht zugestimmt werden. Vgl. hierzu unten S. $226 \mathrm{ff}$.

124 Vgl. Siebert, in: DAR 1937, S. $46 \mathrm{ff}$, und Hueck, in: Festschrift für Hedemann, 1938, S. $312 \mathrm{ff}$.

12s Vgl. die Literaturangaben bei: Hueck/Nipperdey/Dietz, AOG, $\$ 2$ Rdnr. $16 \mathrm{~s}$.

${ }^{126}$ Ebenda heißt es: „Das RAG dagegen weigert sich bis heute, aus der in $\ 2$ II AOG formulierten Treue- und Fürsorgepflicht allein irgendwelche Ansprüche abzuleiten." R. Lehmann, Entwicklung und Inhalt der Fürsorgepflicht des Unternehmers, S. 72 f. meint: „Diese etwas schwankende Haltung ist wohl darin begründet, daß das RAG über das Wesen des Arbeitsverhältnisses noch zu keinem endgültigen Ergebnis gekommen ist. Es kann schwerlich angenommen werden, daß das RAG bei der Erfassung des Arbeitsverhältnisses als ,überwiegend personenrechtlich' oder ,Rechtsverhältnis mit schuldrechtlichem Entstehungsgrund' wird stehenbleiben können."

127 Laut Hueck/Nipperdey/Dietz, AOG, $\$ 2$ Rdnr. 16 s, bemühte es z. B. das „Wesen des Arbeitsverhältnisses als eines auf gegenseitiger Treue und Fürsorge begründeten Gemeinschaftsverhältnisses". Hierher gehören auch der wiederholt herangezogene Gleichbehandlungsgrundsatz und die rechtliche Anerkennung nicht-gesetzeskonformer, aber eingebürgerter (üblicher) betrieblicher Regelungen als „konkrete Ordnung des Betriebs“. Vgl. zu letzterer: Reuss/Siebert, Die konkrete Ordnung des Betriebes, 3.ergänzte Aufl., Berlin-Leipzig-Wien 1943. Die dort an der Judikatur des RAG geäußerte Kritik beruhte letztlich darauf, daß das RAG mit der Anerkennung einer konkreten Ordnung des Betriebes die Autonomie des Arbeitgebers gegenüber der staatlichen Kontrolle durch die Teuhänder der Arbeit betonte. Auf diese Weise schwächte das RAG gelegentlich Tendenzen der arbeitsrechtlichen Normsetzung der Vierjahresplanphase und des Zweiten Weltkriegs ab, die die Kontrollbefugnisse der staatlichen Arbeitsverwaltung gegenüber den Betrieben stärken soll- 
ohne weiteres aus den bestehenden gesetzlichen Regelungen ergaben. Und die Vorbehalte, die z.B. in einem Urteil des RAG vom I 8 . Dezember $1940^{128}$ gegen $\mathbb{2}$ II AOG als „Quelle für besondere Ansprüche des Gefolgsmannes“ aufrechterhalten wurden, waren nur noch äußerst geringfügig ${ }^{129}$.

Es läßt sich also die deutliche Tendenz in der arbeitsrechtlichen Literatur feststellen, die Anwendung schuldrechtlicher Vorschriften auf das Arbeitsverhältnis zurückzudrängen und gegenüber seinem Austauschcharakter den durch verstärkte Treue- und Fürsorgepflichten gekennzeichneten Gemeinschaftscharakter zu betonen. Dieser Tendenz folgte die Rechtsprechung der Arbeitsgerichte - wenn auch mit einem gewissen zeitlichen Abstand und einer etwas vorsichtigeren und flexibleren Haltung und Sprache. Mit der Abschwächung des Austauschcharakters des Arbeitsverhältnisses nahmen die NS-Juristen eine Korrektur vor, die in - vordergründig - vergleichbarer Weise von der Sozialdemokratie in den Beratungen des Dienstvertragsrechts des BGB angestrebt worden war ${ }^{130}$. Auch nach dem Scheitern dieser Bemühungen waren die Stimmen nicht verstummt, die die schuldrechtlichen Vorschriften aus dem Arbeitsverhältnis zurückzudrängen versuchten. So äußerte Sinzheimer in einer Arbeit von 1914: „Die Regeln über die Unmöglichkeit der Leistung, über das Rücktrittsrecht, über die Gesamtschuldverhältnisse werden daraufhin zu überprüfen sein, ob sie, so gut sie für den Sachgüterverkehr passen, auch für den Arbeitsverkehr geeignet sind. " ${ }_{131}$ Natürlich bestand zwischen der im Dritten Reich herrschenden Auffassung und der der Sozialdemokratie und Sinzheimers ein fundamentaler Unterschied: Während die Abwendung vom Schuldrecht des BGB im arbeitsrechtlichen System Sinzheimers und in den politischen Zielsetzungen der Sozialdemokratie die Funktion hatte, eine kraftvolle und unabhängige Mitbestimmung und Selbstverwaltung der Arbeitnehmerschaft zu stützen und zu verstärken, diente sie im Dritten Reich als unzulänglicher Ersatz dafür, daß gerade diese selbständige Interessenwahrung durch die Arbeitnehmerschaft vom NS-Regime mit allen Mitteln unterdrückt wurde. Zudem

ten. Doch darf m. E. diese Auseinandersetzung nicht überbewertet werden, da die von der Rechtsprechung entschiedenen Fälle keine grundlegende Bedeutung hatten.

${ }_{128} \mathrm{ARS}_{4} \mathrm{I}, \mathrm{S}$. 55 ff. (60).

129 Das RAG (ARS 4I, S.60) machte den Anspruch nach $\$ 2$ II AOG nur von „bestimmten Notwendigkeiten, welche sich aus der konkreten Gestaltung des Arbeitsverhältnisses ergeben“, abhängig. Siebert, in: Reuss/Siebert, Die konkrete Ordnung des Betriebs, S. 89, stellte 1943 fest, das RAG habe mit diesem Urteil „seine früher ablehnende und dann schon zunehmend abgeschwächte Ansicht über $\ 2$ II AOG als Anspruchsgrundlage aufgegeben“".

${ }_{130} \mathrm{Vgl}$. hierzu Martin Martiny, Integration oder Konfrontation? Studien zur Geschichte der sozialdemokratischen Rechts- und Verfassungspolitik, Bonn-Bad Godesberg 1976, sowie Thomas Vormbaum, Sozialdemokratie und Zivilrechtskodifikation, Berlin 1977; außerdem die zeitgenössische Kritik von Anton Menger, Das Bürgerliche Recht und die besitzlosen Volksklassen, I890, sowie Otto von Gierke, Der Entwurf eines Bürgerlichen Gesetzbuchs und das Deutsche Recht, I 889.

131 Hugo Sinzheimer, Über den Grundgedanken und die Möglichkeit eines einheitlichen Arbeitsrechts für Deutschland, Heft I der Schriften des Verbandes Deutscher Gewerbe- und Kaufmannsgerichte, Berlin 1914, wieder abgedruckt in: Hugo Sinzheimer, Arbeitsrecht und Rechtssoziologie, Frankfurt und Köln 1976, Bd. I, S. 35 ff. (50). 
diente die Formel vom Gemeinschaftsverhältnis durchaus nicht nur als Vehikel für sozialpolitische Verbesserungen, sondern eröffnete inhaltlich weitgehend nicht festgelegte Interpretationsspielräume für den Rechtsanwender, die ebensogut eine Verstärkung der Pflichtenstellung der Arbeitnehmer oder Arbeitgeber erlaubten. Das Gemeinschaftsdenken führte also zunächst einmal zu größerer Rechtsunsicherheit und setzte den Rechtsanwender verstärkt auch allgemeinpolitischen Argumentationen und damit dem Einfluß der nationalsozialistischen Machthaber aus. Es ist so als eine juristische Form zu verstehen, die, im Verbund mit der steigenden organisatorischen und persönlichen Abhängigkeit der Richter vom NS-Regime, eine stärkere Manipulation der Rechtsanwendung mittels Definition des Inhalts der Gemeinschaft je nach den aktuellen politischen Erfordernissen ermöglichen sollte. Die Diskussion um den Austausch- oder Gemeinschaftscharakter des Arbeitsverhältnisses ist damit auch ein typisches Beispiel dafür, wie die Nationalsozialisten an vorhandene und berechtigte Tendenzen anknüpften, aber durch die Veränderung der faktischen Voraussetzungen ihrer Verwirklichung demagogisch verfälschten und auf diese Weise als sozialen Fortschritt ausgaben, was ihren ganz anders gearteten Zielvorstellungen diente ${ }^{\mathrm{x} 32}$.

\section{Die Bedeutung des $\$ 2$ II AOG für die Fortentwicklung einzelner arbeitsrechtlicher Probleme durch die Rechtsprechung}

Die Generalklauseln des AOG und ihre Funktionen als Auslegungsregel, als Prüfungsmaßstab für die Geltung von individualarbeitsrechtlichen Vorschriften und als unmittelbare Anspruchsgrundlage waren jedoch nicht völlig neu. In der Weimarer Zeit hatten die Arbeitsgerichte aufgrund der schuldrechtlichen Generalklausel des $\$ 242$ BGB ihrer Vorstellung von der gerechten und sachgemäßen Gestaltung des Individualarbeitsverhältnisses Geltung verschafft ${ }^{133}$; und auch der Gemeinschaftsgedanke, den das RAG aus $₫ 66 \mathrm{Nr} . \mathrm{x}, 3$ und 6 BRG ableiten konnte, hatte schon in der Weimarer Zeit zu einer Modifizierung des $\$ 6$ is BGB geführt ${ }^{134}$. Daher stellt sich die Frage, welche spezifischen Auswirkungen die Umorientierung der Literatur und Rechtsprechung auf die Gestaltung des Individualarbeitsverhältnisses im Dritten Reich hatte. Mit anderen Worten: Sind nur die Begründungen für gleichbleibende Ergebnisse ausgetauscht worden, oder haben die neuen Generalklauseln das materielle Ergebnis der Rechtsprechung beeinflußt? Um diese Frage zu beantworten, sol-

132 Ähnlich verhielt es sich beispielsweise auch mit der Verlängerung der Kündigungsfristen im Arbeitsrecht durch Tarifordnungen der Treuhänder der Arbeit. Zwar entsprach diese einer alten Forderung der Gewerkschaften und bezweckte ursprünglich, den gekündigten Arbeitnehmern ausreichend Zeit zur Suche nach einem neuen Arbeitsplatz zu geben. Für das NS-Regime stand jedoch nicht dieser sozialpolitische $Z$ weck, sondern die aus rüstungswirtschaftlichen Gründen angestrebte Erschwerung des Arbeitsplatzwechsels im Vordergrund der Überlegungen. Einen kurzen Überblick über die Entwicklung gibt: Erich Wurche, Die Weiterentwicklung des Arbeitsrechts durch die Reichstreuhänder der Arbeit, Diss. Jena 1942, S. $103 \mathrm{f}$.

${ }_{133}$ Vgl. die bei Otto Kahn-Freund, Das soziale Ideal des Reichsarbeitsgerichts, S. 163 und 174 genannten und kritisierten Entscheidungen.

${ }^{134}$ Vgl. ebenda, S. $174 \mathrm{ff}$. 
len im folgenden einige Streitfragen aus dem Individualarbeitsrecht und ihre Behandlung in der Weimarer Zeit und im Dritten Reich vergleichend untersucht werden; dabei wird nur auf solche Problembereiche eingegangen, in denen bemerkenswerte Änderungen erfolgten oder wenigstens von Autoren im Dritten Reich angestrebt wurden ${ }^{135}$.

\section{Änderung von Arbeitgeberpflichten?}

Bei den Arbeitgeberpflichten ging die Diskussion vor allem um die Ausweitung des Schutzes der Rechtsgüter (Leben, Gesundheit, Eigentum) der Arbeitnehmer im Betrieb, die Gleichbehandlung der Arbeitnehmer bei Zahlung von Gratifikationen und betrieblicher Altersversorgung, die Pflicht zur Gewährung von Urlaub und die Pflicht zur Weiterbeschäftigung bzw. Wiedereinstellung des Arbeitnehmers nach rechtswidriger Kündigung des Arbeitsverhältnisses durch den Arbeitgeber. Im Bereich des Arbeiterschutzes ${ }^{136}$ wirkte sich die Fürsorgepflicht der Arbeitgeber während des Dritten Reiches in mehrfacher Hinsicht zugunsten der Arbeitnehmer aus: Die öffentlichrechtlichen Arbeitgeberpflichten zum Gesundheitsschutz und zur Unfallverhütung wurden als arbeitsvertragliche Mindestpflichten im Rahmen des $\$ 6$ 18 BGB angesehen ${ }^{137}$; die Überwindung der herkömmlichen Abgrenzung zwischen öffentlich-rechtlichen und bürgerlich-rechtlichen Arbeitsschutzvorschriften und damit die Effektivierung des Arbeitsschutzes im Individualarbeitsverhältnis gehörte zwar schon zum Programm von Arbeitsrechtlern verschiedener Grundauffassung während der Weimarer Zeit ${ }^{138}$, konnte sich aber damals noch nicht im vollen Umfang durchsetzen ${ }^{139}$. Dieser Schritt wurde erst im Dritten Reich vollzogen.

Auch dadurch, daß z.B. die Anforderungen an die vom Arbeitnehmer zu erbringenden Beweise gering gehalten wurden ${ }^{14}{ }^{\circ}$ und daß solche Arbeitgeber, die ihre Arbeit-

135 Zu dem Vergleich wurden je eine zuverlässige Darstellung des Arbeitsrechts aus der Phase der Weimarer Republik vor der Weltwirtschaftskrise - Walter Kaskel, Arbeitsrecht, 3. Aufl. Berlin 1928 und aus der Endphase des Dritten Reichs - Hueck/Nipperdey/Dietz, AOG, 4. Aufl. 1943-herangezogen. Im übrigen wird besonders die Rechtsprechung des Reichsarbeitsgerichts berücksichtigt.

${ }_{136}$ Vgl. zur Normsetzung auf diesem Gebiet oben S. $86 \mathrm{ff}$. und $143 \mathrm{ff}$.

137 Hueck/Nipperdey/Dietz, AOG, $\mathbb{2}$ Rdnr. 17.

${ }_{138} \mathrm{Vgl}$. Hugo Sinzheimer, Grundzüge des Arbeitsrechts, 2.Aufl., Jena 1927, S. I6 I f.: „Denn soweit die Schutzpflicht öffentlich-rechtlich geregelt ist, schließt sie auch die privatrechtliche Regelung ein... Diese Regelungen wirken nicht nur öffentlich-rechtlich, sondern auch privatrechtlich." Ähnlich auch H.C. Nipperdey, Die privatrechtliche Bedeutung des Arbeiterschutzes, in: Festgabe für das Reichsgericht, 1929, Bd.IV, S. ${ }_{20}$ ff., der ausführte, daß die öffentlich-rechtlichen Schutzbestimmungen „zur konkretisierenden Ausfüllung der privatrechtlichen Generalklauseln“ heranzuziehen seien.

139 Vgl. zur Auffassung Kaskels, daß sämtliche Pflichten des Arbeitsschutzrechts nur dem Staat und nicht dem Beschäftigten gegenüber bestünden, in: Arbeitsrecht, S. 193 ff., und Kaskels Beitrag zur Festschrift für H. Brunner, Die rechtliche Natur des Arbeiterschutzrechtes.

$1_{40}$ Das RAG formulierte die Anforderungen in seinem Urteil vom 12.6. 1940, ARS 39, 403 (404) wie folgt: „Der Beschäftigte hat nur nachzuweisen, daß Mängel in der Beschaffenheit des Arbeitsraums und damit ein ... vermeidbarer, ordnungswidriger ... gefährdender Zustand vorhanden war, und 
nehmer einem anderen Arbeitgeber zeitweilig überließen und auf dessen Schutzmaßnahmen keinen Einfluß nehmen konnten, doch für dessen Verschulden miteintreten mußten ${ }^{141}$, wurde im Dritten Reich die Durchsetzung von Schadensersatzansprüchen geschädigter Arbeitnehmer durchaus erleichtert. Dabei handelte es sich jedoch nur um bescheidene Verbesserungen in Randbereichen des betrieblichen Gesundheitsschutzes; das wird an einer Entscheidung des RAG vom 27. April $1938^{142}$ deutlich: Kläger war ein an Asthma und Bronchitis leidender, arbeitsunfähiger Schießmeister, der sich seine Leiden durch Gas- und Staubentwicklung, die durch eine neue Trocknungsmethode hervorgerufen wurde, in den Salzlagern der Beklagten zugezogen hatte, bei der er beschäftigt gewesen war. $\mathrm{Da}$ die Erkrankungen des Klägers noch nicht als Berufskrankheiten i.S.d. gesetzlichen Unfallversicherung anerkannt waren und der Kläger daher keine Berufsunfallrente erhielt, verlangte er von der Beklagten Schadensersatz wegen Verletzung ihrer Fürsorgepflicht nach \$6 I 8 BGB. Obwohl das RAG in Übereinstimmung mit den Vorinstanzen feststellte, daß der Kläger sich seine Krankheiten „wesentlich im Betriebe der Beklagten zugezogen habe“, den Kausalzusammenhang zwischen der Verletzungshandlung der Beklagten und der Schädigung des Klägers also bejahte, wies es die Klage mit der Begründung ab, die Beklagte habe die Verletzung nicht verschuldet; denn „die Schädigung [sei] betrieblich nicht zu vermeiden gewesen ... . jedenfalls nicht nach dem damaligen Stand der Technik. Die Beklagte habe seit 1928 ständig versucht, der Staubentwicklung Herr zu werden, das sei ihr aber erst nach einigen Jahren gelungen ${ }^{143}$."

Gegen die Revisionsrüge, die Vorinstanzen hätten den Verschuldensbegriff in diesem Zusammenhang verkannt, verwahrte sich das RAG wie folgt: „Angesichts der tatsächlichen Feststellung, daß die Trocknung der Ammoniaksalze für einen wettbewerbsfähigen Absatz notwendig war, daß die Staubentwicklung dabei betrieblich bedingt gewesen, und daß die Beklagte ständig darauf bedacht gewesen ist, der Staubentwicklung Herr zu werden, ist die Verschuldensfrage mit Recht verneint worden." ${ }^{444}$ Das RAG fand es also keiner Beanstandung wert, wenn ein Arbeitgeber eine (möglicherweise) gesundheitsschädliche neue Produktionsmethode aus Wettbewerbsgründen einführte, ohne ihre Auswirkungen auf die Gesundheit der Arbeitnehmer zuvor überprüft zu haben. Obwohl der Arbeitgeber den Grund für das Gesundheitsrisiko gesetzt hatte, belastete das RAG den Arbeitnehmer und nicht den Arbeitgeber mit den Folgen dieses Gesundheitsrisikos, wenn nur der Arbeitgeber sich im Rahmen seiner wirtschaftlichen und technischen Möglichkeiten um die Entschär-

daß diese Mängel nach dem natürlichen Verlauf der Dinge geeignet waren, die später eingetretenen Gesundheitsschädigungen hervorzurufen oder in ibrer Entwicklung zu fördern." (Nachträgliche Unterstreichungen vom Verf. A. K.)

141 Vgl. RAG, Urteil vom 5.6. 1940, ARS 40, ro.

${ }_{142}$ RAG, ARS 33, 6r; die Fallgestaltung wird vereinfacht und auf das hier diskutierte Problem zugespitzt wiedergegeben.

143 Ebenda, S.65.

144 Ebenda, S.67. 
fung der Gefahren bemüht hatte ${ }^{\mathrm{I} 45}$. Angesichts dieses engen Verschuldensbegriffs blieben die oben dargestellten Entwicklungen zur Verbesserung des betrieblichen Gesundheitsschutzes in der Rechtsprechung der Arbeitsgerichte weitgehend folgenlos. Der Schutz von Arbeitnehmereigentum, das der Arbeitnehmer in den Betrieb mitbrachte, wurde, wohl etwas wirksamer als der Gesundheitsschutz, ebenfalls verbessert. Die Bewachungs- und gegebenenfalls sogar Versicherungspflichten des Arbeitgebers, beispielsweise in bezug auf Kleider des Arbeitnehmers, die dieser vor der Arbeit gewechselt und in einer Baubude aufbewahrt hatte, weiteten sich erheblich aus. Während das RAG $1930^{146}$ insoweit noch „für die Fürsorgepflicht des Arbeitgebers ziemlich enge Grenzen "147 gezogen hatte, war 194I/ $42^{148}$ "ohne weiteres eine Pflicht des Unternehmers anzunehmen, auch für den Schutz des Eigentums des Gefolgschaftsangehörigen Sorge zu tragen “ ${ }^{{ }^{149}}$. Daß darüber hinaus auch die Klage auf Erfüllung der Schutzpflichten im Dritten Reich fast allgemein anerkannt wurde ${ }^{\mathrm{iso}}$, während sie in der Weimarer Zeit sehr umstritten war ${ }^{\text {ssI }}$, hatte für die Praxis kaum Bedeutung; denn derartige Klagen waren, selbst wenn sie anerkannt wurden, gegenüber der individuellen Arbeitsverweigerung, gegenüber der Beschwerde beim Betriebsrat bzw. Vertrauensrat, dem DAF-Betriebsobmann oder dem Arbeitgeber selbst und gegenüber der Anzeige beim Gewerbeaufsichtsamt die weitaus schwerfälligeren und zeitraubenderen Rechtsbehelfe und wurden deshalb kaum einmal erhoben ${ }^{152}$.

In der Weimarer Zeit bestand ein Anspruch auf Gratifikationen nicht schon dann, wenn sie in einem Betrieb bloß jährlich regelmäßig ausgezahlt wurden, sondern erst dann, wenn sie ausdrücklich „vereinbart oder in dem Geschäftszweig so üblich [waren], daß sie als stillschweigend vereinbart [galten]" ${ }^{\text {"s3 }}$. Im Dritten Reich wurde es dagegen aufgrund des aus dem Gemeinschaftsgedanken und der Fürsorgepflicht gefolgerten Gleichbehandlungsgrundsatzes nicht als zulässig angesehen, wenn ein Unternehmer „allgemein im Betriebe Gratifikationen zahlt, einen Beschäftigten will-

145 Die Rechtsprechung verfuhr damit im privatrechtlichen Gesundheitsschutz gemäß $₫ 6$ I 8 BGB ähnlich wie die öffentlich-rechtliche Gesetzgebung zum Betriebsschutz und die Verwaltungspraxis der Gewerbeaufsichtsämter, die ebenfalls i.d.R. die Entscheidung des Arbeitgebers über den Einsatz gefährlicher Produktionsmethoden oder die Verwendung gefährlicher Arbeitsstoffe unangetastet ließen, diese Gefahren jedoch nachträglich einzudämmen versuchten, so gut es ging.

146 RAG, Urteil vom 2.7. 1930, ARS 10, 30; vgl. auch RAG, Urteil vom 30. x I. 1929, ARS 7, S. 482.

147 So Hueck in der Anmerkung zu RAG, ARS 10, S. 30 (33).

${ }_{148}$ RAG, Urteile vom I 8. I I. 194I, ARS 43 , S. 261, und vom 3.7. 1942, ARS 46, S. 49.

149 So die Zusammenfassung bei Hueck/Nipperdey/Dietz, AOG, $\$ 2$ Rdnr. 17.

iso Ebenda.

Isı Vgl. für die Anerkennung: Kaskel, Arbeitsrecht, S. Iss Anm. 2 m. w. Nachw. Gegen die Anerkennung: Sinzheimer, Grundzüge des Arbeitsrechts, S. I 58 m. w. Nachw.; Sinzheimer wies auf die größere Durchschlagkraft des Weigerungsrechts der Arbeitnehmer hin.

is $2 \mathrm{Vgl}$. Hueck/Nipperdey/Dietz, AOG, $\$ 2$ Rdnr. 17. Dort wird für die Zeit von 1933 bis 1943 kein einziges einschlägiges Urteil mitgeteilt.

is3 Kaskel, Arbeitsrecht, S. I 24. 
kürlich davon aus[zu]nehmen ${ }^{\text {s4 }}$." Ebenso verlief die Entwicklung beim Anspruch der Arbeitnehmer auf betriebliche Pensionen ${ }^{\text {Is }}$. Diese Entwicklung des Gleichbehandlungsgrundsatzes durch die Rechtsprechung der Arbeitsgerichte im Dritten Reich hatte allerdings auch eine Kehrseite: Als Ausfluß der Treuepflicht wurde es bezeichnet, daß Arbeitnehmer bei einer ungünstigen wirtschaftlichen Entwicklung des Unternehmens auf ihre Gratifikations- und Pensionsansprüche ganz oder teilweise verzichten mußten und daß sie diese bei Verletzung ihrer Treuepflicht verloren ${ }^{156}$. Die Gleichbehandlung stand also unter dem Vorbehalt wirtschaftlicher Prosperität des Unternehmens und des persönlichen Wohlverhaltens der Arbeitnehmer; sie enthielt damit neben der materiellen Verbesserung Elemente der Disziplinierung und des Leistungsansporns.

Einen Anspruch der Arbeitnehmer auf Gewährung bezahlten Erholungsurlaubs erkannte das RAG sowohl vor ${ }^{157}$ als auch nach ${ }^{158} 1933$ nur dann an, wenn hierfür eine besondere vertragliche oder sonstige Rechtsgrundlage bestand. Wenn auch die Bedeutung dieser Rechtsprechung um so geringer wurde, als schon in der Weimarer Zeit und besonders auch im Dritten Reich für immer weitere Kreise der Arbeitnehmerschaft ein tariflicher ${ }^{159}$ oder sogar gesetzlicher ${ }^{160}$ Urlaubsanspruch geschaffen wurde, ist sie doch aus einem anderen Grund bemerkenswert: Das RAG widersetzte sich hier der sozialen Fortentwicklung eines wichtigen Teilbereichs des Arbeitsrechts, obwohl diese Entwicklung aufgrund des $\$ 2$ AOG ohne weiteres möglich gewesen wäre und alle Zeichen der Zeit für den Schritt zur allgemeinen Anerkennung des Urlaubsanspruchs sprachen: Einer der wesentlichen Aufgabenbereiche der DAF lag im Bereich der Freizeitgestaltung und setzte den (von der DAF auch entsprechend geförderten ${ }^{16 r}$ ) allgemeinen Urlaub voraus. Die arbeitsrechtliche Literatur erkannte allgemein (aufgrund des $\ 2$ AOG oder aufgrund von Gewohnheitsrecht) einen Urlaubsanspruch $\mathrm{an}^{162} . \$ 74$ des Entwurfs eines Gesetzes über das Arbeitsverhältnis sah

is 4 Hueck/Nipperdey/Dietz, AOG, $\ 2$ Rdnr. 17 b mit weiteren Nachweisen der Rechtsprechung des RAG.

iss Kaskel, Arbeitsrecht, S. 126 f., setzte für einen Anspruch des Arbeitnehmers die „Zusage“ des Arbeitgebers voraus. Hueck/Nipperdey/Dietz, AOG, $\$ 2$ Rdnr. 17 c belegen die Rechtsprechung des RAG seit 1937, wonach „die Verpflichtung zur Gewährung eines Ruhegehaltes sich auch aus dem Grundsatz der Gleichbehandlung ergeben kann“".

is6 Hueck/Nipperdey/Dietz, AOG, $\mathbb{\$} 2$ Rdnr. I 7 b und $17 \mathrm{c}$.

157 Kaskel, Arbeitsrecht, S. I 57 f. (I 58 ): „... besteht eine Verpflichtung zur Gewährung von Urlaub nicht schon kraft Gesetzes, sondern nur, soweit sie vertraglich vereinbart ist."

${ }_{158}$ Hueck/Nipperdey/Dietz, AOG, $\ 2$ Rdnr. $17 \mathrm{c}$ : „Es bedarf deshalb keiner besonderen Vereinbarung, um den Anspruch auf Urlaub zu begründen; anders jedoch immer noch das RAG ARS 32, S. $147 ; 45$, S. 98 , das sich auch hier weigert, . . einen Anspruch auf Urlaub unmittelbar aus $\ 2$ abzuleiten, sondern einen besonderen Rechtsgrund verlangt."

159 Vgl. Peter Lahnstein, Fortentwicklung des Arbeitsrechts in den Tarifordnungen seit 1934, Diss. Freiburg/Brsg. 1938, S. $53 \mathrm{ff}$.

${ }^{160}$ Für jugendliche Arbeitnehmer durch $₫ 2$ I JSchG vom 30.4. 1938, RGBl I, S. 437, RABI III, S. 105.

${ }^{161} \mathrm{Vgl}$. hierzu Mason, Sozialpolitik, S. $183 \mathrm{ff}$.

162 Vgl. die Urteilsanmerkung von Hueck zu RAG, Urteil vom 17.7. 1942, ARS 45, S. 98 (ro8) mit ausführlichem Literaturnachweis; Hueck näherte sich hier, wenn er gegenüber der Rechtsprechung 
schon 1938 einen Mindesturlaub von sechs Tagen vor ${ }^{163}$, und die Arbeitsgerichte scheuten sich an anderer Stelle ${ }^{164}$ nicht, die Vorschläge des AVG-Entwurfs zum geltenden Recht zu erheben. Auch die Instanzgerichte ${ }^{165}$ wandten sich zunehmend der neuen Auffassung zu. Offensichtlich wollte das RAG derart weitgehende Funktionen des Gesetzgebers - hier wäre die Bestimmung der jeweiligen Urlaubsdauer durch das RAG erforderlich geworden - nicht übernehmen.

Auch im Bereich des Kündigungsrechts hielt das RAG an seiner vor 1933 schon gefestigten Rechtsprechung fest ${ }^{166}$ und ließ sich hieran nicht durch eine in der arbeitsrechtlichen Literatur stark ${ }^{167}$ aber nicht einhellig ${ }^{168}$ vertretene Auffassung beirren: Das allgemeine ${ }^{169}$ Kündigungsschutzrecht verhalf in der Regel weder vor ${ }^{170}$ noch nach $^{171} 1933$ dem zu Unrecht gekündigten Arbeitnehmer zur Fortsetzung des Arbeitsverhältnisses, sondern nur zu einer Entschädigung für den Verlust des Arbeitsplatzes. Einen wirksamen Schutz gegen den Verlust des Arbeitsplatzes bot demgegenüber nur die Möglichkeit, eine Kündigung als nïchtig anzusehen und ihr damit von

des RAG auf die entgegengesetzte „Auffassung des deutschen Volkes“ verwies, dem in der Strafjustiz so verhängnisvollen "gesunden Volksempfinden“.

163 Aufgestellt vom Arbeitsrechtsausschuß der Akademie für Deutsches Recht, Hamburg 1938.

${ }_{164} \mathrm{Vgl}$. den Leitsatz des Urteils des LAG Leipzig vom I0. 9. I943, ARS 46, S. 142 : „Die in dem Akademie-Entwurfe eines Gesetzes über das Arbeitsverhältnis vorgeschlagenen Bestimmungen über Sonderzuwendungen (Gratifikationen) beruhen auf sorgfältiger Erforschung der schon jetzt in weiten Kreisen des Wirtschaftslebens befolgten Übung und können deshalb schon jetzt als herrschende Rechtsüberzeugung betrachtet werden."

165 Das RAG hob im zitierten Fall, ARS 45 , S. 98 ff., das Urteil des LAG Düsseldorf auf, das den Urlaubsanspruch anerkannt hatte.

166 Vgl. die Urteile des RAG vom 20. 2. 1935 , ARS 23 , S. 58 und vom 7.3. 1936, ARS 28, S. 125, in dem sich das RAG (S. 133) deutlich auf seine bisherige Auffassung beruft.

${ }_{167}$ Führend auch hier Wolfgang Siebert, Das Arbeitsverhältnis in der Ordnung der nationalen Arbeit, S. I 3 ff. Vgl. auch die weiteren in RAG, ARS 28 , S. $125 \mathrm{ff}$. (I $3 \mathrm{Iff}$.) sowie bei Hueck/Nipperdey/ Dietz, AOG, $\$ 2$ Rdnr. $17 \mathrm{~g}$ aufgeführten Autoren.

168 Wichtig war vor allem, daß Mansfeld als einer der herausragenden Männer im RAM ebenfalls die herkömmliche Meinung vertrat (DAR 1934, S. 329 und zustimmende Urteilsanmerkung zu RAG, ARS 23 , S. 58 ff. [8I]). Vgl. auch die bei Hueck/Nipperdey/Dietz, AOG, $\mathbb{\$} 2$ Rdn. I 7 g genannten Autoren.

169 Außer Betracht bleiben hier die Kündigungsschutzvorschriften für besondere Arbeitnehmergruppen, vor allem die Betriebsräte bzw. Vertrauensräte.

170 Die Arbeitsgerichte konnten in Kündigungsschutzangelegenheiten aufgrund der $\$ \$ 84,86$ und 87 BRG i.V.m. \2 I Nr. 4 ArbGG 1926 angerufen werden und den Arbeitgeber gegebenenfalls zur „Weiterbeschäftigung" verurteilen; doch führte selbst eine solche Verurteilung im Ergebnis nur zur Entschädigungspflicht, da der Arbeitgeber nicht zur tatsächlichen Beschäftigung gezwungen, sondern bei deren Ablehnung nur zur Zahlung einer Entschädigung verurteilt werden konnte. Vgl. hierzu im einzelnen Kaskel, Arbeitsrecht, S. 157 und 173.

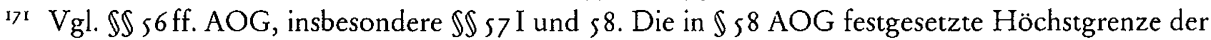
Entschädigung ( $4 / 12$ des Jahresarbeitsverdienstes) wurde durch das Gesetz zur Erweiterung des Kündigungsschutzes vom 30. I I. 1934 (RGBI I, S. 1193 , RABl I, S. 273) auf die volle Höhe des letzten Jahresarbeitsverdienstes erhöht, um die Unternehmer wirksamer zur Weiterbeschäftigung anzuhalten, als $\$ 58$ AOG alter Fassung dies vermocht hatte. Vgl. hierzu die amtliche Begründung des Gesetzes vom 30. I I. 1934 in RABl I, S. 274, sowie Mansfeld in DAR 1934, S. 329. 
vorneherein die Wirkung der Beendigung des Arbeitsverhältnisses zu nehmen. Das RAG machte von dieser Möglichkeit vor und nach 1933 in besonders gravierenden Fällen Gebrauch und begründete die Nichtigkeit mit den $\$ \int$ I 34 und 138 BGB. Demgegenüber wollten Siebert ${ }^{172}$ und andere Autoren ${ }^{173}$ den Kündigungsschutz ausschließlich auf die im AOG und im Gesetz vom 30. November 1934 normierte Kündigungswiderrufsklage beschränken, sahen also diese Regelung gegenüber den $\$ \int{ }_{34}$ und $\mathrm{I} 8 \mathrm{BGB}$ als vorrangig und abschließend an. Das RAG konnte, indem es sich dieser Auffassung verschloß, einige Härten des Kündigungsschutzrechtes durch Anwendung von Vorschriften des BGB ausgleichen. Dagegen schloß sich die arbeitsrechtliche Rechtsprechung in 2. Instanz - Urteile des RAG sind insoweit nicht bekannt ${ }^{174}$ nicht den Urteilen mehrerer Arbeitsgerichte (I. Instanz) ${ }^{175}$ an, die aus der Fürsorgepflicht sogar die Verpflichtung des Arbeitgebers ableiten wollten, unter besonderen Umständen einen wirksamen gekündigten Arbeitnehmer wieder einzustellen, sofern der ursprüngliche Kündigungsgrund später weggefallen war ${ }^{176}$.

\section{Änderung von Arbeitnebmerpflichten?}

Bei den Pflichten der Arbeitnehmer ging es um die folgenden Streitpunkte: den Einfluß der öffentlich-rechtlichen Arbeitszeitvorschriften auf das Maß der vertraglich geschuldeten Arbeitszeit, die Ausweitung des Weisungsrechts des Arbeitgebers, die Verteilung des Betriebsrisikos und Haftungsbeschränkungen bei leicht fahrlässig verschuldeten Handlungen des Arbeitnehmers, die beim Arbeitgeber einen Schaden verursachten. Beim Problem des Zusammenspiels der öffentlich-rechtlichen und der bürgerlich-rechtlichen Arbeitszeitbestimmungen handelte es sich im wesentlichen darum, ob die Arbeitnehmer im Verhältnis zum Arbeitgeber verpflichtet waren, Mehrarbeit zu leisten, wenn die Mehrarbeit unter dem Gesichtspunkt des Arbeitszeitschutzes vom Staat - sei es allgemein durch Gesetz oder Verordnung, sei es im Einzelfall durch Ausnahmegenehmigung des Gewerbeaufsichtsamtes - zugelassen wurde.

In der Weimarer Zeit ging man überwiegend von einer Trennung der Wirkungen der öffentlich-rechtlichen ${ }^{177}$ und der bürgerlich-rechtlichen ${ }^{178}$ Arbeitszeitbestimmungen

172 Wolfgang Siebert, Das Arbeitsverhältnis in der Ordnung der nationalen Arbeit, Hamburg 1935.

173 Erich Molitor, Die Kündigung, 1935, S. 162 ff., Bodmann, in: Arbeitsrecht und Volkstum 1935, Sp. 72 ff., und Krause, in: JW r935, S. I 3 I I.

174 Vgl. die Kommentierung bei Hueck/Nipperdey/Dietz, AOG, $\mathbb{2} 2$ Rdnr. 17 i d dort wird nur das Urteil des LAG Duisburg vom 8.4. 1937, ARS 30, S. 179, mitgeteilt.

175 Arbeitsgericht Gelsenkirchen, Urteile vom 10. 10. 1934, ARS 23, S.230, und vom 20.5. 1936, ARS 27, S. 93, sowie Arbeitsgericht Hindenburg, Urteil vom 30. I I. 1937, ARS 31, S. 93.

${ }_{176}$ Es handelte sich meist um Fälle, in denen Arbeitnehmer wegen Arbeitsmangels in der Wirtschaftskrise entlassen oder durch Änderungskündigung auf schlechter bezahlte Arbeitsplätze versetzt worden waren.

177 AO über die Regelung der Arbeitszeit gewerblicher Arbeiter, vom 23. I I. 1918, RGBI I, S. I 334 , RABl S. 880; mit Ergänzungen (für Arbeiter) vom 17. 12. 1918, RGBl I, S. 1436, RABl 1919, S. 75 ; (für Angestellte) vom 18.3. 1919, RGBI I, S. 315 , RABI S. 235; abgeändert durch die VO über die Arbeitszeit (AZVO) vom 21 1. 1 2. 1923, RGBI I, S. I 249, RABl I, S. 1924, S. 14 ; mit Änderung vom 14. 4. 1927, RGBI I, S. I09, RABl I, S. 117. 
aus: Die öffentlich-rechtlichen Bestimmungen hatten danach im Grundsatz ${ }^{179}$ keinen Einfluß darauf, wie lange ein Arbeitnehmer zu arbeiten verpflichtet war, sondern legten lediglich Grenzen fest, über die hinaus ein Arbeitnehmer nicht oder nur mit Genehmigung des Gewerbeaufsichtsamtes beschäftigt werden durfte. In der Literatur ${ }^{180}$ wurde teilweise die Auffassung vertreten, daß mangels einer vertraglichen Vereinbarung über die geschuldete Dauer der Arbeitszeit die öffentlich-rechtlich bestimmten Arbeitszeitgrenzen vom Arbeitgeber voll ausgeschöpft werden könnten; diese Auffassung blieb jedoch sehr umstritten ${ }^{18 r}$. In mehreren Urteilen folgerte das RAG allerdings aus der „Betriebsverbundenheit" der Arbeitnehmer, daß Arbeitnehmer zur Leistung von Mehrarbeit über das vertraglich Geschuldete hinaus verpflichtet sein könnten, ohne im Grundsatz der Auffassung Kaskels beizutreten ${ }^{182}$.

Im Dritten Reich prägten die öffentlich-rechtlichen Arbeitszeitbestimmungen in weit stärkerem Maße als in der Weimarer Republik die vom Arbeitnehmer geschuldete Dauer der Arbeitszeit. Insbesondere wenn ein öffentliches Interesse, d. h. ein Interesse des NS-Regimes an einer Verlängerung der Arbeitszeit bestand, wurde allgemein angenommen, daß auch bei fehlender vertraglicher Vereinbarung die verlängerte Arbeitszeit von den Arbeitnehmern einzuhalten war ${ }^{183}$. Die Arbeitsgerichte wurden im Dritten Reich mit derartigen Streitigkeiten äußerst selten befaßt ${ }^{184}$; offensichtlich wehrten sich nur wenige Arbeitnehmer gegen zu hohe Arbeitszeiten, da die Mehrarbeit eine der wenigen Möglichkeiten zur Erhöhung des Arbeitsverdienstes bot.

Bei der Ausweitung des Weisungsrechts des Arbeitgebers ging es vor allem um die Frage, ob der Arbeitgeber einem Arbeitnehmer einen anderen, auch schlechter bezahlten Arbeitsplatz zuweisen konnte, als vertraglich vereinbart war. In der Weimarer Zeit ließ das RAG zunächst derartige Versetzungen in relativ weitem Umfang zu, betonte dann aber immer stärker, „daß das Direktionsrecht vor allem im Inhalt des Arbeitsvertrages seine Schranken finde ${ }^{\text {" } 185}$. Nur wenn eine Bestimmung des Arbeitsvertrags, einer Betriebsvereinbarung oder eines Tarifvertrags die mit einer Lohnkürzung

${ }_{178}$ Einzelarbeitsvertrag, Betriebsvereinbarung, Tarifvertrag.

179 Ausnahmen wurden durch die AZVO vom 21. 12. 1923 geschaffen, z. B. die Pflicht zur Mehrarbeit bei Notarbeiten.

${ }_{180}$ Kaskel, Arbeitsrecht, S. 217.

${ }_{18 \mathrm{I}} \mathrm{Vgl}$. Sinzheimer, Grundzüge des Arbeitsrechts, 2. Aufl. Jena 1927, S. 182 Fn. 1, sowie Flatow, in: Das Gewerbe- und Kaufmannsgericht, Bd. 29, Sp. 273.

${ }_{182} \mathrm{Vgl}$. Kahn-Freund, Das soziale Ideal des Reichsarbeitsgerichts, S. I 8 I ff., sowie RAG, Urteile vom 12. I 2. 1928, ARS 4 , S. 381 , und vom 19.6. 1929, ARS 6, S. 253.

${ }_{183}$ Hueck/Nipperdey/Dietz, AOG, $\ 2$ Rdnr. 20: „Soweit von den dazu zuständigen Stellen aus Notwendigkeiten der Rüstungsindustrie, der Ernährungssicherung und aus ähnlichen allgemeinen Gesichtspunkten eine Überschreitung der gewöhnlichen Arbeitszeit zugelassen wird, wird man in aller Regel auch eine Verpflichtung zur Leistung von Überarbeit annehmen müssen."

${ }_{184}$ Ebenda, $\ 2$ Rdnr. 20 findet sich nur der Hinweis auf das Urteil des LAG Leipzig vom 2.3. 1937, ARS 30, S. 109, in dem die Pflicht zur Leistung von Überstunden sehr weit gefaßt wurde.

185 So Hueck in einer zustimmenden Anmerkung zu den Urteilen des RAG vom 16.4. und 17.5. 1932, ARS is, S. 164 und 168 ( 17 r); vgl. zum Wandel der Rechtsprechung zu diesem Problembereich die bei Hueck zitierten Urteile des RAG. 
verbundene Versetzung zuließ, war sie rechtens ${ }^{186}$. An dieser Auffassung hielt das RAG auch im Dritten Reich grundsätzlich fest ${ }^{187}$, doch ließ es immer mehr Ausnahmen zu und sah die Zuweisung von anderen als den vertraglich vereinbarten Arbeiten zunehmend als zulässig an ${ }^{188}$. Damit folgte das RAG der Entwicklung der Betriebsordnungen ${ }^{189}$ und des Kriegsarbeitsrechts ${ }^{190}$, die die Weisungsbefugnisse der Arbeitgeber erheblich ausweiteten. Während das RAG $\$$ I 8 II KWVO durchaus extensiv anwandte ${ }^{191}$ und in weitem Umfang kriegsbedingte Lohnkürzungen zuließ, schränkte es derartige Maßnahmen, soweit sie auf Betriebsordnungen gestützt wurden, eher ein, zumindest ließ es unklare Bestimmungen in den Betriebsordnungen nicht zu Lasten der Arbeitnehmer gehen ${ }^{192}$; in diesen Fällen sprach es häufig den betroffenen Arbeitnehmern den vollen bisherigen Lohn zu und verhinderte damit die mit der Versetzung verbundene Lohnkürzung.

Beim Problem des Betriebsrisikos ging es darum, ob die Arbeitgeber den Arbeitnehmern auch dann das Arbeitsentgelt zu zahlen hatten, wenn diese wegen eines Betriebsstillstandes ${ }^{193}$ ihre Arbeitsleistung nicht erbringen konnten. Das RAG hatte in der Weimarer Zeit die vom Reichsgericht ${ }^{194}$ entwickelte, von der Regelung des $\$ 6$ is BGB abweichende Risikoverteilung übernommen ${ }^{195}$ und daraus in ständiger Rechtsprechung die sogenannte Sphärentheorie entwickelt; danach hatten die Unternehmer die in ihren Verantwortlichkeitsbereich fallenden Ereignisse und die Arbeitnehmer die in ihrer Sphäre auftretenden Ereignisse ${ }^{196}$ zu vertreten, ohne daß es dabei auf ein Verschulden ankam ${ }^{197}$. Erst ${ }^{198}$ in einer Entscheidung vom 26. November 1940

$186 \mathrm{Vgl}$. auch Kaskel, Arbeitsrecht, S. I I I.

187 Vgl. z. B. RAG, Urteil vom I 8. 12. 1940, ARS 4I, S. 67: „Die dauernde Übertragung von geringer bezahlter Stundenlohnarbeit an einen Akkordarbeiter ist aufgrund des Weisungsrechts allein nicht zulässig."

${ }_{188}$ Vgl. RAG, Urteile vom 12.6. 1942, ARS 45 , S.41, und vom 24.4. 1940, ARS 39, S. 198, wo die Entscheidung nicht mehr auf den Vertragsinhalt allein, sondern zusätzlich auf allgemeine Gerechtigkeitserwägungen gestützt wurde.

$189 \mathrm{Vgl}$. die in den Urteilen des RAG vom 20.5. 194I, ARS 42 , S. 163 (I64), und vom 20.2. 1942, ARS $_{44}$, S. I I 2 (I $I_{3}$ ), auszugsweise abgedruckten Betriebsordnungen.

190 Insbesondere $\$$ I 8 II KWVO vom 4.9. 1939, RGBI I, S. I609, RABl I, S. 403.

191 RAG, ARS 44 , S. I I 2, LS 3 und Anm. von Hueck (S. I I 7).

192 RAG, ARS 45, S. 4 r.

193 Gründe hierfür waren beispielsweise Naturereignisse, der Krieg, Ausfall der Energiezufuhr, Rohstoffmangel, Ausfall von Vorfabrikaten wegen Transportstörungen oder Arbeitskämpfen in anderen Betrieben und Teilstreiks im selben Betrieb.

194 Urteil vom 6. 2. $1923, \mathrm{RGZ}$ 106, S. 272.

195 Vgl. vor allem das Urteil des RAG vom 20.6. 1928, ARS 3 , S. I 16.

${ }_{196}$ Praktisch ging es dabei nur um Streiks; insofern war die Sphärentheorie in der arbeitsrechtlichen Literatur heiß umstritten. Vgl. Franz Neumann, Die politische und soziale Bedeutung der arbeitsgerichtlichen Rechtsprechung, Berlin 1929, S. I I, 3 I f.

197 Vgl. die Zusammenfassung bei Hueck/Nipperdey/Dietz, AOG, $\ 2$ Rdnr. 25 .

198 Bis dahin hatte das RAG noch mehr oder weniger deutlich an der Sphärentheorie festgehalten; vgl. die etwas gewundene Argumentation im Urteil des RAG vom I 2.6. I940, ARS 39, S. 407 (410, 2. Abs.), die den Übergang von der Sphärentheorie zur neuen Auffassung andeutete. 
rückte das RAG von der Sphärentheorie völlig $a b^{199}$, da sie „sich nicht mit der Anschauung über das Arbeitsverhältnis als ein zwischen dem Unternehmer und den Gefolgschaftsmitgliedern bestehendes, durch das Band der Treue und Fürsorge zusammengeschlossenes Gemeinschaftsverhältnis [vertrage], das eine Aufspaltung zwischen ihnen, wie sie jenem Gedanken [der Sphärentheorie] zugrunde liegt, nicht zuläßt“. Aus der umfassenden Entscheidungsbefugnis und aus der Fürsorgepflicht des Arbeitgebers leitete das RAG ${ }^{200}$ - durchaus folgerichtig - ab, daß der Arbeitgeber grundsätzlich allein „die Verantwortung für den Fortgang des Betriebes“ zu tragen und in Fällen der Betriebsgefahr das Arbeitsentgelt fortzugewähren habe. Diese Änderung der Rechtsprechung mußte sich fast zwangsläufig daraus ergeben, daß Streiks, die praktisch als einzige der in Betracht kommenden Betriebsgefahren zur Sphäre der Arbeitnehmer gerechnet worden waren, kein gesellschaftlich und rechtlich anerkannter Konfliktlösungsmechanismus mehr waren, sondern systematisch unterdrückt und polizeilich und strafrechtlich verfolgt wurden. Als individuelles kriminelles Fehlverhalten konnten Streiks aber kaum mehr eine „solidarische“ Haftung aller Arbeitnehmer begründen; dem Zweck der Kriminalisierung streikender Arbeitnehmer, diese von der übrigen Arbeitnehmerschaft zu isolieren, hätte es widersprochen, wenn die solidarische Haftung aufrechterhalten worden wäre.

Hatte das RAG die Anerkennung des Gleichbehandlungsgrundsatzes bei Zahlung betrieblicher Gratifikationen und Alterspensionen unter den Vorbehalt wirtschaftlicher Prosperität des Unternehmens und persönlichen Wohlverhaltens der Arbeitnehmer gestell $t^{201}$, so fügte es auch der neuen Verteilung des Betriebsrisikos einen Vorbehalt bei, der die „arbeitnehmerfreundliche“ Wirkung der neuen Rechtsprechung in vielen Fällen wieder in Frage stellte: Denn bei „ernstlicher Gefährdung des Betriebes“ wurde den Arbeitnehmern zugemutet, daß sie ihr „Interesse der Notwendigkeit, den Betrieb zu erhalten, unterodnet[en] ${ }^{{ }_{202}}$ und auf ihr Arbeitsentgelt ganz oder teilweise verzichteten. Das RAG stützte diese Auffassung auch auf die Gemeinwohlformel des \ I AOG und betonte, daß derartige Lohnverzichte den Arbeitnehmern insbesondere im Krieg abzuverlangen seien ${ }^{203}$.

Im Bereich der Arbeitnehmerhaftung begründete das RAG ${ }^{204}$ erst während des Zweiten Weltkriegs die Rechtsprechung zur Haftungsbeschränkung bei schadens- oder gefahrgeneigter Arbeit. Bis dahin ${ }^{205}$ hatte es derartige Haftungserleichterungen, die die Verschuldensregelung des $\ 276$ BGB durchbrachen, noch (wie schon vor $1933^{206}$ ) abgelehnt. Nach der neuen Rechtsprechung hafteten Arbeitnehmer, denen wegen der Eigenart ihrer Arbeit erfahrungsgemäß auch bei gewissenhafter Ausführung einmal

\footnotetext{
199 RAG, Urteil vom 26. I I. 1940, ARS 41, S. 43.

200 ARS $_{41}$, S. $_{43}$ (50).

201 Vgl. hierzu oben S. $36 \mathrm{I}$.

${ }^{202}$ Hueck/Nipperdey/Dietz, AOG, $\mathbb{\$} 2$ Rdnr. $x 7 \mathrm{~b}$ und $25 \mathrm{~d}$ m. N. der Rechtsprechung.

203 RAG, Urteil vom 26. I I. 1940, ARS 4I, S. 43 (Leitsatz 4).

${ }^{204}$ Urteil vom I 8. I 2. 1940, ARS 4I, S. 55, mit Anm. Hucck (S.64).

205 Vgl. RAG, Urteil vom 23. I I. 1938, ARS 34, S. 357

${ }^{206}$ Kaskel, Arbeitsrecht, S. $117 \mathrm{f}$.
} 
ein Fehlgriff unterlaufen konnte, insbesondere Kraftfahrer, nur bei Vorsatz und grober Fahrlässigkeit ihrem Arbeitgeber für den verursachten Schaden in vollem Umfang. Bei geringeren Verschuldensgraden wurde die Haftung herabgesetzt oder konnte bei leichtester Fahrlässigkeit ganz entfallen.

Das RAG leitete die Haftungsbeschränkung im Grunde allein aus $\ 2$ II AOG ab ${ }^{207}$; es wurde in diesem Bereich rechtsschöpferisch tätig, vor allem auch insofern, als es selbst eine Art von Richtlinien für die Aufteilung des Schadens zwischen Arbeitgeber und Arbeitnehmer aufstellte ${ }^{208}$. Das RAG folgte, indem es seine Rechtsprechung in dieser Hinsicht änderte, der Tendenz, die Arbeitnehmer durch Haftpflichtversicherungen von der Haftung im Kraftverkehr freizustellen ${ }^{209}$ bzw. die Haftung der Arbeitnehmer durch allgemeine Richtlinien in Betriebsordnungen oder (im öffentlichen Dienst) in Dienstanweisungen ${ }^{210}$ bei leichter Fahrlässigkeit einzuschränken. Da aufgrund dieser Vorschriften und aufgrund der tatsächlichen Übung der meisten Arbeitgeber, auf die Geltendmachung von Schadensersatzansprüchen schon wegen der geringen Chance ihrer Realisierung zu verzichten, ohnehin nur selten Arbeitnehmer in Anspruch genommen wurden, bedeutete es nur einen kleinen Schritt, auch für diese Ausnahmefälle eine Haftungsbeschränkung einzuführen.

\section{Resümee der Rechtsprechung zu $\ 2$ II $A O G$}

Der Überblick über einige Problembereiche der arbeitsrechtlichen Rechtsprechung zeigt, daß das RAG sich nur zögernd von der vor 1933 gültigen Auffassung des Arbeitsverhältnisses als eines durch den Grundsatz von Treu und Glauben modifizierten, im Prinzip aber immer noch schuldrechtlichen Austauschverhältnisses löste und die Formel von dem durch Treue- und Fürsorgepflicht geprägten Gemeinschaftsverhältnis mit den in der Literatur geforderten Konsequenzen akzeptierte. Unter der Geltung des AOG und der weiteren arbeitsrechtlichen Regelungen des NS-Regimes hatte diese Haltung des RAG uneinheitliche Folgen ${ }^{21 I}$ für die betroffenen Arbeitnehmer und Arbeitgeber.

207 RAG, ARS 41, S. 55 (60), und hierzu Siebert, in: Reuss/Siebert, Die konkrete Ordnung des Betriebes, 3. ergänzte Aufl. 1943, S. 89.

${ }_{208}$ RAG, ARS $4 \mathrm{I}, \mathrm{S} .55$ (6I ff.).

209 Vgl. das Gesetz über die Einführung der Pflichtversicherung für Kraftfahrzeughalter ... vom 7. I r. 1939, RGBI I, S. 2223.

210 Vgl. die im Urteil des RAG, ARS 4I, S. 55 (6I) zitierte Dienstanweisung der Deutschen Reichspost vom I. März 1938.

$2:$ Im Ergebnis ähnlich spricht Rüthers, Die unbegrenzte Auslegung, S. 379 ff., davon, daß dem RAG mit dem Arbeitsvertrag als schuldrechtlicher Grundlage für Ansprüche aus dem Arbeitsverhältnis und dem Gemeinschaftsargument als Auslegungsmaßstab und als Grundlage für die Gesetzesablehnung „ein elastisches Instrumentarium zur Entwicklung einer außergesetzlichen, richterrechtlich begründeten Rechtsordnung des Arbeitsverhältnisses" zur Verfügung stand. Dies Instrumentarium wurde jedoch nicht nach freiem Belieben des RAG einmal so und einmal anders - je nach gewünschtem Ergebnis - gehandhabt, wie es nach Rüthers' weiteren Ausführungen (S. 394 f.) scheinen könnte, sondern es ist festzustellen, daß das RAG sich in einer kontinuierlichen Entwicklung immer mehr an nationalsozialistisches Gedankengut anpaßte. 
Soweit das RAG zögerte, aus $\ 2$ II AOG unmittelbar Ansprüche abzuleiten, blieben den Arbeitnehmern soziale Verbesserungen - insbesondere der Urlaub - vorenthalten. In vielen Bereichen hat das RAG diese Zurückhaltung gegenüber der sozialen Fortentwicklung des Individualarbeitsrechts über $\$ 2$ II AOG jedoch mehr oder weniger schnell und deutlich aufgegeben (in den Bereichen Arbeiterschutz, Gleichbehandlung, Betriebsrisiko, Haftungsbeschränkung). Andererseits erhielt das RAG mit seiner abwartenden, eher "konservativen“ als betont nationalsozialistischen Haltung teilweise einen Rest von Rechtssicherheit und setzte der totalen Verfügung der Arbeitgeber über die Arbeitnehmer doch noch gewisse - aus dem Schuldrecht des BGB abgeleitete - Grenzen, so bei der Fortsetzung seiner Rechtsprechung zur Nichtigkeit von Kündigungen und bei der Rechtsprechung zur Lohnkürzung bei Versetzungen. In manchen Bereichen läßt sich dagegen eine andere Tendenz feststellen und zwar bei

- Verlängerung der Arbeitszeiten durch Weisung des Arbeitgebers,

- Zuweisung anderer, schlechter bezahlter Arbeitsplätze durch den Arbeitgeber sowie

- dem erzwungenen Verzicht der Arbeitnehmer auf ihr Arbeitsentgelt zum Zweck der Erhaltung gefährdeter Betriebe.

In diesen Bereichen stand nicht mehr der isolierte Interessenausgleich zwischen Arbeitnehmern und Arbeitgebern im Mittelpunkt der richterlichen Beurteilung, sondern es ging in stärkerem Maße um den Ausgleich zwischen dem individuellen Interesse einzelner Arbeitnehmer und dem „gemeinen Nutzen von Volk und Staat" ( I AOG). Diese Generalklausel ${ }^{212}$, die in vielen Regelungen des Arbeitseinsatzes und des Kriegsarbeitsrechts in abgewandelter Form wiederkehrte, verkörperte den Anspruch des NS-Regimes, durch staatliche Anordnung und Zwangsanwendung in die Arbeitsbeziehungen einzugreifen, um Aufrüstung und Kriegführung durch planmäßigen Einsatz von Arbeitskräften und autoritäre Gestaltung der Löhne und Arbeitsbedingungen zu ermöglichen ${ }^{213}$. Das RAG berücksichtigte in seiner Rechtsprechung diese von der „Volksgemeinschaft" an die „Betriebsgemeinschaft" und damit auch an den einzelnen Arbeitnehmer herangetragenen Anforderungen in aller Regel ${ }^{214}$. Das bedeutete, daß Konflikte in diesen Bereichen mehr und mehr zuungunsten der betroffenen Arbeitnehmer entschieden wurden. Denn die Interessen der Arbeitgeber, die wirtschaftliche Vorteile aus der Ausweitung der Arbeitszeiten, der Befugnis zur $\mathrm{Zu}$ weisung schlechter bezahlter Arbeitsplätze oder der vorübergehenden Freistellung von der Pflicht zur Entgeltzahlung zogen, wurden um so mehr mit den Rüstungs-

${ }^{212}$ Mit der Gemeinwohlformel des $\$ I AOG und den entsprechenden Generalklauseln in den späteren arbeitsrechtlichen Regelungen des Dritten Reichs hat sich ausführlich Stolleis, Gemeinwohlformeln im nationalsozialistischen Recht, S. $127 \mathrm{ff}$., auseinandergesetzt.

${ }_{213} \mathrm{Vgl}$. hierzu ausführlicher oben $\mathrm{S} .73-85$ und $129-134$.

214 Vgl. zur Zuweisung eines geringer bezahlten Arbeitsplatzes: RAG Urteil vom I 8. 12. 1940, ARS 4I, ${ }_{7}$ (Zulässigkeit nur, wenn die Versetzung auf einer durch den Krieg bedingten Umstellung des Betriebs beruhte); zur Beschränkung und zeitweise völligen Aussetzung des Anspruchs auf Entgeltzahlung wegen kriegsbedingter Betriebsrisiken: RAG Urteil vom 26. I I. 1940, ARS 4I, 43. 
und Produktionszielen des NS-Regimes identisch, als die Bereiche der Rüstungs- und Kriegswirtschaft im Lauf der Vorkriegs- und Kriegsjahre auf Kosten anderer Gewerbezweige erweitert wurden ${ }^{215}$.

Doch wurden nur sehr wenige der Konflikte, in denen es um den Widerstreit zwischen dem Einzelinteresse eines Arbeitnehmers und den unter das "Gemeinwohl“ subsumierten Zielen des NS-Regimes ging, vor den Arbeitsgerichten ausgetragen ${ }^{216}$. Denn die Anwendung der Gemeinwohlformeln lag nur in seltenen Fällen in den Händen der Arbeitsgerichte, in aller Regel dagegen bei den Arbeitsämtern, den Treuhändern der Arbeit oder den Gewerbeaufsichtsämtern; an deren Entscheidungen waren die Arbeitsgerichte gebunden, sofern eine von der Arbeitsverwaltung entschiedene Streitsache überhaupt noch vor ein Arbeitsgericht gebracht wurde. Aus diesem Grund findet sich in der Kommentarliteratur auch kaum Judikatur, die sich allein oder vorrangig auf $\rrbracket_{I}$ AOG stützte ${ }^{217}$; die Gemeinwohlformel wurde von den Arbeitsgerichten jedoch in den aufgeführten Streitfällen ergänzend zu $\$ 2$ II AOG herangezogen und bewirkte i.d.R., daß Pflichten der Arbeitnehmer verschärft bzw. Pflichten der Arbeitgeber gelockert wurden ${ }^{218}$.

Läßt sich der Rückgang der arbeitsgerichtlichen Verfahren auch aus einem Mißtrauen der Arbeitnehmer gegen die Entscheidungspraxis der Arbeitsgerichte erklären? Der Überblick über die Problembereiche dieser Rechtsprechung, in denen das Individualarbeitsrecht durch die Arbeitsgerichte fortentwickelt wurde oder eine solche Fortentwicklung nahelag, läßt diese Erklärung nur teilweise plausibel erscheinen; denn die Fortentwicklung des Arbeitsrechts durch die Arbeitsgerichte im Dritten Reich, soweit sie hier untersucht wurde, benachteiligte die Arbeitnehmer im Vergleich zur Weimarer Zeit nur insofern stärker, als das „Gemeinwohl“ tangiert war. Letztlich bedeutet dies, daß die Einschränkungen der Arbeitnehmerrechte im wesentlichen nicht auf einer für die Arbeitnehmerschaft besonders ungünstigen Auslegung der Generalklauseln des AOG durch die Arbeitsgerichte beruhten, sondern weit mehr auf die spätere staatliche Normsetzung (Verordnungen der Vierjahresplanphase und des Kriegsarbeitsrechts) sowie auf deren verwaltungsmäßige, kaum je gerichtliche Durchsetzung zurückzuführen waren.

21s Vgl. auch Stolleis, Gemeinwohlformeln im nationalsozialistischen Recht. Stolleis berichtet über Fälle aus den Anfangsjahren des Dritten Reichs, in denen die Gemeinwohlformel zum Schutz der durch die Massenarbeitslosigkeit unter Druck gesetzten Arbeitnehmer angewandt wurde, und fährt dann auf S. 138 fort: „Nach der Beseitigung der Arbeitslosigkeit und mit dem Beginn der Aufrüstung ging die sozialpolitische Gemeinwohlbindung zu Lasten der Arbeitnehmer, wenn auch die Rechtsprechung mit Hilfe des $\ 2$ II AOG (Fürsorgepflicht des Arbeitgebers) beachtliche sozialpolitische Fortschritte erzielen konnte." Diese Fortschritte fielen bescheidener aus als Stolleis meint, können aber auch nicht völlig geleugnet werden.

${ }^{216} \mathrm{Vgl}$. zur Verlagerung der Konfliktentscheidungen weg von den Arbeitsgerichten und hin zur Arbeitsverwaltung in diesem Kapitel oben.

2.7 Bei Hueck/Nipperdey/Dietz, AOG, Kommentierung des \I AOG, wird keine derartige Entscheidung mitgeteilt.

${ }_{218}$ Vgl. Hueck/Nipperdey/Dietz, AOG, $\ 2$ Rdnr. 20, 24 und 25 , sowie die dort aufgeführte Literatur. 


\section{Zusammenfassung: Zur Bedeutung der alltäglichen Entscheidungspraxis der Arbeitsgerichte in der nationalsozialistischen Arbeitsverfassung}

Die Analyse der Rechtsprechung der Arbeitsgerichte zum Individualarbeitsrecht und insbesondere zur Treue- und Fürsorgepflicht des $\ 2$ II AOG könnte jedoch zu falschen Schlüssen führen und das Bild einer relativ neutralen, in ihrer alltäglichen Entscheidungspraxis von den politischen Umwälzungen kaum berührten Arbeitsgerichtsbarkeit entstehen lassen, die sich in Teilbereichen sogar gegen spezifisch nationalsozialistische Rechtsanschauungen wandte oder gegen eine allzu starke Ausweitung des Zuständigkeitsbereichs der vom NS-Regime geschaffenen neuen Verwaltungszweige mit einer gewissen Zähigkeit zur Wehr setzte.

So sehr diese Aspekte auch zutreffen, dürfen sie doch nicht isoliert gesehen werden. Es ist zu bedenken, daß auch diese „normal“ erscheinende Rechtsprechung bestimmte Funktionen für das NS-Regime erfüllte: Gerade die Beibehaltung bewährter staatlicher Institutionen wie der Arbeitsgerichtsbarkeit konnte zur Legitimation des NSRegimes beitragen. Die Arbeitsgerichte halfen, den sozialen Frieden und das „Vertrauen“ der Arbeitnehmer zu „organisieren “219, indem sie die neuen arbeitsrechtlichen Lehren relativ langsam übernahmen und damit die soziale Komponente des Arbeitsrechts so vorsichtig weiterentwickelten, daß klassenkämpferisch forcierte Forderungen aus der Arbeitnehmerschaft durch diese Rechtsprechung keinen Auftrieb erhielten. Selbst der Kompetenzkonflikt zwischen den Arbeitsgerichten und den Treuhändern der Arbeit, der dazu führte, daß bei bestimmten, zunächst vielleicht etwas einseitig geregelten Problemen besser funktionierende Lösungen gefunden wurden, trug letzten Endes eher zur Stabilisierung als zur Beeinträchtigung des Herrschaftssystems bei. Zudem erfaßt die Analyse der zu $\mathbb{2}$ II AOG ergangenen arbeitsgerichtlichen Rechtsprechung nur einen wichtigen Aspekt der Entscheidungspraxis der Arbeitsgerichte im Dritten Reich. Es stellt sich die weitere und mindestens ebenso gravierende Frage, wie sich die Arbeitsgerichte gegenüber politisch besonders wichtigen Entwicklungen im Dritten Reich verhielten.

\section{Die Liquidierung der Gewerkschaften in der Rechtsprechung des Reichsarbeitsgerichts}

Zur Ausschaltung der Gewerkschaften nahm das RAG in einer berühmten Entscheidung vom 28. Februar 1934 Stellung ${ }^{220}$. In diesem Urteil ging es um die Klage eines ehemaligen Gewerkschaftssekretärs einer dem ADGB angeschlossenen Einzelgewerkschaft gegen die DAF. Nach der Ausschaltung der freien Gewerkschaften am 2. Mai 1933 war der Kläger noch für kurze Zeit von der NSBO weiterbeschäftigt und dann - zunächst unter Einhaltung der Kündigungsfrist, später sogar fristlos gekündigt worden. Er hielt die fristlose Kündigung nicht für gerechtfertigt und

\footnotetext{
${ }_{219}$ Vgl. das Motto „Organisierung des Vertrauens“, unter das Mansfeld, DAR 1933, S. 78, die neu zu schaffende Arbeitsverfassung des Dritten Reichs stellte.

${ }_{220}$ RAG Urteil vom 28. 2. 1934, ARS 20, 102; RABl I, S.64; auszugsweise abgedruckt bei: Blanke/ Erd/Mückenberger/Stascheit (Hrsg.), Kollektives Arbeitsrecht, Bd. 2, Reinbek 1975, S. 47 ff.
} 
verlangte mit der Klage Zahlung seines Gehaltes bis zum Ende der ordentlichen Kündigungsfrist. Seine Klage richtete er gegen die DAF, weil er diese für die Rechtsnachfolgerin der freien Gewerkschaften hielt; denn die DAF hatte nach seiner Auffassung den Mitgliederbestand und das Vermögen der Gewerkschaften übernommen.

Das RAG entschied gegen den Kläger und begründete dies vor allem damit, daß die DAF nicht Rechtsnachfolgerin der Gewerkschaften geworden sei; diese rechtliche Beurteilung stützte das RAG auf eine Betrachtung der tatsächlichen Vorgänge bei der Zerschlagung der Gewerkschaften im Mai 1933; dabei war dem RAG offensichtlich klar, daß das NS-Regime bei der Besetzung der Gewerkschaftshäuser, der Absetzung der Gewerkschaftsführer und den weiteren Gewaltmaßnahmen schwerste Rechtsund Verfassungsbrüche, insbesondere gegen Art. 165 I, S. 2 WRV, in dem der Bestand der Gewerkschaften garantiert war, begangen hatte; wenn das RAG davon sprach, daß die „Umbildung ... im Zuge der nationalen Erhebung nicht unter Beobachtung der satzungsgemäßen Formen, sondern durch ein Eingreifen der NSDAP als der Inhaberin der Macht im Staate mit Billigung der legalen Staatsgewalt unter den Augen der Öffentlichkeit" erfolgte, so kennzeichnete es - zwar verklausuliert, aber dennoch deutlich erkennbar - die Zerschlagung der Gewerkschaften als einen Akt der Macht und Gewalt.

Einer Auseinandersetzung mit den einschlägigen Artikeln der WRV sah sich das RAG schon durch die in der öffentlich-rechtlichen Literatur herrschende Auffassung $^{221}$ enthoben, wonach die WRV auch ohne ausdrückliche Aufhebung nicht mehr galt, sondern vom „Ermächtigungsgesetz ${ }^{\text {“222 }}$ als dem „vorläufigen Verfassungsgesetz

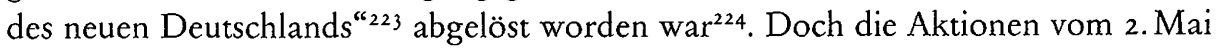
1933 gegen die freien Gewerkschaften durchbrachen selbst die Scheinlegalität ${ }^{225}$ des „Ermächtigungsgesetzes“ und der Notverordnungen vom 28. Februar $1933^{226}$ : Diese Vorschriften sahen zwar Verfassungsdurchbrechungen durch Gesetze der Reichsregierung, aber nicht durch gewaltsame Maßnahmen von Gliederungen der NSDAP vor. Indem das RAG auf diese Gewaltmaßnahmen die rechtliche Beurteilung des zu entscheidenden Falles stützte, verlieh es ihnen den Schein der Rechtmäßigkeit und machte sie sich zu eigen. Kurz gesagt vollzog es mit dieser Entscheidung die ausdrückliche Kapitulation des Rechts vor der Macht und bescheinigte dem NS-Regime,

\footnotetext{
221 Vgl. den Überblick bei Helmut Ridder, Zur Verfassungsdoktrin des NS-Staates, KJ 1969, S. 22 I ff. (insbesondere S. $234 \mathrm{ff}$.).

222 RGBl I, S. x4x, RABl 1933 I, S. 96.

${ }^{223}$ So Carl Schmitt, Staat, Bewegung, Volk. Die Dreigliederung der politischen Einheit, 3. unveränderte Aufl. Hamburg 1935, S. 7. Vgl. auch Huber, Verfassungsrecht, S. $46 \mathrm{ff}$.

224 Vgl. die Darstellung bei Volker Neumann, Der Staat im Bürgerkrieg. Kontinuität und Wandlung des Staatsbegriffs in der politischen Theorie Carl Schmitts, Frankfurt-New York 1980, S. I 4 off.

225 Zur Frage der Legalität der nationalsozialistischen Machtübernahme vergleiche die klassische Studie von K.D. Bracher, Stufen der Machtergreifung, S. 235 f., sowie neuerdings aus staatsrechtlicher Sicht Volker Neumann, Der Staat im Bürgerkrieg, S. $140 \mathrm{ff}$.

${ }^{226}$ RGBI I, S. 83 und 85 .
} 
daß sein „revolutionärer“ Erfolg schwerer wog als seine Verfassungs- und Rechtsbrüche $^{227}$.

\section{Die arbeitsrechtliche Bebandlung jüdischer Arbeitnebmer in der \\ Rechtsprechung des Reichsarbeitsgerichts}

Die arbeitsrechtliche Behandlung der Juden im Dritten Reich führte schrittweise zu einer immer stärkeren arbeitsrechtlichen Diskriminierung der Juden und zu ihrer Verdrängung aus dem Arbeitsleben; diese krasse Benachteiligung entsprach der allgemeinen rassistischen Diskriminierung und Verfolgung der Juden im Dritten Reich ${ }^{228}$. Schon 1933 wurden die jüdischen Beschäftigten fast vollständig aus dem öffentlichen Dienst entfernt; viele wurden auch aus privaten Diensten entlassen, so daß häufig als einzige Verdienstmöglichkeit die Beschäftigung in einer jüdischen Firma blieb. Seit den Nürnberger Rassegesetzen von 1935 und nochmals seit der offenen Terrorisierung der jüdischen Bevölkerung in der „Reichskristallnacht" (9./10. November 1938) verschärfte sich die umfassende Diskriminierung der Juden durch staatliche Gesetze und Verordnungen erheblich. So entfiel die Möglichkeit zur Selbsthilfe dadurch, daß seit dem I. Januar 1939 Juden nicht mehr Betriebsführer sein konnten ${ }^{229}$. Am Ende dieser Eskalation stand die Vernichtung der Juden in den Konzentrationslagern zum Teil durch die unmenschliche Ausbeutung der Arbeitskraft unter dem zynischen Motto „Arbeit macht frei“.

Das RAG beteiligte sich bereits vor der hier vorrangig zu besprechenden Entscheidung $^{230}$ an der arbeitsrechtlichen Diskriminierung der Juden, indem es beispielsweise eine drastische Herabsetzung der betrieblichen Altersversorgung allein aus dem Grunde, weil der Pensionär Jude war, für gerechtfertigt hielt ${ }^{231}$. Bis 1940 waren jedoch noch kein Gesetz und keine andere allgemeine Bestimmung erlassen worden, die die jüdischen Arbeitnehmer als solche gegenüber den deutschen Arbeitnehmern benachteiligten; es blieb dem RAG ${ }^{232}$ vorbehalten, diesen Schritt noch vor dem nationalsozialistischen Gesetzgeber ${ }^{233}$ zu tun und damit die arbeitsrechtliche Diskriminierung der Juden auf die Spitze zu treiben. In dem Urteil des RAG ging es um die Klage eines jüdischen Arbeitnehmers, der die Bezahlung dreier Wochenfeiertage, darunter des „Nationalen Feiertags des Deutschen Volkes“ am r. Mai sowie des so. Geburts-

${ }_{227}$ Vgl. zum revolutionären Charakter der nationalsozialistischen Machtübernahme einerseits David Schoenbaum, Die braune Revolution. Eine Sozialgeschichte des Dritten Reichs, Köln/Berlin 1968, S. $26 \mathrm{f}$., andererseits Volker Neumann, Der Staat im Bürgerkrieg, S. 147.

${ }^{228}$ Vgl. hierzu die ausführliche und differenzierende Darstellung bei: Adam, Judenpolitik im Dritten Reich, Königstein-Düsseldorf 1979.

229 VO zur Ausschaltung der Juden aus dem deutschen Wirtschaftsleben vom I2. I1. 1938, RGBI I, S. 1580.

${ }^{230}$ Urteil des RAG vom 24.7. 1940, ARS 39, S. 383.

${ }^{231}$ Vgl. z. B. das Urteil des RAG vom 9. I. I 940, ARS 38, S. 262 (280); es ging allerdings nicht ganz so weit wie der Arbeitgeber in diesem Fall, der die Pension überhaupt nicht mehr zahlen wollte.

${ }^{232}$ ARS 39, S. 383.

${ }_{233}$ VO über die Beschäftigung von Juden vom 3. 10. 1941, RGBl I, S.675, RABl I, S.496, und DVO hierzu vom 31. 10. 194 I, RGBI I, S.68 I, RABI I, S. 496. 
tags Hitlers am 20. April 1939, von seinem Arbeitgeber verlangte; die Pflicht zur Bezahlung dieser Feiertage ergab sich aus drei Vorschriften, die die Juden von dieser Vergünstigung nicht ausnahmen ${ }^{234}$.

Obwohl das AOG und die anderen arbeitsrechtlichen Vorschriften des Dritten Reichs bis I940 durchaus auch auf Arbeitsverhältnisse von Juden angewandt worden waren, leitete das RAG nunmehr daraus, daß das durch die $\mathbb{S} \mathrm{I}, 2$ und 35 AOG geprägte Gemeinschaftsverhältnis "germanischer, besonders deutschrechtlicher Anschauung" entspreche, ab, daß die für dieses Gemeinschaftsverhältnis geltenden Vorschriften nicht ohne weiteres auf die Arbeitsverhältnisse von Juden anzuwenden seien. Im konkreten Fall wies es die Klage des jüdischen Arbeitnehmers ab, da die genannten Vorschriften über die Lohnzahlung an Feiertagen nur für deutsche "Gefolgschaftsmitglieder“", nicht aber für die jüdischen „Angestellten und Arbeiter“ gälten.

Inwieweit das RAG sich auch die rassistischen Denkformen des NS-Regimes zu eigen gemacht hatte, geht aus dem folgenden Auszug der Urteilsbegründung hervor ${ }^{235}$ : „An solcher Gemeinschaft kann der Jude, dem jene Anschauung fremd ist, nach seiner ganzen, auf die Förderung persönlicher Interessen und die Erlangung wirtschaftlicher Vorteile gerichteten rassischen Veranlagung keinen Anteil haben, und es ist ihm nach seiner Natur verwehrt, sich als Glied in diese Gemeinschaft einzufügen und sein Denken und Handeln nach der Gefolgschaftsidee auszurichten. Daraus ergibt sich die notwendige Folge, daß das Arbeitsordnungsgesetz, sowie die sonstigen im besonderen in neuerer Zeit getroffenen arbeitsrechtlichen Bestimmungen nicht ohne weiteres und uneingeschränkt auf einen jüdischen Arbeiter Anwendung finden können." Die Leistung des RAG, den Willen des nationalsozialistischen Gesetzgebers, der etwa eineinhalb Jahre nach diesem Urteil in der Verordnung vom 3 . Oktober $194 \mathrm{I}^{236}$ in ganz ähnlichen Formulierungen zum Ausdruck kam, erkannt und angewandt zu haben, wurde von Mansfeld aus der Sicht des RAM in der Urteilsanmerkung ${ }^{237}$ gebührend gewürdigt: „Die Entscheidung des RAG, der nichts hinzuzufügen ist, kann bis zu einer Sondergesetzgebung schlechthin als die Grundlage der arbeitsrechtlichen Stellung der Juden bezeichnet werden."

Rüthers ${ }^{23}{ }^{8}$ hat das Urteil des RAG vom 24. Juli 1940 in einem anderen Zusammenhang besprochen und es in einen Gegensatz zur Entscheidung des RAG vom I 3. Sep-

234 Gesetz über die Lohnzahlung am Nationalen Feiertag des Deutschen Volkes vom 26.4. 1934, RGBI I, S. 337, RABI I, S. r r6; AO des Beauftragten für den Vierjahresplan über die Lohnzahlung an Feiertagen vom 3. I2. 1937, RABI I, S. 320; Gesetz über einmalige Sonderfeiertage vom 17.4. 1939, RGBl I, S. 763 , RABI I, S. 178, i. V.m. der VO des RMI hierzu vom 17.4. 1939, RGBI I, S. 764 , RABL I, S. I 78 .

${ }_{235}$ ARS $39, S_{3} 3_{3}$ (386).

${ }_{236}$ VO über die Beschäftigung von Juden vom 3. 10. 194 I, RGBI I, S.675, RABI I, S. 496, sowie DVO hierzu vom 3I. I0. 194I, RGBI I, S.68I, RABI I, S. 496. \I der DVO lautete: „Der Jude kann als Artfremder nicht Mitglied einer deutschen Betriebsgemeinschaft sein, die sich auf dem Grundsatz der gegenseitigen Treuepflicht aller im Betrieb Schaffenden aufbaut.“

${ }_{237}$ ARS 39, S. 39I.

${ }^{238}$ Bernd Rüthers, Die unbegrenzte Auslegung, S. 396. 
tember $1939^{239}$ gestellt, die ebenfalls einen jüdischen Arbeitnehmer betraf. Er meinte, das Urteil vom I 3. September 1939 sei „ein Angriff auf die Wertgrundlage des nationalsozialistischen Arbeitsrechtes, vielleicht sogar ein Akt bewußten richterlichen Widerstandes gegen die antisemitischen Maßnahmen der Zeit“. Mit dem Urteil vom 24. Juli 1940 habe diese Haltung des RAG eine „Korrektur“ erfahren. Richtig ist an dieser Einschätzung, daß das Urteil vom 24. Juli 1940 - verglichen mit der vorhergehenden Judikatur zu Arbeitsverhältnissen jüdischer Arbeitnehmer - die arbeitsrechtliche Diskriminierung der Juden erheblich verschärfte und insofern einen nicht zu unterschätzenden Wandel bedeutete. Doch geht es zu weit, die vorangegangene Rechtsprechung des RAG zu Arbeitsverhältnissen jüdischer Arbeitnehmer in die Nähe des Widerstandes gegen den Nationalsozialismus zu rücken. Die Rechtsprechung des RAG entsprach vielmehr der allgemein immer stärker zunehmenden Diskriminierung der Juden, die eben im Jahre 1939 trotz aller verbrecherischen Übergriffe durch den Gesetzgeber des Dritten Reichs wie die Parteigliederungen der NSDAP noch nicht ihren Höhepunkt erreicht hatte. Dies wird deutlich, wenn man das von Rüthers zur Stützung seiner Ansicht allein angeführte Urteil vom I3. September $1939^{240}$ und ein weiteres Urteil des RAG vom 5.Juli $1939^{241}$ näher untersucht.

Im Urteil vom 5.Juli 1939 entschied das RAG über die Klage mehrerer jüdischer Lehrlinge gegen die vorzeitige Auflösung ihrer Lehrverträge. Der Lehrherr hatte die Kündigung vor allem darauf gestützt, daß er Schwierigkeiten bei der Vergabe von Heeresaufträgen bekomme, wenn er weiter jüdische Arbeitnehmer beschäftigte. Die beiden Vorinstanzen hatten zugunsten der jüdischen Kläger entschieden; das RAG hob dagegen das Berufungsurteil auf und verwies die Sache zur erneuten Verhandlung und Entscheidung an das LAG. Die Bedenken des RAG richteten sich gegen die Auffassung des LAG, daß der Lehrherr „nur dann zur vorzeitigen Auflösung der Lehrverträge und zur Entfernung der jüdischen Lehrlinge [berechtigt sei], wenn das Unternehmen ... in seinem Bestande und damit auch die Gefolgschaftsmitglieder in ihren Stellungen bei der Beklagten gefährdet seien"242. "Diese Ausführungen des LAG wurden nach Auffassung des RAG „der infolge der Entwicklung des rassepolitischen

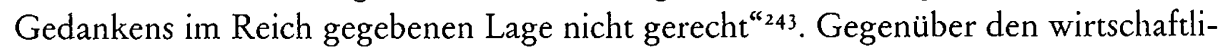
chen Folgen der Beschäftigung von Juden für das Unternehmen, die das LAG als maßgeblich ansah, müsse „ein noch stärkeres Gewicht den rassepolitischen Anschauungen der Nationalsozialisten beigemessen werden. Ihre Auswirkung auf die Rechtsbeziehungen der Parteien muß im Vordergrund stehen ${ }^{244}$." Mit dieser Entscheidung stieß das RAG also ein vom positiven Recht her nicht zu beanstandendes Urteil des LAG allein aufgrund der - nach seiner Auffassung offensichtlich dem positiven

\footnotetext{
239 ARS $_{37}$, S. $_{230 .}$

240 ARS 37, S. 230.

${ }^{241}$ ARS 36, S. 392.

${ }^{242}$ ARS 36, S. 392 (395).

${ }^{243}$ Ebenda.

${ }^{244}$ ARS 36, S. 392 (396).
} 
Recht übergeordneten - rassepolitischen Anschauungen der Nationalsozialisten um.

Auch in dem zweiten Fall eröffnete das positive Recht eine für den jüdischen Kläger günstigere Entscheidungsmöglichkeit als das vom RAG getroffene Urteil ${ }^{245}$; weil Rüthers diese nicht erwähnt, kommt er zu seiner oben kritisierten Einschätzung der Behandlung jüdischer Arbeitnehmer durch das RAG. In diesem Fall hatte das RAG über die Klage eines jüdischen Buchhalters auf Zahlung seines Gehalts bis zum Ende der ordentlichen Kündigungsfrist zu entscheiden. Dem Kläger war fristlos gekündigt worden, weil die Gestapo ihm aus Gründen, die von den Inhabern des Arbeitgeberunternehmens herbeigeführt worden waren, verboten hatte, die Geschäftsräume des Arbeitgebers zu betreten. Die fristlose Kündigung war wegen gesellschaftsrechtlicher Fehler nicht rechtswirksam. Daher stellte sich das Problem, ob dem Kläger sein Gehalt bis zum Ende der ordentlichen Kündigungsfrist zustand, obwohl er seine Arbeit seit dem Gestapo-Verbot nicht mehr hatte leisten können. Das LAG hatte im Berufungsurteil der Klage des jüdischen Arbeitnehmers in vollem Umfang entsprochen und seine Entscheidung damit begründet ${ }^{246}$, daß der beklagte Arbeitgeber selbst die Unmöglichkeit der Arbeitsleistung herbeigeführt habe und daher nach $\ 324$ BGB weiter zur Gehaltszahlung verpflichtet sei.

Um diese - vom positiven Recht her ebenfalls nicht zu beanstandende - Argumentation des LAG aus den Angeln zu heben, griff das RAG zur Formel vom „personenrechtlichen, auf Treue und Fürsorge gegründeten Gemeinschaftsverhältnis“"247: „Mit diesem Wesen des Arbeitsverhältnisses“ seien „insbesondere die Bestimmungen der $\iint 323$ bis $326 \mathrm{BGB}$ “ nicht vereinbar; diese paßten vor allem „um deswillen nicht auf das Arbeitsverhältnis, weil sie nur den Fortfall oder das Bestehenbleiben der Gegenleistungen kennen, bei diesem aber Billigkeit und soziales Empfinden häufig gerade ein zeitweiliges oder teilweises Fortbestehen oder einen Ausgleich zwischen den Beteiligten erfordern kann ${ }^{\text {“248 }}{ }^{8}$. Billigkeit und sozialem Empfinden des RAG entsprach es dann, die zwischen dem Kläger und der Beklagten vereinbarte außergewöhnlich lan$\mathrm{ge}^{249}$ Kündigungsfrist auf das gesetzlich vorgesehene Maß zu reduzieren und nur das für diese wesentlich kürzere Zeit zustehende Gehalt zuzusprechen. Das RAG verwandte die Formel vom personenrechtlichen Gemeinschaftsverhältnis nicht im Widerspruch zu ihrer nationalsozialistischen Wertgrundlage, wie Rüthers meinte, sondern zu dem Zweck, den nationalsozialistischen rassistischen Anschauungen entgegen der schuldrechtlichen Vorschrift des $\ 324$ BGB und entgegen der ausdrücklich vertraglich verlängerten Kündigungsfrist - Geltung zu verschaffen. Daß das RAG sich hierbei nicht mit dem Vorgehen der Gestapo identifizierte, macht zwar eine

245 ARS 37, S. 230.

${ }^{246}$ ARS 37, S. $230(236)$.

247 Ebenda.

${ }^{248}$ ARS 37, S. 230 (237).

249 ARS 37 , S. 230 (239). Wahrscheinlich sollte gerade diese lange Kündigungsfrist dem Kläger als Juden eine gewisse Sicherheit vor rassistisch diskriminierenden Maßnahmen des - ursprünglich jüdischen, später von Deutschen übernommenen - Unternehmens bieten. 
gewisse Distanz zum NS-Regime deutlich. Als Widerstandsäußerung läßt sich jedoch nur das für den Kläger und Juden wesentlich günstigere Urteil der Vorinstanz charakterisieren ${ }^{250}$. Dem RAG kam dagegen die prekäre Rolle zu, einen Kompromiß zwischen den im Grunde unüberbrückbar divergierenden Standpunkten des LAG und der Gestapo zu finden, oder, um es mit Fraenkel ${ }^{251}$ auszudrücken, den unübersehbaren Riß zwischen „Normenstaat" und „Maßnahmenstaat“ notdürftig zu kitten. Das RAG suchte die Einheit einer Rechtsordnung zu wahren, die weder einheitlich noch Rechtsordnung war.

\section{Die Soziale Ehrengerichtsbarkeit}

Eine der auffälligsten Neuerungen, die das AOG schuf', war die Soziale Ehrengerichtsbarkeit. Sie läßt sich kurz als eine Art Disziplinargerichtsbarkeit charakterisieren, der nicht nur die Arbeitnehmer, sondern - und das war das eigentlich Bemerkenswerte - sogar in erster Linie die Arbeitgeber unterlagen. Für jeden Bezirk eines Treuhänders der Arbeit (Wirtschaftsgebiet) wurde ein Soziales Ehrengericht gebildet (I. Instanz) ${ }^{2}$; die Zahl der Ehrengerichte wuchs mit der Eingliederung neuer Wirtschaftsgebiete ins Deutsche Reich (Saarland, Österreich, Sudetenland) von ${ }_{1} 3$ im Jahre 1934 auf 23 im Jahre $1943^{3}$. Von Anfang an war vorgesehen, daß jedes Ehrengericht nur aus einem Spruchkörper bestehen sollte4. Dem Spruchkörper gehörten der Vorsitzende und zwei Laienbeisitzer an; der Vorsitzende mußte „richterlicher Beamter" sein und war vom RMJ im Einvernehmen mit dem RAM zu ernennen'; das Amt konnte auch als Nebenamt neben einer anderen richterlichen Tätigkeit verliehen wer$\operatorname{den}^{6}$. Wie weit es mit der allgemeinen Auffassung von der Unabhängigkeit der Richter im Dritten Reich gekommen war, zeigt die Kommentierung des $\rrbracket_{4} \mathrm{x}$ II AOG durch den Standard-Kommentar von Hueck, Nipperdey und Dietz ${ }^{7}$ : Aus der gesetz-

250 Vgl. in diesem Zusammenhang auch Rüthers, Die Betriebsverfassung im Nationalsozialismus, AuR 1970, S. 97 ff. (107). Wenn Rüthers ausführt, daß häufig „die Gerichte hinter einem Schwall politisch zeitgemäß klingender Argumente versuchten, allgemeine Billigkeitsgesichtspunkte gegen die totalitäre Parteiideologie wenigstens nicht völlig untergehen zu lassen", so trifft dies eher auf einige - bei weitem nicht alle - Arbeitsgerichte der I. und 2. Instanz zu als auf das RAG. Aus der Argumentation dieser Instanzgerichte war dann aber meist herauszuhören, daß sie sich bewußt von der Parteiideologie absetzten.

2si Vgl. Fraenkel, Der Doppelstaat, S. 2 r.

Vgl. IS 35-5S AOG.

2 Vgl. $\$ 4$ IIAOG.

3 Hueck/Nipperdey/Dietz, AOG, $§$ I8 Rdnr. 4-6 und $\rrbracket_{4}$ I Rdnr. I (mit Angabe des Sitzes der Ehrengerichte).

$4 \S_{4}$ III AOG.

s Ebenda.

6 Krause, Stellung und Aufgabenkreis des Vorsitzenden eines Ehrengerichts, RABl II 1934, S. 299 (300).

7 Hueck/Nipperdey/Dietz, AOG, $\$ 4$ I Rdnr.9. 
lichen Formulierung, daß der Vorsitzende vom RMJ zu ernennen war, sowie daraus, daß das AOG keine Bestimmung über die Amtsdauer des Vorsitzenden enthielt, schlossen die Kommentatoren, daß er ,jederzeit vom RMJ wieder seines Amtes enthoben werden kann.“ Die Laienbeisitzer, je einen „Betriebsführer“ und einen „Vertrauensmann", entnahm der Vorsitzende einer Vorschlagsliste, die die DAF aufstell$\mathrm{te}^{8}$. Die Abhängigkeit der Vorsitzenden vom RMJ und die Bestimmung der Beisitzer durch die DAF sicherten die politische Zuverlässigkeit der Sozialen Ehrengerichte im Sinne des Nationalsozialismus.

Als zweite und letzte Instanz der Sozialen Ehrengerichtsbarkeit wurde der Reichsehrengerichtshof (REG) gebildet, der seinen Sitz in Berlin hatte; er überprüfte auf die Berufung des Treuhänders der Arbeit oder eines zu einer höheren Strafe Verurteilten hin die Urteile der Ehrengerichte in sachlicher und rechtlicher Hinsicht ${ }^{9}$; bei der personellen Besetzung des REG ${ }^{10}$ war das juristische Element durch einen zweiten Juristen als Stellvertreter des Vorsitzenden sowie das politische Element durch einen weiteren Beisitzer betont, der nicht wie die Arbeitgeber- und Arbeitnehmerbeisitzer von der DAF, sondern von der Reichsregierung bestimmt wurde.

Das Verfahren vor den Sozialen Ehrengerichten lehnte sich an die Vorschriften der StPO an ${ }^{11}$, war aber insgesamt wesentlich flexibler gestaltet ${ }^{12}$. Die „Besonderheiten des Sozialen Ehrengerichtsverfahrens" bezweckten „die Beschleunigung, Vereinfachung und weitgehendste elastische Gestaltung des Verfahrensganges" und waren

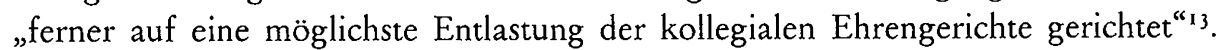
Den Antrag auf Einleitung des ehrengerichtlichen Verfahrens konnte nur der zuständige Treuhänder der Arbeit stellen ${ }^{14}$; da er nach politischer Opportunität - gegebenenfalls auf Weisung des RAM - darüber entscheiden konnte, ob das ehrengerichtliche Verfahren eingeleitet ${ }^{15}$ oder weitergeführt ${ }^{16}$ werden sollte, kam ihm eine beherrschende Stellung im Gang des ehrengerichtlichen Verfahrens zu. Auch diese Regelung weist auf die politische Steuerung des neuen Instruments hin.

Die Soziale Ehrengerichtsbarkeit hatte „gröbliche Verletzungen der durch die Betriebsgemeinschaft begründeten sozialen Pflichten ... als Verstöße gegen die soziale

${ }^{8} \S_{4}$ I II 2 AOG.

9 Vgl. im einzelnen $\$ 49 I$ AOG.

$10 \mathrm{Vgl}$. hierzu $₫$ sっAOG.

if $\$ 40$ AOG.

12 Vgl. die 3. DVO zum AOG vom 28.3. 1934, RGBl I, S. 255, SS I I-27; danach waren beispielsweise die Bestellung eines Verteidigers von Amts wegen $(\$ \mathrm{I} 8)$ und der Umfang der Beweisaufnahme $(\$ 20)$ in das freie Ermessen des Vorsitzenden bzw. des Gerichts gestellt.

13 Krause, Stellung und Aufgabenkreis des Vorsitzenden eines Ehrengerichts, RABI II 1934, S. 299.

${ }_{14} \iint_{4} \mathrm{I}$ I und 43 S. 2 und 3 AOG.

is Hueck/Nipperdey/Dietz, AOG, $\mathbb{S}_{43}$ Rdnr.6. Die Geltung des Opportunitätsprinzips war unter den juristischen Kommentatoren umstritten, prägte jedoch die Praxis.

16 Nach $\$$ 52 AOG konnte der Treuhänder der Arbeit seinen Antrag bis zum Abschluß des Verfahrens in I. Instanz zurücknehmen, nach Hueck/Nipperdey/Dietz, AOG, $\$ s 2 Rdnr. I, „,nach freiem Ermessen". 
Ehre" zu sühnen ${ }^{17}$. Als ehrengerichtliche Strafen konnten verhängt werden ${ }^{18}:$ Warnung, Verweis, Geldstrafe bis 10000 RM, Aberkennung der Befähigung, Betriebsführer oder Vertrauensmann zu sein, sowie Entfernung vom bisherigen Arbeitsplatz. Der Begriff der „sozialen Ehre" wurde in $\ 35$ AOG durch vier weitere, ebenso pathetische wie vielsagende Generalklauseln umschrieben: gewissenhafte Pflichterfüllung, achtenswertes Verhalten, Verantwortungsbewußtsein und Unterordnung unter das gemeine Wohl. Das neue „Ethos der Betriebsgemeinschaft" war also geprägt durch die Betonung der Pflichten der Angehörigen der Betriebsgemeinschaft und durch den Grundsatz „Gemeinnutz geht vor Eigennutz“. Doch dieser äußerst weite Begriff der „sozialen Ehre“ war eher ein politisch-propagandistischer als ein juristischer - eine Bestrafung konnte nicht aufgrund eines allgemeinen Verstoßes gegen die „soziale Ehre", sondern nur aufgrund eines Verstoßes gegen einen der in $₫ 36$ I AOG näher aufgeführten Tatbestände erfolgen ${ }^{19}$.

Tabelle 3: Entwicklung der ehrengerichtlichen Verfahren von 1934 bis 1942

\begin{tabular}{|c|c|c|c|c|c|c|c|}
\hline $\begin{array}{c}1934 \\
(a b \text { I. } 5 .)\end{array}$ & 1935 & 1936 & I937 & 1938 & 1939 & 1940 & $194 \mathrm{I}$ \\
\hline
\end{tabular}

\begin{tabular}{|c|c|c|c|c|c|c|c|c|}
\hline $\begin{array}{l}\text { Zahl der Personen, } \\
\text { gegen die ein ehren- } \\
\text { gerichtliches Verfahren } \\
\text { eingeleitet wurde }\end{array}$ & 65 & 223 & 279 & 366 & 153 & 80 & 68 & 34 \\
\hline $\begin{array}{l}\text { - davon Arbeitgeber und } \\
\text { Aufsichtspersonen aus: }\end{array}$ & 59 & 205 & 225 & $35 \mathrm{I}$ & I 39 & 75 & 66 & 30 \\
\hline$=$ der Industrie & & 57 & 37 & 76 & I2 & I4 & 13 & 8 \\
\hline$=$ dem Handwerk & & 28 & 45 & $8 \mathrm{r}$ & 32 & 8 & 7 & 4 \\
\hline$=$ der Landwirtschaft & & 45 & 37 & 65 & 32 & 24 & 10 & 4 \\
\hline$=$ dem Einzelhandel & & 20 & 20 & 23 & 9 & 4 & 6 & 2 \\
\hline$=$ dem Großhandel & & & 2 & 6 & $\circ$ & $\mathrm{I}$ & 2 & 2 \\
\hline$=$ dem Verkehrswesen & & & 14 & 10 & 4 & 0 & $\circ$ & 0 \\
\hline $\begin{aligned}= & \text { dem } \\
& \text { Gaststättengewerbe }\end{aligned}$ & & 17 & 9 & 19 & I I & 4 & I0 & 2 \\
\hline - davon Arbeitnehmer & 6 & 18 & 54 & 15 & 14 & 5 & 2 & 4 \\
\hline
\end{tabular}

Zahl der Urteile, die auf die folgenden Strafarten erkannten:
(Die restlichen Verfahren endeten durch Freispruch, Zurücknahme der Anträge, Ablehnung der Eröffnung des Verfahrens, bzw. waren am Stichtag der Erhebung noch nicht erledigt)

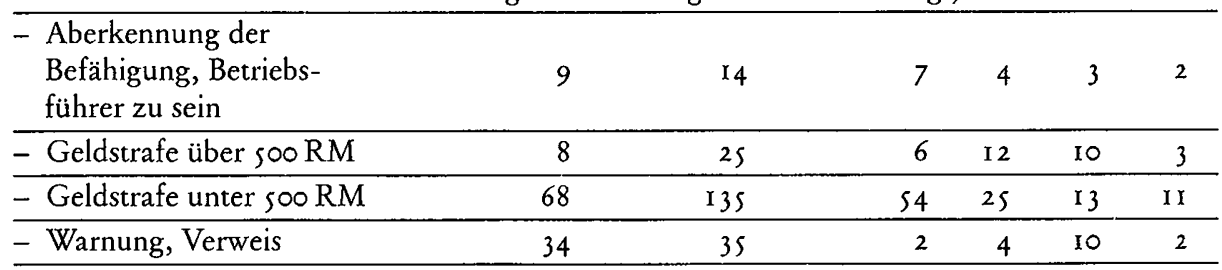




\section{Die Entscheidungspraxis der Sozialen Ehrengerichte}

von 1934 bis 1942

In der Praxis der Ehrengerichte spielten insbesondere die in $\$ 36$ I Nr. I und 3 AOG aufgeführten Tatbestände, die vor allem Unternehmer, „Betriebsführer“ und Aufsichtspersonen betrafen ${ }^{20}$, eine wichtige Rolle ${ }^{2 x}$. Von Anfang an beruhten die vor den Ehrengerichten eingeleiteten Verfahren überwiegend auf dem Vorwurf der böswilligen Ausnutzung der Arbeitskraft und der Ehrenkränkung; so hatten sich von den insgesamt 223 Personen, gegen die 1935 ein Antrag gestellt wurde, 170 wegen dieser Tatbestände zu verantworten ${ }^{22}$. Seit 1936 wuchs auch die Zahl der nach $\ 36$ I Nr. 3 (hartnäckiges Zuwiderhandeln gegen schriftliche Anordnungen der Treuhänder der Arbeit) eingeleiteten Verfahren, von denen weit überwiegend ebenfalls Arbeitgeber betroffen waren; in den meisten Fällen hatten diese Arbeitgeber gegen Tarifordnungen, Richtlinien oder Einzelanweisungen der Treuhänder der Arbeit verstoßen oder sich deren Kontrolle durch Nichtbeantwortung von Anfragen zu entziehen versucht. So gliedern sich die 1939 nach dieser Vorschrift eingeleiteten 48 Verfahren (von insgesamt ${ }_{142}$ Verfahren mit I 53 betroffenen Personen) wie folgt auf ${ }^{23}$ : Zehn Verstöße gegen Tarifordnungen, zwei Verstöße gegen Anordnungen zur Durchführung der Betriebsordnung, zehn Verstöße gegen Anordnungen über die Bildung eines Vertrauensrates, 26 Fälle der Nichtbeantwortung von Anfragen. Die Soziale Ehrengerichtsbarkeit wurde damit zunehmend - bis zur Einführung einer eigenen Ordnungsstrafgewalt der Treuhänder der Arbeit durch das Kriegsarbeitsrecht - zu einem Instrument der Treuhänder der Arbeit, mit dem diese ihren Anordnungen durch die Androhung eines gerichtlichen Verfahrens zusätzliches Gewicht verleihen konnten. Gegenüber diesen vorrangig an Arbeitgeber und Beschäftigte mit Arbeitgeberfunktionen gerichteten Vorschriften nahmen die an die Arbeitnehmer gerichteten, die in $\S_{36}$ I Nr. 2 und 4 AOG enthalten waren, in der Praxis der Sozialen Ehrengerichte ei-

$7 \$ 36$ AOG.

18 Ebenda.

19 Hueck/Nipperdey/Dietz, AOG, $\mathbb{3} 6$ Rdnr. I.

20 Sie lauten: „Derartige Verstöße liegen vor, wenn r. Unternehmer, Führer des Betriebs oder sonstige Aufsichtspersonen unter Mißbrauch ihrer Machtstellung im Betriebe böswillig die Arbeitskraft der Angehörigen der Gefolgschaft ausnutzen oder ihre Ehre kränken; ... 3. Angehörige der Betriebsgemeinschaft wiederholt leichtfertig unbegründete Beschwerden oder Anträge an den Treuhänder der Arbeit richten oder seinen schriftlichen Anordnungen hartnäckig zuwiderhandeln."

${ }^{21} \mathrm{Vgl}$. zu den nachfolgenden Angaben: Entwicklung der Sozialen Ehrengerichtsbarkeit, SozPr 1938, S. 43 ff. und ror ff.; dazu die Jahresübersichten in: SozPr 1935, S. 5 I (für 1934); 1936, S. 559 (für 1935); DAR 1937, S. 319 (für 1936); DAR 1938, S. 164 (für 1937); RABl V, 1940, S. 347 (für 1939); 194 I, S. 3 II (für 1940); 1942, S.415 (für 194 I); 1943, S. 47 I (für 1942).

Die Jahresübersichten wurden nicht regelmäßig in einer Zeitschrift veröffentlicht und sind auch in ihrem Gehalt etwas unterschiedlich; für 1938 konnte keine Jahresübersicht ermittelt werden. Entsprechend ist die Zusammenstellung in dem Schaubild auf S. 234 nicht ganz vollständig.

22 Soziale Ehrengerichtsbarkeit 1935, in: SozPr 1936, S. 559 (561).

23 RABI V I940, S. 347. 
nen völlig untergeordneten Rang ein. So wurden 1939 nur zwölf Verfahren, also weniger als $10 \%$ aller Verfahren, wegen „Störung des Gemeinschaftsgeistes“ oder „böswilliger Verhetzung der Gefolgschaft" ( $\$ 36 \mathrm{I}$ Nr. 2 AOG) eingeleitet, und in den Jahren 1934 bis 1942 kein einziges Verfahren wegen „unbefugter Offenbarung von vertraulichen Angaben, Betriebs- oder Geschäftsgeheimnissen durch Mitglieder der Vertrauensräte“ ( $\$ 36 \mathrm{I} \mathrm{Nr.4} \mathrm{AOG)})^{24}$.

\section{Die geringe Bedeutung der Sozialen Ehrengerichte für die \\ Disziplinierung der Arbeitnebmerschaft}

Mit Sicherheit ist anzunehmen, daß weit mehr Arbeitnehmer als Arbeitgeber gegen die Grundsätze der nationalsozialistischen Betriebsgemeinschaft verstießen und daß diese Verstöße auch bekannt wurden. Die Verstöße wurden auch geahndet, jedoch geschah dies nicht durch die Soziale Ehrengerichtsbarkeit, die sich in dieser Hinsicht als überflüssig erwies. Denn dem Arbeitgeber standen Abmahnung, Schadensersatzanspruch und Kündigung als zivilrechtliche Reaktionsmöglichkeiten, sowie die Betriebsbußen ${ }^{25}$ als betriebsverfassungsrechtliche Sanktionen zu Gebote, um die Arbeitnehmer von derartigem Verhalten abzuhalten bzw. sie dafür zur Rechenschaft zu ziehen. In der brutalen Denk- und Schreibweise des Dritten Reichs drückte dies die Schriftleitung der Zeitschrift „Soziale Praxis“ wie folgt aus ${ }^{26}$ : „Die Betriebe pflegen mit solchen asozialen Betriebsangehörigen meist ohne Eingreifen der Reichstreuhänder fertig zu werden und merzen sie notfalls selbst aus der Betriebsgemeinschaft aus. So liegen hier bisher grundlegende Entscheidungen des REG nicht vor." Soweit es sich um politisch motivierte Verstöße („böswillige Verhetzung der Gefolgschaft") handelte, war die Verfolgung durch die Gestapo oder die Strafjustiz ohnehin die weit wirksamere Methode. Daß die Soziale Ehrengerichtsbarkeit für die Disziplinierung der Arbeitnehmer weitgehend bedeutungslos war, wird an einer der äußerst seltenen Entscheidungen eines Sozialen Ehrengerichts über eine Streikführerin deutlich ${ }^{27}$. Das Gericht ging in seinem Urteil davon aus, daß die Angeklagte zum Streik aufgerufen habe; Streiks seien zwar nicht ausdrücklich verboten, verstießen aber gegen den obersten Grundsatz des AOG „Gemeinnutz geht vor Eigennutz“, wonach die Gemeinschaftsarbeit zum gemeinen Nutzen von Volk und Staat im Vordergrund jedes Arbeitsverhältnisses stehe; Streiks seien daher im nationalsozialistischen Staat „undenkbar ${ }^{\text {“28. }}$. Wegen dieses wohl schwersten Verstoßes gegen $\$ 36$ AOG habe die Angeklagte an sich die schwerste Strafe, die Entfernung vom bisherigen Arbeitsplatz, verwirkt; wörtlich fährt die Urteilsbegründung dann fort ${ }^{29}$ : „Diese an sich angemessene Strafe kann gegen die Angeklagte nicht verhängt werden, weil sie wegen ihres

24 RABIV I943, S. 47 I (472).

25 Vgl. If 27 I Nr. 4 und 28 AOG.

${ }_{26}$ Entwicklung der Sozialen Ehrengerichtsbarkeit, SozPrr 1938, S. IOI (IO4).

27 Soziales Ehrengericht Mitteldeutschland, Urteil vom 19. I1. 1935, ARS 26, S. 193.

28 So wörtlich der Leitsatz des Urteils ARS 26, S. 193.

29 ARS 26, 193 (196f.). 
Verhaltens bereits am gleichen Tage (8.8. 1935) fristlos entlassen worden ist. Als nächstangemessene Ordnungsstrafe wäre eine hohe Geldstrafe am Platze. Bei der völligen Vermögenslosigkeit der Angeklagten wäre der Ausspruch einer hohen Geldstrafe bedeutungslos. Diese Erwägung in Verbindung mit der Tatsache, daß die Angeklagte das Gesetzwidrige ihrer Handlungsweise eingesehen und erkennbar bereut hat, hat dem Ehrengericht Veranlassung gegeben, gegen die Angeklagte einen, Verweis' auszusprechen."

\section{Die Sozialen Ehrengerichte als Disziplinargerichte für Arbeitgeber und leitende Angestellte}

Während also die Sanktionen der Sozialen Ehrengerichtsbarkeit gegenüber Arbeitnehmern nicht griffen, weil die arbeits- und strafrechtlichen Sanktionen wirksamer waren, waren die Arbeitgeber bis 1934 einer vergleichbaren sozialen Kontrolle nicht unterworfen worden ${ }^{3}$. Die Wirkungsweise der Sozialen Ehrengerichte gegenüber Arbeitgebern und „sonstigen Aufsichtspersonen“ änderte für sie die Situation. Vor allem die Möglichkeit, die Befähigung als Betriebsleiter und damit die Direktionsgewalt als Arbeitgeber zu verlieren, mußte für sie eine einschneidende Gesetzesänderung bedeuten. Die Zahl der insgesamt durchgeführten Verfahren war auch hier sehr gering (s. Schaubild S. 234). Der Schwerpunkt der Tätigkeit der Sozialen Ehrengerichte lag vor dem Krieg; die Höchstzahl wurde mit 342 Verfahren gegen 366 Personen ${ }^{31}$ im Jahre 1937 erreicht. Dennoch ist auch diese Zahl relativ niedrig, wenn man bedenkt, daß auf jedes der $14^{32}$ Sozialen Ehrengerichte im Jahresdurchschnitt nur ca. ${ }_{24}$ Verfahren kamen, oder wenn man die Zahl mit der Zahl der bei den Arbeitsgerichten anhängigen Verfahren vergleicht, die in den ersten Jahren des Dritten Reiches zwar sank, aber 1937 immer noch 167895 betrug 33 . Schon 1939 war die Zahl der Verfahren um mehr als die Hälfte gegenüber der Höchstzahl gesunken, und während des Krieges verloren die Sozialen Ehrengerichte mangels Beschäftigung vollends ihre Bedeutung; 29 Anträge gegen 34 Personen im Jahre 1942 bedeuteten einen jährlichen Arbeitsanfall für jedes der mittlerweile ${ }_{23}$ Gerichte von ein bis zwei Verfahren ${ }^{34}$. Bis auf das Jahr 1936, in dem die Zahl der angeklagten Arbeitnehmer ${ }^{35}$ ca. $20 \%$ betrug $^{36}$,

${ }^{30}$ Die allgemeine strafrechtliche Verantwortlichkeit für Beleidigungen, Sittlichkeitsdelikte, Sozialversicherungs- und Konkursdelikte sowie fahrlässige Körperverletzung und Tötung durch Vernachlässigung des Betriebsschutzes deckte weder die neuen Tatbestände des $\$ 36$ AOG völlig ab, noch glichen die Strafarten einander.

${ }^{31}$ In manchen Verfahren wurden also mehrere Personen angeklagt.

32 I 935 war das Saarland ins Deutsche Reich eingegliedert worden und bildete zusammen mit der Pfalz einen neuen Wirtschaftsbezirk. Dadurch erhöhte sich die Zahl der Sozialen Ehrengerichte I 935 von 13 auf 14 .

33 Statistisches Jahrbuch für das Deutsche Reich 1938, S.617.

34 Da die Vorsitzenden wohl i.d. R. nebenamtlich und die Beisitzer ohnehin ehrenamtlich tätig waren, ließ sich dieser Rückgang ohne organisatorische Konsequenzen verkraften.

35 Ohne die Arbeitnehmer mit Arbeitgeberfunktionen.

${ }^{36}$ In diesem Jahr wurde eine verhältnismäßig große Zahl von vertragsbrüchigen Landarbeitern wegen Verstoßes gegen die Tarifbestimmungen über Kündigungsfristen ( $\$ 36 \mathrm{I} \mathrm{Nr.3}$ AOG) angeklagt. Seit 
lag der Anteil der Arbeitnehmer an der Gesamtzahl der Angeklagten um oder unter $10 \%$.

Schlüsselt man die Zahl der angeklagten Arbeitgeber nach Branchenzugehörigkeit auf, so zeigt sich, daß bis 1939 die Zahl der Kleingewerbetreibenden (Einzelhandel, Gaststätten, Landwirtschaft, Handwerk) die Zahl der Angeklagten aus Industrie und Großhandel weit überwog. Während des Krieges erhöhte sich insbesondere der Anteil der Industrie deutlich: Waren 1939 noch 32 Handwerker und nur zwölf Industrielle angeklagt worden, so hatte sich das Verhältnis in den Jahren 1940 bis 1942 nahezu umgekehrt: 35 Industrielle standen 19 Handwerkern gegenüber.

Eine Durchsicht der veröffentlichten ehrengerichtlichen Urteile vermittelt den Eindruck, daß die betroffenen Industriellen eher zur mittelständischen als zur Großindustrie zu zählen waren. Ein zeitgenössischer Beobachter ${ }^{37}$ erklärte diesen Befund damit, „daß die Gedanken des neuen Sozialrechts sich in den größeren Betrieben schneller durchzusetzen vermochten als in den kleineren". Die Ironie der Geschichte $^{38}$ wollte es also, daß die „ehrlosen“, „asozialen“ und „pflichtvergessenen“ Betriebsführer ${ }^{39}$ sich zum überwiegenden Teil gerade in den Schichten fanden, die zur Massenbasis des Nationalsozialismus vor 1933 gehört und viel zu seinen Wahlerfolgen beigetragen hatten ${ }^{40}$. So mußten sich selbst „alte Nationalsozialisten “41 oder „Anhänger und Förderer" aus der Kampfzeit der Partei ${ }^{42}$ vor den Sozialen Ehrengerichten verantworten ${ }^{43}$. Viele ehrengerichtliche Urteile ${ }^{44}$, insbesondere aus den Jahren 1934 bis 1937 , geben ein plastisches ${ }^{45}$ Bild von den sozialen Mißständen in Kleinbetrieben, deren Inhaber ihre wirtschaftlichen Schwierigkeiten auf dem Rücken der

Ende 1936 bot die Zurückhaltung des Arbeitsbuchs durch den Arbeitgeber eine einfachere Handhabe gegen derartige Verstöße; vgl.: Entwicklung der sozialen Ehrengerichtsbarkeit, SozPr 1938, S. 43 ( $44 \mathrm{f}$.).

37 Entwicklung der sozialen Ehrengerichtsbarkeit, SozPr 1938, S. 43 ff. (45).

${ }^{8}$ Sie beruhte auf dem sozialpolitischen Opportunismus der Nationalsozialisten, die zur Durchführung ihrer Rüstungspläne eher der Großindustrie als ihrer Stammanhänger aus Mittelstand und Kleinbürgertum bedurften.

39 So die moralisierenden Attribute, die Norden (Geltungsbereich und Sinn der Ehrengerichtsbarkeit, SozPri935, S. 1353) verwendet.

40 Vgl. hierzu die differenzierte und kritische Darstellung und Diskussion des neueren Forschungsstandes von Eike Hennig, Bürgerliche Gesellschaft und Faschismus in Deutschland, Frankfurt 1977, besonders in den Kapiteln über "die Mitgliederstruktur der NSDAP“ (S. I 57-171) und „zur Struktur der NSDAP-Wähler" (S. 188-226).

${ }^{41}$ REG, Urteil vom 1 3. 3. 1935, ARS 23, 24 I (254).

${ }^{42}$ REG, Urteil vom 16.4. 1935, ARS 24, I 18 (125).

43 Die politische Einstellung der Angeklagten wurde zwar strafmildernd berücksichtigt, konnte aber im Fall ARS 23, 24I nicht verhindern, daß dem Angeklagten die Befähigung als Betriebsführer seines bisherigen Betriebs abgesprochen wurde.

44 Vgl. die zusammenfassenden Darstellungen bei Norden, Geltungsbereich und Sinn der Ehrengerichtsbarkeit, SozPr 1935, Sp. I353, sowie: Entwicklung der sozialen Ehrengerichtsbarkeit, SozPr I938, S. 43 ff.

45 Häufig wurde das „soziale Umfeld“ einer Tat genauer erforscht als im Verfahren vor den Arbeitsgerichten. 
„Gefolgschaft“ austragen wollten oder zur „Menschenführung“ ungeeignet waren. Am häufigsten verhängten die Sozialen Ehrengerichte Geldstrafen; dabei überwogen niedrigere und mittlere Geldstrafen bis 500 RM mit einem Anteil von über $60 \%$ aller Verurteilungen gegenüber etwa $12 \%$ für höhere Geldstrafen. Von Geldstrafen erhoffte man sich offensichtlich die größte erzieherische Wirkung. Die rein erzieherischen Mittel, die nur an die „Ehre“ des Verurteilten appellierenden Warnungen und Verweise, erwiesen sich wohl als wenig effektiv; jedenfalls wurden sie nur in den Anfangsjahren in nennenswerter Zahl angewandt; sie hatten insgesamt nur einen Anteil von fast $20 \%$ aller Verurteilungen.

Die härteste Strafe, die Aberkennung der Befähigung, Betriebsführer zu sein, wurde am seltensten, in etwa $8 \%$ aller Verurteilungen, verhängt. Diese Strafe wirkte sich so aus, daß einem Unternehmer die Möglichkeit genommen wurde, die spezifischen Arbeitgeberfunktionen auszuüben, also beispielsweise Arbeitnehmer einzustellen oder ihnen Weisungen zu erteilen; für diese Arbeitgeberfunktionen mußte dann eigens ein „Betriebsführer" bestellt werden; hingegen blieb dem Unternehmer bei Aberkennung der Betriebsführerbefähigung seine Eigentümerstellung; er konnte also weiterhin frei über sein Unternehmen entscheiden, beispielsweise es veräußern oder Rationalisierungen vornehmen. In der Praxis gerade eines kleineren Betriebes mußte diese Unterscheidung zwischen der Unternehmer- und der Arbeitgeberstellung zu Unzuträglichkeiten führen oder war von vornherein nicht durchführbar. Das ist der Hintergrund dafür, daß Mansfeld in einer Anmerkung zu einem Urteil des REG ${ }^{46}$ diese Strafart als Notbehelf bezeichnete und anregte, die Möglichkeit zu schaffen, „auch der Unternehmerstellung eines asozialen Betriebsführers ein Ende zu machen".

Der nationalsozialistische Gesetzgeber schuf durchaus derartige Möglichkeiten; doch übertrug er die Aufgabe, der Unternehmerstellung wirtschaftlich unzuverlässiger und charakterlich ungeeigneter „Betriebsführer“ ein Ende zu machen, nicht den Sozialen Ehrengerichten. Vielmehr wurden im letzten Vorkriegsjahr und während des Krieges gesetzliche Möglichkeiten zur „Auskämmung“ übersetzter Zweige des Handwerks ${ }^{47}$ und des Einzelhandels ${ }^{4}$ sowie zur Stillegung ${ }^{49}$ vor allem kleinerer Betriebe der Konsumgüterindustrie geschaffen, um zusätzliche Arbeitskräfte zu rekrutieren $^{\varsigma \circ}$. Die zitierten Vorschriften betrafen den gleichen Personenkreis, aus dem die Mehrzahl der Angeklagten vor den Sozialen Ehrengerichten kam. Die Stillegung unwirtschaftlicher und schlecht geführter Betriebe reduzierte die Aufgaben der Sozialen Ehrengerichte. Die Einführung einer Ordnungsstrafgewalt der Reichstreuhänder der Arbeit sowie die Verschärfung der allgemeinen Strafvorschriften des Kriegsarbeits-

\footnotetext{
${ }^{46}$ REG, Urteil vom I 8.6. 1935, ARS 24, 284 (288f.).

47 DVO zum VJP auf dem Gebiet der Handwerkswirtschaft vom 22. 2. 1939, RABl I, S. 243.

$4^{8}$ VO zur Beseitigung der Übersetzung im Einzelhandel vom 26. 3. 1939, RABl I, S. 247.

49 VO über die Stillegung von Betrieben zur Freimachung von Arbeitskräften vom 21. 3. I940, RABI I, S. I25.

so Diese Maßnahmen wurden von der Arbeitseinsatzverwaltung in Zusammenarbeit mit der Wirtschaftsverwaltung durchgeführt.
} 
rechts trugen ebenfalls zum Rückgang der Verfahren vor den Sozialen Ehrengerichten während des Krieges bei. Hierauf und weniger auf erfolgreiches erzieherisches Wirken der Sozialen Ehrengerichtsbarkeit in der Vorkriegszeit ist es zurückzuführen, daß die Sozialen Ehrengerichte schnell wieder zur fast völligen Bedeutungslosigkeit herabsanken.

Auch wenn ein kritischer zeitgenössischer Beobachter ${ }^{51}$ aus naheliegenden Gründen den Wert der Erziehungsarbeit der Sozialen Ehrengerichte „nicht hoch genug veranschlagen" konnte, so mußte er doch bei näherer Betrachtung der Entwicklung feststellen, daß die Bedeutung der Sozialen Ehrengerichtsbarkeit immer geringer wurde. Als Gründe hierfür wurden angeführt: das durch den Arbeitskräftemangel zugunsten der Arbeitnehmer veränderte Betriebsklima; die Sinnlosigkeit des Appells an die soziale Ehre in einem System der Unfreiwilligkeit; die anderweitige Verfolgung von Rechtsbrüchen der Arbeitnehmer; die unter kriegswirtschaftlichen Verhältnissen praktisch undenkbare Verhängung der Höchststrafen, die den Betrieben nur Arbeitskräfte entzogen hätte, und die Entschärfung mancher Gegensätze durch die Maßnahmen der betrieblichen Sozialpolitik. Aufgrund dieser Überlegungen lag der Schluß nahe, daß „die bedeutsamste Zeit für die Soziale Ehrengerichtsbarkeit ... selbst bei späterer Rückkehr zu normalen arbeitseinsatzmäßigen Verhältnissen ... bereits vorüber sein" dürftes .

Ebenso wie manche anderen Einrichtungen, die das AOG vorsah ${ }^{53}$, wurde also auch das soeben erst geschaffene Instrument der Sozialen Ehrengerichtsbarkeit von der auf den Krieg hindrängenden Dynamik der Arbeitsrechtsentwicklung beiseite geschoben $^{54}$. In der Vorkriegszeit konnte es einen gewissen Beitrag zum sozialen Frieden und damit zur Konsolidierung des NS-Regimes insofern leisten, als es den Arbeitnehmern eine neue staatlich kontrollierte Schutzmöglichkeit gegen rechtswidrige und allgemein als anstößig angesehene Übergriffe von Arbeitgebern eröffnete und damit einen - wenn auch nur schwachen - Ersatz für die 1933 beseitigten Selbsthilfemöglichkeiten der Arbeitnehmerorganisationen schuf. Dieser Beitrag lag jedoch angesichts der geringen Zahl und tatsächlichen Bedeutung der vor den Sozialen Ehrengerichten

¿1 Hans Reichel, Die Entwicklungstendenzen in der deutschen Sozialverfassung, SozPr 1941, Sp. 7 or ff. $(708-710)$.

s2 Ebenda, Sp.7ro.

\$3 Vgl. nur das Verhältnis von Tarifordnung und Betriebsordnung! \$ 32 II AOG sah Tarifordnungen nur für den Fall vor, daß sie „zum Schutze der Beschäftigten . . . zwingend geboten “waren, im übrigen sollten die Arbeitsentgelte durch den Betriebsführer in einer Betriebsordnung festgesetzt werden $(\$ 27$ III AOG). Auch hierüber gingen spätere Verordnungen stillschweigend hinweg.

\$4 Am schärfsten hat diese Entwicklung Rhode, Arbeitsrecht - Sozialrecht - Gemeinschaftsrecht, Berlin 1944, S. 5 f., beobachtet: „Tatsächlich sind die tragenden Gedanken, die das AOG für alle Zeiten zu vermitteln schien, weithin durch andersgeartete Bestimmungen überdeckt worden.... So läßt es sich nicht mehr verkennen, daß das AOG in der großen Mehrzahl seiner Bestimmungen heute keine praktische Rechtsquelle mehr ist. "Unfreiwillig deckte er damit die sozialpolitische Prinzipienlosigkeit des Nationalsozialismus, die Unterordnung der Sozialpolitik unter Rüstung und Krieg, im Dritten Reich auf. 
durchgeführten Verfahren vorrangig auf propagandistischem Gebietss - in diesem Zusammenhang fällt auf, daß für damalige Verhältnisse ungewöhnlich detaillierte statistische Daten ${ }^{56}$ gerade über die Verfahren vor den Sozialen Ehrengerichten veröffentlicht wurden und diese sich damit weit größerer Publizität erfreuten als beispielsweise die weit zahlreicheren Arbeitsgerichtsverfahren.

ss Franz Neumann, Behemoth, charakterisierte die Sozialen Ehrengerichte mit den Worten, sie seien „wenig mehr als Staffage“ und dienten allenfalls dazu, „der Arbeiterschaft das soziale Verantwortungsbewußtsein des NS-Regimes zu demonstrieren“" (S. 494).

s6 Vgl. oben das Schaubild zur Entwicklung der ehrengerichtlichen Verfahren von 1934 bis 1942. 